University of Tennessee Health Science Center

UTHSC Digital Commons

\title{
Understanding Structural And Functional Mechanisms of Emi1 Inhibition of the Anaphase Promoting Complex
}

\author{
Edmond Randall Watson \\ University of Tennessee Health Science Center
}

Follow this and additional works at: https://dc.uthsc.edu/dissertations

Part of the Medical Microbiology Commons

\section{Recommended Citation}

Watson, Edmond Randall (http://orcid.org/0000-0001-7756-4099), "Understanding Structural And Functional Mechanisms of Emi1 Inhibition of the Anaphase Promoting Complex" (2016). Theses and Dissertations (ETD). Paper 372. http://dx.doi.org/10.21007/etd.cghs.2016.0397.

This Dissertation is brought to you for free and open access by the College of Graduate Health Sciences at UTHSC Digital Commons. It has been accepted for inclusion in Theses and Dissertations (ETD) by an authorized administrator of UTHSC Digital Commons. For more information, please contact jwelch30@uthsc.edu. 


\title{
Understanding Structural And Functional Mechanisms of Emi1 Inhibition of the Anaphase Promoting Complex
}

\begin{abstract}
Healthy, reproducing cells create and destroy proteins in an ordered manner. Both the concentration and localization of protein pools is important to regulate the many cellular processes necessary for the life of the cell. In order to produce new proteins, cells degrade existing materials such as proteins and organelles that are dispensable or troublesome in order to recycle their raw components. Degradation is accomplished largely through two major pathways: in bulk through processes such as autophagy and phagocytosis, or in a targeted manner through the ubiquitin-proteasome pathway. Autophagy utilizes an encompassing body to encapsulate targets and surrounding materials for decomposition in a regulated but relatively non-specific manner. The ubiquitin-proteasome pathway, however, is an exquisitely precise method of degradation capable of targeting specific pools of protein substrates. So-called ubiquitination generates a signal for degradation by the $26 \mathrm{~S}$ proteasome machinery. In order to establish the degradation signal, the cell utilizes a cascade of 3 enzymes working in concert to organize substrates and ubiquitin. By using enzymes capable of substrate specificity, the cell can regulate large pools of proteins in a specific spatio-temporal manner.

In the present study, we employ biochemical and structure-based techniques to study proteins involved in an essential ubiquitination pathway involved in maintenance of the cell cycle. A mitotic regulator called the Anaphase Promoting Complex, also called Cyclosome (APC/C), modifies myriad substrates that control cell cycle activities. The APC/C is a ubiquitin ligase complex; it is the final enzyme in a tri-enzyme cascade and catalyzes the final step of Ub transfer from an E2 enzyme directly to substrates. A protein called Emi1 is responsible for directly binding and inhibiting the APC/C throughout interphase, when APC/ $\mathrm{C}$ substrates are stabilized. We set out to study domains of Emi1 responsible for binding and inhibiting the APC/C and its association with E2 enzymes or substrates, with the aim of charcterizing both the mechanism of the inhibitor and the essential functional requirements of the APC/C, which are not well understood. We aim to visualize the APC/C in complex with Emi1 through electron microscopy and to accurately interpret the location and orientation of Emi1 within this density.
\end{abstract}

The APC/C is a large, $1,200 \mathrm{kDa}$ multi-protein complex, and Emi1 is a single protein of only $50 \mathrm{kDa}$. Despite its small size, even a small subdomain of Emi1 potently inhibits the APC/C through a combination of not well-characterized mechanisms. Emi1 has an APC/C recognition motif called a D-box that is typically found within APC/C substrates. Emi1's D-box is recruited to the substrate-binding sites of APC/C and serves as a pseudo-substrate inhibitor. Emi1 also inhibits through distinct mechanisms both of the E2 enzymes that coordinate with APC/C function. An essential, folded Zinc-binding Region (ZBR) and a helical "Linker" sequence cooperate to bind and block APC/C from recruiting one of two APC-specific E2 enzymes, Ubch10. Emi1 also has a conserved C-terminal motif, with charge and sequence similar to the other APC/C- specific E2 enzyme, Ube2s. Emi1 competes directly with Ube2s for APC/C recruitment, and it is through the combination of these three mechanisms that are afforded by many motifs within Emi1, that makes Emi1 a potent APC/C inhibitor. When associated with Emi1, the APC/C is inefficient at both recruiting substrates and binding E2 enzymes, allowing for stabilization of APC/C substrates, which is important for regulation of timing of cell cycle processes.

\section{Document Type}

Dissertation

Degree Name

Doctor of Philosophy (PhD) 


\section{Program}

Biomedical Sciences

\section{Research Advisor}

Brenda A. Schulman, Ph.D.

\section{Keywords}

Emi1

\section{Subject Categories \\ Medical Microbiology | Medical Sciences | Medicine and Health Sciences}

\section{Comments}

Healthy, reproducing cells create and destroy proteins in an ordered manner. Both the concentration and localization of protein pools is important to regulate the many cellular processes necessary for the life of the cell. In order to produce new proteins, cells degrade existing materials such as proteins and organelles that are dispensable or troublesome in order to recycle their raw components. Degradation is accomplished largely through two major pathways: in bulk through processes such as autophagy and phagocytosis, or in a targeted manner through the ubiquitin-proteasome pathway. Autophagy utilizes an encompassing body to encapsulate targets and surrounding materials for decomposition in a regulated but relatively non-specific manner. The ubiquitin-proteasome pathway, however, is an exquisitely precise method of degradation capable of targeting specific pools of protein substrates. So-called ubiquitination generates a signal for degradation by the $26 \mathrm{~S}$ proteasome machinery. In order to establish the degradation signal, the cell utilizes a cascade of 3 enzymes working in concert to organize substrates and ubiquitin. By using enzymes capable of substrate specificity, the cell can regulate large pools of proteins in a specific spatio-temporal manner.

In the present study, we employ biochemical and structure-based techniques to study proteins involved in an essential ubiquitination pathway involved in maintenance of the cell cycle. A mitotic regulator called the Anaphase Promoting Complex, also called Cyclosome (APC/C), modifies myriad substrates that control cell cycle activities. The APC/C is a ubiquitin ligase complex; it is the final enzyme in a tri-enzyme cascade and catalyzes the final step of Ub transfer from an E2 enzyme directly to substrates. A protein called Emi1 is responsible for directly binding and inhibiting the APC/C throughout interphase, when APC/ $\mathrm{C}$ substrates are stabilized. We set out to study domains of Emi1 responsible for binding and inhibiting the APC/C and its association with E2 enzymes or substrates, with the aim of charcterizing both the mechanism of the inhibitor and the essential functional requirements of the APC/C, which are not well understood. We aim to visualize the APC/C in complex with Emi1 through electron microscopy and to accurately interpret the location and orientation of Emi1 within this density.

The APC/C is a large, 1,200 kDa multi-protein complex, and Emi1 is a single protein of only $50 \mathrm{kDa}$. Despite its small size, even a small subdomain of Emi1 potently inhibits the APC/C through a combination of not well-characterized mechanisms. Emi1 has an APC/C recognition motif called a D-box that is typically found within APC/C substrates. Emi1's D-box is recruited to the substrate-binding sites of APC/C and serves as a pseudo-substrate inhibitor. Emi1 also inhibits through distinct mechanisms both of the E2 enzymes that coordinate with APC/C function. An essential, folded Zinc-binding Region (ZBR) and a helical "Linker" sequence cooperate to bind and block APC/C from recruiting one of two APC-specific E2 enzymes, Ubch10. Emi1 also has a conserved C-terminal motif, with charge and sequence similar to the other APC/C- specific E2 enzyme, Ube2s. Emi1 competes directly with Ube2s for APC/C recruitment, and it is through the combination of these three mechanisms that are afforded by many motifs within Emi1, that makes Emi1 a potent APC/C inhibitor. When associated with Emi1, the APC/C is inefficient at both 
recruiting substrates and binding E2 enzymes, allowing for stabilization of APC/C substrates, which is important for regulation of timing of cell cycle processes. 


\title{
Understanding Structural and Functional Mechanisms of Emi1 Inhibition of the Anaphase Promoting Complex
}

\author{
A Dissertation \\ Presented for \\ The Graduate Studies Council \\ The University of Tennessee \\ Health Science Center \\ In Partial Fulfillment \\ Of the Requirements for the Degree \\ Doctor of Philosophy \\ From The University of Tennessee
}

By

Edmond Randall Watson

May 2016 
Copyright (C) 2016 by Edmond R. Watson. All rights reserved. 


\section{DEDICATION}

I dedicate this work to my loving parents, Ed and Cathy Watson, who have believed in me and supported me for my entire life. 


\section{ACKNOWLEDGEMENTS}

To properly acknowledge the contributions of others, one must first acknowledge their own inadequacies. When I joined the IPBS and began my dissertation research in Brenda's lab, I had absolutely no skill set for the work of a structural biologist, and almost no knowledge about our field or our science. Brenda courageously accepted me under her tutelage, and for years provided both the means and the direct advisement that developed me into the scientist I have become today. Her unparalleled dedication to both her work and my own have shown me what is truly possible through scientific research: the ability to attack the unknown, solve invisible mysteries, and establish a thorough and reliable groundwork for the progression of scientific information. She took me to multiple international conferences and meetings and taught me a great deal about the "behind the scenes" world of science. These first-hand experiences with so many worldclass scientists and thinkers provide an important perspective that most students don't get to experience. I will be forever grateful for the opportunities that have been given to me by UTHSC, St Jude, and especially Brenda Schulman.

I would also like to acknowledge Dr. Eric Enemark, Dr. Lawrence Pfeffer, Dr. Charles Rock, and Dr. Stephen White who served as my faculty committee. They developed and mentored me through years of graduate school and offered key ideas and advice to move my project forward. Despite their incredibly busy schedules, they took the time to meet with me, plan my experiments, edit my documents, and I am very thankful for their selfless leadership.

On a daily basis, I have had the pleasure of working with an incredibly talented and motivated postdoc, Nick Brown. We have accomplished quite a bit together, and we have been a two-way sounding board for ideas and for making sure our experiments are designed and performed at the highest level. Nick has an innate drive to move projects forward at all costs, and I have benefitted not only from his discoveries and technical advice, but also from his mentorship and leadership role. The bar is now incredibly high for how to perform in my own postdoc.

At the onset of this project, Jeremiah Frye and I were in the trenches together, working to the point of complete exhaustion through desperation, and I share many of the results in this thesis with him. I especially cherish the many personal and professional discussions we shared in our office space, everything from literature to religion to science to life goals. I wish the best for this good friend, wherever life takes him.

I am so proud of the character and content of the Schulman lab over the years. Many incredibly hard-working and brilliant postdocs, senior scientists, and technicians have cycled through our lab over the course of my tenure: Matt Calabrese was my first direct mentor, and the combination of positivity and effectiveness he brought to every day in the lab has left me something to aspire to. Ryan made incredible improvements to generation and purification of APC/C and his selfless efforts make all of our work possible. Hari, Steve, and Asad were among "the greats" that I looked up to from my 
first days. Danny and Dave, leaders of the fraternity environment within the lab, make it clear that a life in science can be interesting, light-hearted, and still top-notch and massively productive. KP, Qiu, Masaya, Manjeet, Brian, and all of the rest of the postdocs show me how hard I must work at the next step. These guys are incredible and I am humbled to work along side them. I hold Shanshan near and dear as we both developed alongside each other and had a friendly relationship on and off campus. Peter has been a great friend and we especially love to get pizza and chat about life and work. All of the lab youngsters, Julie, Alan, Vlad, Omar, Shein, Khee, Yumei, Michael, and David Y provide incredible promise for the future of our type of work, and have made the job more than just a job; they are a close group of friends participating in sports, celebrations, and helping each other through the tough times. Especially good memories were made with Marc and Vlad in Memphis, NYC, and Austria, and watching these guys become successful throughout life is going to be a great pleasure. Arkansas :)

The Schulman lab only works because of the extraordinary efforts of our fantastic lab manager, David Miller. He is a brilliant scientist, engineer, and organizer, and my favorite person to have long chats with in the workplace. The task of managing so many people with their many demands is an incredibly difficult one, and Miller made it happen while being a friend and mentor at the same time. Thanks for all of the stimulating lunch conversations and for making sure to put me on your right side so we could be as animated as we always are. Our lab also travels, schedules, and maintains supplies because of the kindest and warmest administrator in the world, Shelia Bozeman. We are so spoiled to have this wonderful, motherly figure making our complicated scientific careers more simple and achievable, and I wish her all the best with retirement, golf, photos, and family. 


\begin{abstract}
Healthy, reproducing cells create and destroy proteins in an ordered manner. Both the concentration and localization of protein pools is important to regulate the many cellular processes necessary for the life of the cell. In order to produce new proteins, cells degrade existing materials such as proteins and organelles that are dispensable or troublesome in order to recycle their raw components. Degradation is accomplished largely through two major pathways: in bulk through processes such as autophagy and phagocytosis, or in a targeted manner through the ubiquitin-proteasome pathway. Autophagy utilizes an encompassing body to encapsulate targets and surrounding materials for decomposition in a regulated but relatively non-specific manner. The ubiquitin-proteasome pathway, however, is an exquisitely precise method of degradation capable of targeting specific pools of protein substrates. So-called ubiquitination generates a signal for degradation by the $26 \mathrm{~S}$ proteasome machinery. In order to establish the degradation signal, the cell utilizes a cascade of 3 enzymes working in concert to organize substrates and ubiquitin. By using enzymes capable of substrate specificity, the cell can regulate large pools of proteins in a specific spatio-temporal manner.
\end{abstract}

In the present study, we employ biochemical and structure-based techniques to study proteins involved in an essential ubiquitination pathway involved in maintenance of the cell cycle. A mitotic regulator called the Anaphase Promoting Complex, also called Cyclosome (APC/C), modifies myriad substrates that control cell cycle activities. The $\mathrm{APC} / \mathrm{C}$ is a ubiquitin ligase complex; it is the final enzyme in a tri-enzyme cascade and catalyzes the final step of Ub transfer from an E2 enzyme directly to substrates. A protein called Emil is responsible for directly binding and inhibiting the $\mathrm{APC} / \mathrm{C}$ throughout interphase, when APC/C substrates are stabilized. We set out to study domains of Emil responsible for binding and inhibiting the $\mathrm{APC} / \mathrm{C}$ and its association with E2 enzymes or substrates, with the aim of characterizing both the mechanism of the inhibitor and the essential functional requirements of the $\mathrm{APC} / \mathrm{C}$, which are not well understood. We aim to visualize the $\mathrm{APC} / \mathrm{C}$ in complex with Emil through electron microscopy and to accurately interpret the location and orientation of Emil within this density.

The APC/C is a large, $\sim 1,200 \mathrm{kDa}$ multi-protein complex, and Emi1 is a single protein of only $50 \mathrm{kDa}$. Despite its small size, even a small subdomain of Emi1 potently inhibits the APC/C through a combination of not well-characterized mechanisms. Emi1 has an $\mathrm{APC} / \mathrm{C}$ recognition motif called a D-box that is typically found within $\mathrm{APC} / \mathrm{C}$ substrates. Emil's D-box is recruited to the substrate-binding sites of APC/C and serves as a pseudo-substrate inhibitor. Emil also inhibits through distinct mechanisms both of the E2 enzymes that coordinate with APC/C function. An essential, folded Zinc-binding Region (ZBR) and a helical "Linker" sequence cooperate to bind and block APC/C from recruiting one of two APC-specific E2 enzymes, Ubch10. Emi1 also has a conserved Cterminal motif, with charge and sequence similar to the other $\mathrm{APC} / \mathrm{C}$ - specific E2 enzyme, Ube2s. Emil competes directly with Ube2s for APC/C recruitment, and it is 
through the combination of these three mechanisms that are afforded by many motifs within Emi1, that makes Emil a potent APC/C inhibitor. When associated with Emi1, the $\mathrm{APC} / \mathrm{C}$ is inefficient at both recruiting substrates and binding E2 enzymes, allowing for stabilization of $\mathrm{APC} / \mathrm{C}$ substrates, which is important for regulation of timing of cell cycle processes. 


\section{TABLE OF CONTENTS}

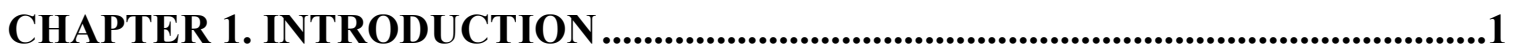

Introduction to the Ubiquitination Pathway for Selective Protein Degradation .............. 1

The Ubiquitin Protein as a Signaling Moiety .......................................................... 1

Ubiquitin Is Attached to Substrates by an Enzymatic Cascade .................................. 1

Understanding the Transfer of Ubiquitin from E1 to E2 Enzymes ............................4

E2 Enzymes Coordinate with Functionally Distinct Families of E3 Ligases to

Transfer Ubiquitin to Substrates .....................................................................4

Cullin-RING E3s Utilize a Cullin Protein to Scaffold E2 and Substrate

Interactions with a Flexibly Tethered RING Domain..........................................5

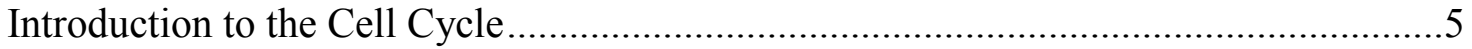

The Cell Cycle Consists of Four Distinct Phases ...................................................6

Cells Polarize Their Genetic Information and Organize Division in the Mitotic

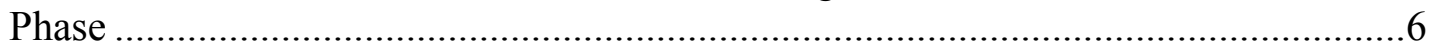

The Anaphase Promoting Complex/Cyclosome ..........................................................8

The APC/C Is Comprised of Many Subunits....................................................... 8

The APC/C Coordinates with Coactivator Proteins Cdc20 and Cdh1 to Recruit

Substrates and Activate the Platform for Catalysis................................................ 10

Many Substrates Are Targeted for Destruction by the APC/C ...............................10

Primarily Two E2 Enzymes Work in Conjunction with the APC/C to Deliver

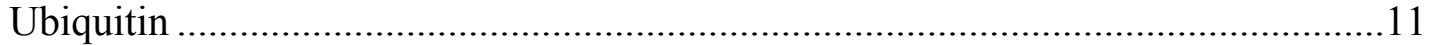

The Mitotic Checkpoint Complex Binds to the Core of APC/C and Inhibits

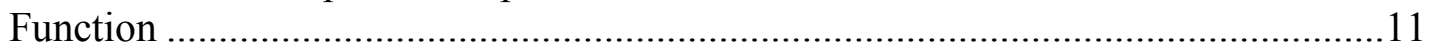

Emi1 Is Responsible for Inhibition of the APC/C Throughout Interphase .................12

Emi1 - The Interphase Inhibitor of APC/C Polyubiquitination ..................................12

Multiple Domains of Emil Are Suggested to Participate in APC/C Inhibition ........12

Emi1 Itself Is Regulated by Phosphorylation and Ubiquitination by SCF ................14

Specific Timing and Localization of APC/C Inhibition Within the Cell Cycle ........14

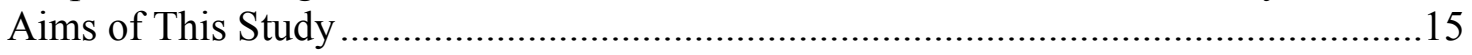

\section{CHAPTER 2. EXPRESSION AND PURIFICATION OF EMI1 AND UBE2S} FOR BIOCHEMICAL AND STRUCTURAL STUDIES ......................................16

Emi1 Expression and Purification ..........................................................................16

Expression of Recombinant Emi1-Skp1 Protein Complex in E. coli Cells ................16

Expression of Emi1-Skp1 in High-Five Insect Cells .............................................18

Individualized Purification of Emil Constructs ...................................................18

N-terminal Constructs of Emi1 Are Unstable and Require High Ionic Strength.......18

Emi1 FDLZT Is Easily Purified in Complex with Skp1 ..........................................20

The C-terminal Inhibitory Region of Emil Requires Optimization of Purification

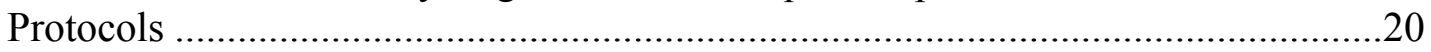

Utilizing Assays That Segregate the Functions of the APC/C-specific E2s Ubch10 and Ube2s 


\section{CHAPTER 3. MAPPING THE DOMAINS WITHIN EMI1 THAT CONTRIBUTE TO APC/C INHIBITION}

Introduction to Emil as a Multi-Modal Inhibitor .......................................................28

Alanine Scanning Mutagenesis of the Conserved Zinc-binding Region of Emi1 .........29 Selective Mutant Emil Proteins Exhibit Deficiency for APC/C Inhibition in an E2-independent Manner .....................................................................................29

Discovering a Single Surface of the Emi1 ZBR That Mediates Activity ………........30

Discovery of an Essential Linker Domain Between Emil's D-box and ZBR

Domains

Wholesale Deletion of a Linker Region of Emil Reveals a Functional

Requirement for This Region

Residues Within Emil's Linker Region Are Required for Inhibition .........................33

Emi1 Contains a Relatively Weak D-box and an Essential RL-Tail............................35

Strengthening Emil's Pseudosubstrate Activity Through Fusion with the D-box

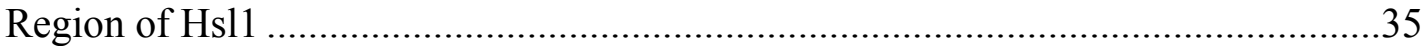

Emil's C-terminal RL-Tail Inhibits Ube2s Specifically ……………….....................37

Visualizing an APC/C-Cdh1-Emil Complex Through Electron Microscopy ............37

Insertions of Globular Domains Reveal Emi1 Position and Orientation on the $\mathrm{APC} / \mathrm{C}$

\section{CHAPTER 4. MAPPING EMI1-APC/C AND UBE2S-APC/C INTERACTIONS THROUGH BPA PHOTOCROSSLINKING}

Introduction to Photocrosslinking as a Strategy for Mapping Transient Protein-

Protein Interactions .43

para-Benzoyl-phenylalanine (BPA) Photo-crosslinker

Considerations for Substitution of a Photocrosslinker in Place of Native Amino

Acids

Development of Methods for Incorporation of BPA to Proteins ....................................44

Tryptophan Scanning Mutagenesis .............................................................................44

in vivo Incorporation of BPA to Central Residues of Emi1 and Ube2s......................46

Purification of BPA-containing Emil or Ube2s Following in vivo Incorporation ....48

Introduction of Fmoc BPA to C-terminal Residues of Emil and Ube2s...................48

Establishing Positive Controls for Capturing Protein-Protein Interactions with BPA

Using Emil as a Positive Control for APC/C-specific Crosslinking and

Detection

Ube2s Interactions with APC/C at Multiple Locations Are Captured Through

BPA Crosslinking

C-terminal Helices C and D of Ube2s Crosslink Specifically to APC2 and APC4 ..53

CHAPTER 5. DISCUSSION

APC/C-Cdh1-Emi1 Structure at High Resolution

Emil D-box Engages the Cdh1 and APC10 Co-receptors

Emi1 ZBR Alanine Scan Informs on Residues in the Interface 
Functional Linker Domain Between the D-box and ZBR Is Visualized and

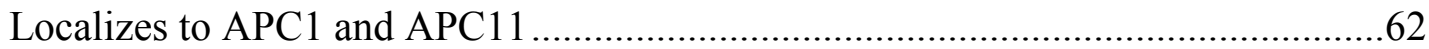

Emil Tail Binds APC/C at the Base of the Platform and Inhibits Ube2s Tail .........62

Retrospective Analysis of BPA Incorporation Methodologies..................................62

Multisite Binding as a General Mechanism of Inhibition..........................................64

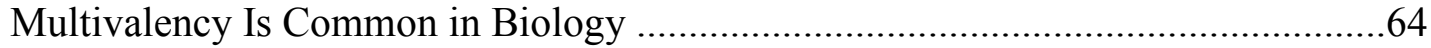

Targeting APC/C with Pharmacological Inhibitors .............................................66

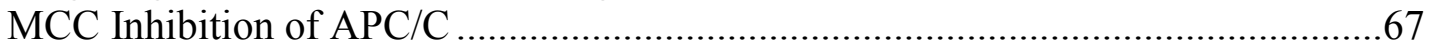

Cand1 Is Both a Competitor and Activator of CRLs.............................................68

Could Emil's Multisite Binding Provide More Than an Inhibitory Role? ...............68

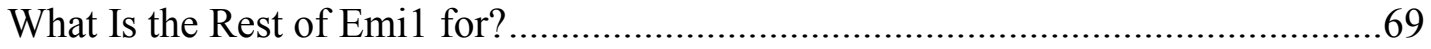

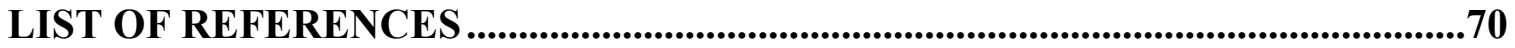

VITA 


\section{LIST OF TABLES}

Table 2-1. Emil Constructs Are Named According to Their Inclusive Domains. ........17 


\section{LIST OF FIGURES}

Figure 1-1. Ubiquitin as a Signaling Moiety. ……………......................................

Figure 1-2. Enzymatic Cascade for Substrate Ubiquitination. ..........................................

Figure 1-3. Schematic Diagram of the Cell Cycle...........................................................

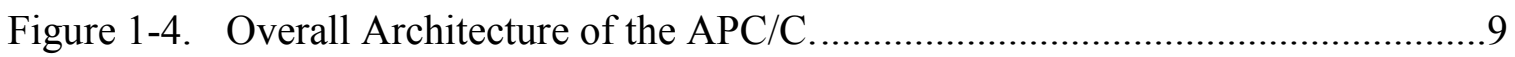

Figure 1-5. Domain Orientation of Emil to Scale ......................................................13

Figure 2-1. Emi1-NFDLZT Purification on Cation Exchange........................................19

Figure 2-2. Emi1-DLZT Dissociates from Nucleotides during IEX...............................22

Figure 2-3. Increased Ionic Strength and DNAse Treatment Do Not Prevent

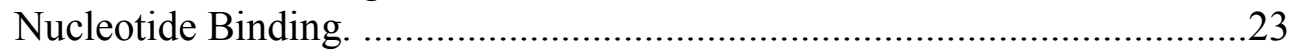

Figure 2-4. On-column Cleavage Effectively Purifies Emi1-DLZT from GST in

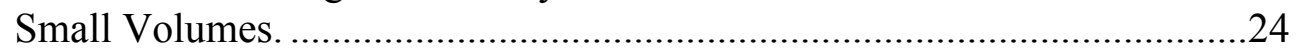

Figure 2-5. Optimized Purification Strategy Yields Pure Ube2s and Emi1...................25

Figure 2-6. Emil Is a Potent Inhibitor of APC/C Mechanism in Assays That Segregate Both E2 Enzymes. .....................................................................2

Figure 3-1. Alanine Scan of Emil's ZBR Reveals Amino-acids Required for Function.

Figure 3-2. Alanine Scanning Mutagenesis Reveals a Single Surface Required for Inhibition.

Figure 3-3. Relative Analysis for Mutations of Emi1 D-box, ZBR, and Functional Linker Domain Between Them.

Figure 3-4. Emi1 D-box in Isolation Is an Inefficient Inhibitor of APC/C.

Figure 3-5. Emil C-terminal Tail Is Conserved Throughout Evolution, Among Homologs, and with Ube2s.

Figure 3-6. Emi1-ZT Inhibits Ube2s-generated High Molecular Weight Products.

Figure 3-7. Emi1-FDLZT-Skp1 with Doa1 Insertions Are Purified Well Despite Their Relatively Large Size.

Figure 3-8. Difference Maps for Emi1-FDLZT-Skp1 Containing Beta-Propeller Insertions in the Linker Domain and C-terminus. 
Figure 4-1. Emil C-terminal Tail Residues Are Mutated to Tryptophan to Mimic BPA Incorporation and Tested as Inhibitors in APC/C assays.

Figure 4-2. Incorporation Efficiencies Are Evident from GST-Ube2s Pulldowns Following in vivo BPA Incorporation.

Figure 4-3. Ube2s BPA Using New Clones with C-terminal Deletion.

Figure 4-4. Sortase-mediated Transpeptidation Attaches an Emil Tail Peptide to Emil Protein.

Figure 4-5. Gankyrin and S6C Are a Positive Control for BPA Crosslinking. 52

Figure 4-6. His-Emil with BPA Reporting on D-box, Linker, and Tail Interactions with $\mathrm{APC} / \mathrm{C}$.

Figure 4-7. Crosslinking Between Residue E153 of Ube2s and APC/C-Cdh1 .............56

Figure 4-8. Crosslinking Between Residue I154 of Ube2s and APC/C-Cdh1...............57

Figure 4-9. Crosslinking Between Residue A158 of Ube2s and APC/C-Cdh1.............58

Figure 5-1. Emil D-box Is Co-recruited to Cdh1 and APC10..................................60

Figure 5-2. Emi1 ZBR Associates with APC11 and Utilizes the Surface Discovered in the ZBR Alanine Scan, and the Functional Linker Forms a Helix Between APC11 and APC1...

Figure 5-3. Emil Traverses the APC/C Architecture as Visualized by Negative Stain EM Experiments. 


\section{LIST OF ABBREVIATIONS}

$\AA$

ABBA motif

$\mathrm{APC} / \mathrm{C}$

ATP

BPA

Cdc20

Cdh1

CRL

C-terminal

CV

$\mathrm{Da}$

D-box

Di-Gly

DNA

DTT

E1

E2

E3

EM

Emi1

$\mathrm{EtBr}$

F-box

FLAG

G1

G2

HECT

Hi-5

His6

IEX

IPTG

K11-linked

$\mathrm{kDa}$

KEN box

LPETGG

M-phase

MCC

NEBD

Nedd8

N-terminal

Plk1

RING

RL Tail
Angstrom

$\mathrm{APC} / \mathrm{C}$ recruitment motif, named for presence in Cyclin A, Bub3, Bubr1, and Acm1

Anaphase Promoting Complex/Cyclosome

Adenosine 5'-Triphosphate

para-Benzoyl Phenylalanine Photocrosslinker

Cell division cycle 20

Cdc20 homolog 1

Cullin RING Ligase

Carboxy-terminal

Column volume, a resin bed with $1 \mathrm{~mL}$ sepharose has a $1 \mathrm{~mL} \mathrm{CV}$

Dalton

Destruction box $(\operatorname{Rxx} \operatorname{Lxxx}(\mathrm{x}) \mathrm{N})$

Glycine-Glycine C-terminal Residues of Ubiquitin

Deoxyribonucleic Acid

Dithiothreitol

Ubiquitin-activating enzyme

Ubiquitin-conjugating enzyme

Ubiquitin-ligating enzyme

Electron Microscopy

Early Mitotic Inhibitor 1

Ethidium Bromide

named for presence in CyclinF

Peptide sequence DYKDDDDK

Gap Phase 1

Gap Phase 2

Homologous to E6AP C-terminus

High-five, Trichoplusia $n i$ ovarian cells

Peptide sequence HHHHHH

Ion Exchange Chromatography (anion or cation)

Isopropyl- $\beta$ - D- thiogalactopyranoside

Lysine 11 of Ubiquitin is modified with a Ubiquitin

kiloDalton, 1000 Daltons

Lysine-Glutamate-Asparagine degron motif

synthetic peptide, recognition site for Sortase transpeptidation

Mitotic Phase

Mitotic Checkpoint Complex

Nuclear Envelope Breakdown

Neural precursor cell expressed developmentally down-regulated protein 8

Amino terminal

Polo-like kinase 1

Really Interesting New Gene

Arginine-Leucine C-terminal residues (also LRRL tail) 


$\begin{array}{ll}\text { SCF } & \text { Skp1-Cul1-F-box protein } \\ \text { SEC } & \text { Size-exclusion Chromatography } \\ \text { Sf9 } & \text { Spodoptera frugiperda ovarian cells } \\ \text { S-phase } & \text { Synthesis Phase } \\ \text { Strep tag } & \text { Peptide sequence SAWSHQFEK that tightly binds streptavidin } \\ \text { TEV } & \text { Tobacco-Etch Virus protease } \\ \text { TPR } & \text { Tetratricopeptide Repeat } \\ \text { tRNA } & \text { Transfer Ribonucleic Acid } \\ \text { UAA } & \text { Unnatural Amino Acid } \\ \text { Ub } & \text { Ubiquitin } \\ \text { WHB } & \text { Winged-Helix B } \\ \text { WT } & \text { Wild type } \\ \text { ZBR } & \text { Zinc-binding Region }\end{array}$




\section{CHAPTER 1. INTRODUCTION}

\section{Introduction to the Ubiquitination Pathway for Selective Protein Degradation}

The attachment of a $8.5 \mathrm{kDa}$ protein called Ubiquitin to target proteins is essential to eukaryotic cellular fitness and survival. This conjugation of Ubiquitin, termed Ubiquitination, to innumerable substrates is in some way involved in every process and signaling pathway that the cell employs for function. Ubiquitination, does not occur randomly, but through the activities of a selective cascade of enzymes. This form of post-translational modification is similar in scope and importance to phosphorylation. Modification of substrates with Ubiquitin ( $\mathrm{Ub}$ ) can alter the function or fate of the target by directing the localization, conformation, interactions, or degradation of the target protein through targeting to proteasomal machinery for proteolysis and amino acid recycling.

\section{The Ubiquitin Protein as a Signaling Moiety}

The Ubiquitin protein itself is small, only 76 amino acids, with a globular structure. Many important features are contained within this $8.5 \mathrm{kDa}$ protein that make it a versatile signaling moiety. Notably, a C-terminal di-Gly (GG) motif directs thioester bond formation with Cysteine residues and isopeptide bond formation with primary amines typically found in Lysine side-chains within proteins. Ubiquitin itself contains 7 Lysine residues and an intact N-terminal primary amine, so is accordingly also a target for modification in 8 ways. The conserved structural fold of Ubiquitin exposes all 7 of its own Lysines (K6, K11, K27, K29, K33, K48, K63) for modification by other Ubiquitin molecules. (Figure 1-1) Multiple modifications of this type, called polyubiquitination, generates a variety of morphologically and functionally distinct chains (Varadan, Walker et al. 2002, Tenno, Fujiwara et al. 2004). For instance, chains formed by modification of Ubiquitin's Lys 11, have a different signaling output from chains of Lys 63. So-called K11-linked chains are targeted for proteasomal recognition, while K63 chains direct cellular signaling (Dikic, Wakatsuki et al. 2009, Komander and Rape 2012, Berndsen and Wolberger 2014). To compound the system's complexity, target proteins may be modified on several different lysines concurrently, with either homotypic or heterotypic linkages, or with branched chains consisting of a mixture of Ub-linkages. The extent and topology of substrate-linked ubiquitin chains is thought to directly influence the rates of substrate degradation and is an important area of active research (Hershko and Heller 1985, Ikeda and Dikic 2008, Komander and Rape 2012).

\section{Ubiquitin Is Attached to Substrates by an Enzymatic Cascade}

Regulation of such a complex signaling system is achieved by directed attachment of Ubiquitin through the concerted action of three classes of enzymes. (Figure 1-2) Firstly, a Ubiquitin activating enzyme, also called E1, binds and activates Ubiquitin by 

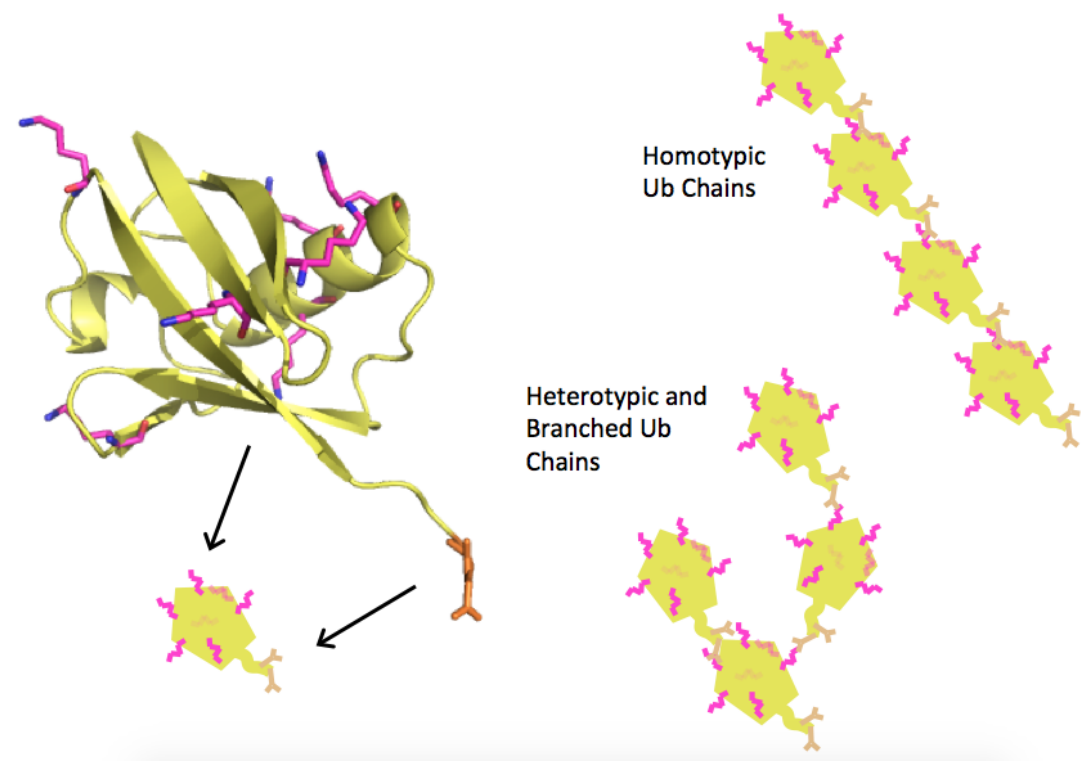

Figure 1-1. Ubiquitin as a Signaling Moiety.

Structural Representation of Ubiquitin from the Protein Data Bank (1UBQ.pdb) with 7 surface-exposed Lysine residues represented as magenta sticks, and the C-terminal GlyGly motif represented as orange sticks. Heterotypic chains contain multiple different Ubiquitin linkages, whereas homotypic chains arise from repeats of a single Ub linkage. 


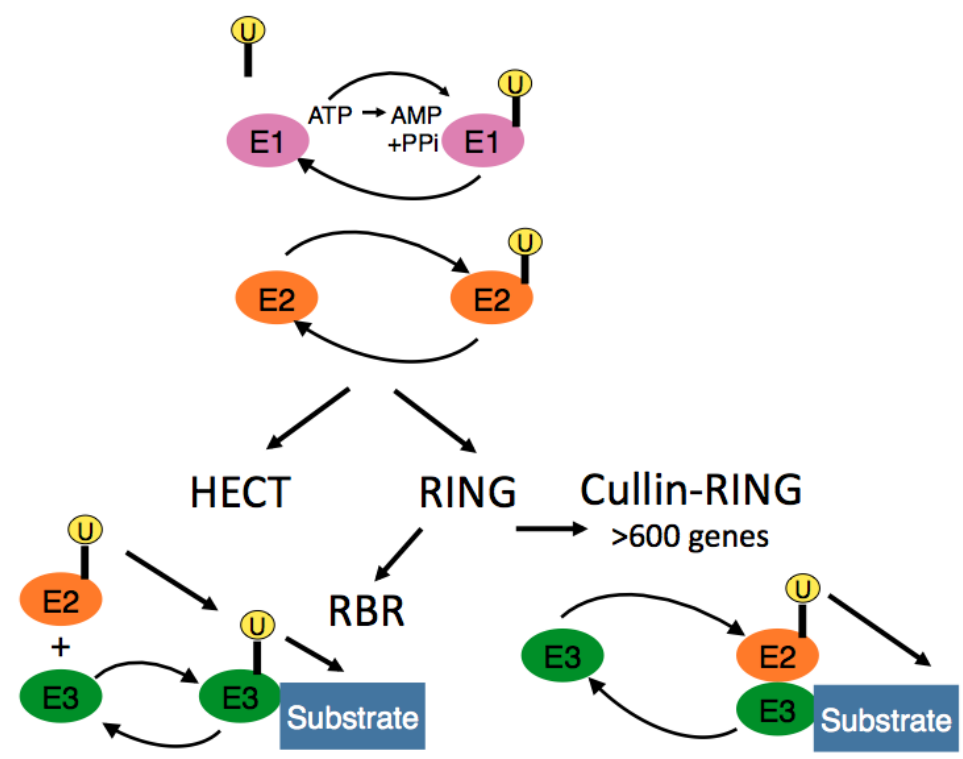

Figure 1-2. Enzymatic Cascade for Substrate Ubiquitination.

Ubiquitin, yellow sphere, is conjugated to the E1, shown in pink, in an ATP-dependent step. E1 Ub then transfers to an E2 enzyme, shown in orange, which collaborates with E3 enzymes of several types, shown in green. Cullin-RING and Simple RING E3s coordinate E2 Ub and substrates for direct transfer, whereas HECT and RBR E3s participate in the reaction. 
ATP-dependent adenylation of its C-terminal Glycine residue. Following thioester linkage of Ubiquitin to a Cysteine residue within the E1, Ubiquitin's C-terminus is transferred to a Cysteine residue within a conjugating enzyme, also called E2. This E2 Ubiquitin bond is also a labile, thioester bond, and Ubiquitin is easily discharged to form an isopeptide bond with substrate Lysines when the E2 Ubiquitin conformation is appropriate and substrate is properly positioned as an acceptor (Pickart and Eddins 2004, Eletr, Huang et al. 2005, Ye and Rape 2009). In many cases this catalytic architecture is achieved through a third, ligating enzyme, also called an E3 enzyme. Over 600 E3 ligases are known to catalyze Ubiquitin transfer through a variety of mechanisms discussed later in this document. Generally speaking, E3 ligases recruit both Ubiquitinloaded E2s and substrates to both position and mechanistically facilitate Ubiquitin transfer.

\section{Understanding the Transfer of Ubiquitin from E1 to E2 Enzymes}

Much of what we currently understand about the nature of the E1-E2 Ubiquitin transfer reaction comes from early work in our own lab (Huang, Miller et al. 2004, Huang, Paydar et al. 2005). By studying an analogous cascade of Neddylation, wherein a Ubiquitin-like protein called Nedd8 is transferred through a similar tri-enzyme cascade, the authors showed how a heterodimeric E1, APPBP1-UBA3, recruits the E2, UBC12. APPBP1-UBA3 harbors an N-terminal strand from UBC12 for optimal recruitment, and simultaneously provides a Ubiquitin-like (UBL) domain which binds the E2 mimicking a standard Ubiquitin interaction with a Ubiquitin-binding domain. Though E1 and E2 interactions were characterized, what confounded researchers was a large gap between where Ubiquitin's C-terminus was bound to the E1, and where it was going to bind on the E2 catalytic cysteine. The authors suggest that a substantial conformational reorientation would be required to place the E1 and E2 catalytic cysteine residues in close proximity. This rearrangement was later visualized for Ubiquitin through active-site disulfide crosslinking of UBA1-UBC4 Ubiquitin (E1-E2 UB) (Olsen and Lima 2013). These observations underscore much of the mechanism of ubiquitination intermediates: proteins are first recruited together through a variety of interactions, and subsequent conformational changes create a chemical environment suitable for faithful transfer of Ubiquitin through the enzymatic cascade or to the substrate.

\section{E2 Enzymes Coordinate with Functionally Distinct Families of E3 Ligases to Transfer Ubiquitin to Substrates}

E3 enzymes have been categorized into functional classes including HECT-type, RING-IBR-RING, simple RING, and Cullin-RING. HECT and RING-IBR-RING ligases not only bring $\mathrm{Ub} \sim \mathrm{E} 2$ in proximity to substrate, but also receive Ubiquitin to participate in the reaction. Cullin-RING proteins, on the other hand, utilize substratebinding modules called substrate adaptors to provide multifunctionality to a small group of nine Cullin proteins (Figure 1-2). By recognizing first a wide variety of adaptors that 
can each recognize a variety of substrates, cells can achieve both regulation and substrate specificity across the many thousand targets of Cullin-RING ubiquitination.

Cullin-RING ligases (CRLs) are the largest family of E3 ligase complexes. Within this family, architecture nucleated by a Cullin protein precisely positions the Ubthioester-E2 adjacent to the substrate (Willems, Schwab et al. 2004, Sarikas, Hartmann et al. 2011). This example of structural scaffolding underscores one important feature of E3 ligase activity: E3s utilize several accessory proteins to recruit and organize a variety of substrates with specific Ub-loaded E2s to mediate catalysis. Serving as an assembly platform for the E2 and substrate is not the only role for E3 enzymes, though. E3s also activate E2 enzymes for transfer of otherwise stable E2 Ub conjugates. (Wu, Hanlon et al. 2003, Summers, Pan et al. 2008).

\section{Cullin-RING E3s Utilize a Cullin Protein to Scaffold E2 and Substrate Interactions with a Flexibly Tethered RING Domain}

Though only nine Cullin proteins have been discovered so far, their utilization of a variety of types of substrate adaptor complexes gives them an impressive family size of over 600 genes, more than are involved in the well-studied process of protein phosphorylation (Deshaies and Joazeiro 2009). Included in these genes are those that encode proteins containing a RING domain (Really Interesting New Gene)(Freemont, Hanson et al. 1991, Deshaies and Joazeiro 2009), collectively called RING proteins. Cullin and RING proteins coordinate with substrate adaptors and E2 enzymes, and are commonly referred to as the CRL pathway of protein ubiquitination, for Cullin-RING ligase. Essential to the catalytic function of CRLs, RING proteins are responsible for binding and activating E2 enzymes for Ubiquitin release. RING domains, which are flexibly tethered to Cullins by association into an intermolecular Beta sheet, are capable of loose rotation relative to Cullin. Through this motion, RINGs bind a loaded E2 on a conserved face of the RING's surface, and bind the substrate proximal to the acceptor lysine (Dou, Buetow et al. 2012, Plechanovova, Jaffray et al. 2012, Pruneda, Littlefield et al. 2012, Scott, Sviderskiy et al. 2014).

\section{Introduction to the Cell Cycle}

Cellular reproduction occurs first by duplication of all cellular components and then separation to equal halves of the cell before splitting into two daughter cells. Faithful duplication and separation of genomic DNA is essential to proper cell division and cellular fitness, so the events surrounding these processes have been divided into four functional phases of a highly regulated cell cycle. Catastrophic failure of either genome duplication or DNA distribution leads to cell cycle arrest and eventual cell death. Failure to arrest can lead to aneuploidy, developmental defects such as trisomy, and cancer (Penas, Ramachandran et al. 2011, Bochis, Fetica et al. 2015). Though the relative fraction of the four phases of the cell cycle is variable with cell type, a considerably large fraction of eukaryotic cell life is spent in Gap-phases where the cells recover from 
stresses and prepare for growth and development with time-consuming processes such as protein expression and organelle growth (Figure 1-3).

\section{The Cell Cycle Consists of Four Distinct Phases}

Following a Gap-phase called G1, cells enter the synthesis phase (S-phase) wherein the entire genome is faithfully replicated to produce an identical set of twin chromatids, called sister chromatids. These sister chromatids are held together by several protein complexes throughout the next Gap-phase, G2, until entering the division phase, called M-phase (Mitotic phase). During mitosis, cells progress through a number of checkpoint stages characterized by molecular functions occurring within the cell. A crucial checkpoint in mitosis occurs between metaphase and anaphase, where the cell must decide whether DNA can be properly segregated into 2 identical halves and can therefore proceed through cytokinesis, or division of the cell body to two daughter cells. Without completion of this Spindle Assembly Checkpoint, for instance, cells will arrest in late metaphase and wait for molecular signals suggesting they are ready to progress. Completion of the Spindle Assembly Checkpoint releases the aptly named Anaphase Promoting Complex, which ubiquitinates and destroys many essential cell-cycle regulatory proteins. Degradation of these proteins drives the cell cycle thorough metaphase to Anaphase, allowing for eventual cell division. These duplicated cells then enter G1 phase again, growing and preparing to repeat the process again.

\section{Cells Polarize Their Genetic Information and Organize Division in the Mitotic Phase}

During mitosis, two sister chromatids of identical genetic information are organized along a central axis and divided to opposite poles through the action of a large number of protein activities. To do this consistently in a regulated and concerted way, the intracellular space undergoes severe morphological changes that can be classified to a number of distinct mitotic phases named Prophase, Pro-metaphase, Metaphase, Anaphase, and Telophase. In Prophase and Pro-metaphase, following nuclear envelope breakdown (NEBD), the DNA is compacted and folded into chromatids held together by kinetochores to make mitotic chromosomes. These chromatids are aligned to a central axis by spindle fibers in Metaphase. Following proper bi-orientation, where each sister chromatid of each chromosome is tethered to opposite spindle poles, the APC/C is released from the Spindle Assembly Checkpoint and becomes active. Immediately prior to Anaphase, APC/C-mediated degradation of a substrate called Securin allows an enzyme called Separase to cleave Cohesin. Cohesin cleavage disassembles the kinetochore and allows for each chromatid to be separated by microtubule motor proteins to opposite spindle poles within the cell. During Telophase, two nuclear membranes reform around the chromosomes, which unwind into chromatin. At the end of Telophase, the cell body is split in a process called cytokinesis and two identical cells enter G1 phase to complete and restart the cycle. 


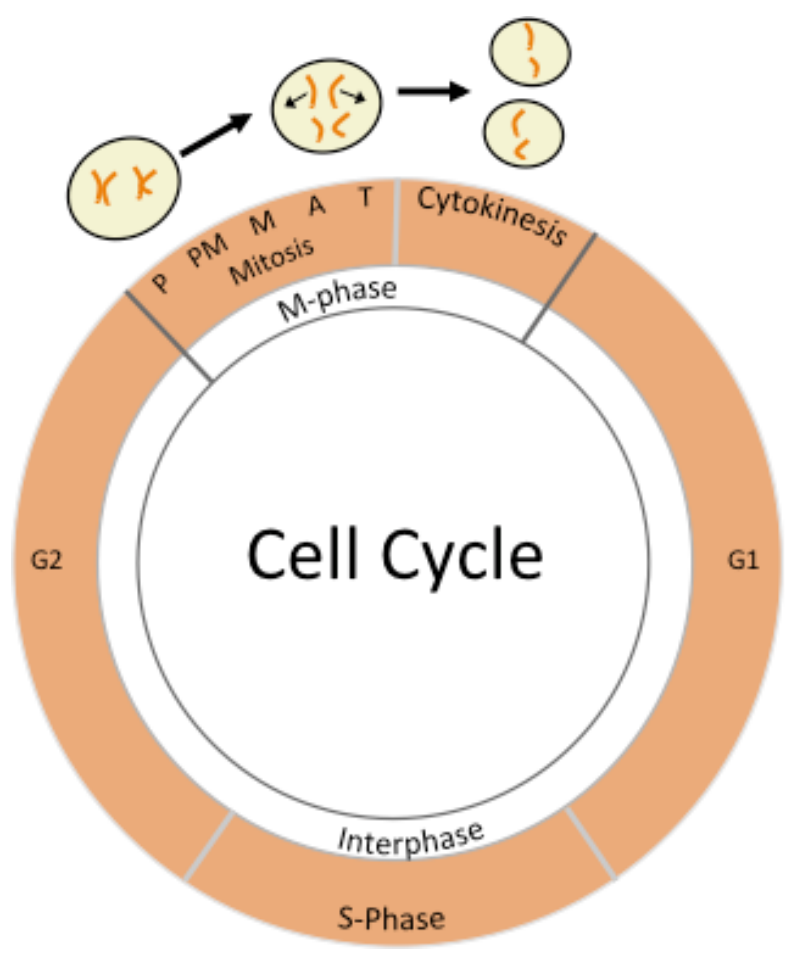

Figure 1-3. Schematic Diagram of the Cell Cycle. 


\section{The Anaphase Promoting Complex/Cyclosome}

The Anaphase Promoting Complex, simultaneously discovered and named the Cyclosome, is a large assembly of at least 18 proteins expressed from 14 genes. It was discovered as an E3 Ubiquitin ligase for its role in Cyclin degradation at the end of mitosis in collaboration with an E2 enzyme called Ubch10 (King, Peters et al. 1995, Sudakin, Ganoth et al. 1995).

The APC/C remains assembled throughout the life of the cell but exists in an inhibited state following mitosis and completely through interphase. This allows for accumulation of $\mathrm{APC} / \mathrm{C}$ substrates that are essential for chromosomal duplication and cell maintenance. Only when released from two major inhibitors, Emi1 and MCC, and by association with accessory coactivator proteins, $\mathrm{Cdc} 20$ or $\mathrm{Cdh} 1$, does the $\mathrm{APC} / \mathrm{C}$ become active for ubiquitination of target substrates. Substrates of the APC/C include a variety of cell-cycle regulatory proteins, notably mitotic Cyclins and a number of kinases. It has been suggested that the final stages of mitotis are governed exclusively by dephosphorylation of Cdk substrates and by the APC/C-mediated degradation (Morgan 2007).

\section{The APC/C Is Comprised of Many Subunits}

The APC/C is a large complex of structurally diverse proteins (Peters 2006). The complex has been divided into rough halves, where an arc-lamp provides structural scaffolding through a number of semi-repetitive TPR-repeat containing proteins as well as substrate recruitment, and a platform provides the basis for catalysis (Figure 1-4). Structural conservation among the TPR repeat proteins APC7, APC8, APC3, and APC6, present as homodimers and held together by Cdc26 and APC16, provide a wall of helices surrounding an inner core (Zhang, Chang et al. 2013). These arc-lamp proteins also provide multiple docking points for the coactivators Cdh1 and Cdc20; two proteins responsible for recruitment of substrates to the complex, discussed later in this document. The structural diversity of the platform provides several mobile points of contact for catalytic machinery such as E2 enzymes and substrates. This gives rise to an overall architecture that looks similar to a cupped left hand. With fingers for the arc-lamp and the palm for platform, a central cavity is formed, inside which catalysis is presumed to occur. Importantly, along with APC1, APC4, APC5, APC15, and APC10, the APC/C platform contains a cullin and RING module comprised of APC2 and APC11, respectively(Schreiber, Stengel et al. 2011). APC2 primary sequence suggests it contains 3 cullin-repeats at its $\mathrm{N}$-terminus, a $\mathrm{C}$-terminal four-helix bundle and alpha-beta domain and is terminated by a WHB domain, similar to other cullin proteins (Duda, Borg et al. 2008). APC11 is a small protein of only $9.8 \mathrm{kDa}$, but it is predicted to be structurally homologous to the other small RING proteins Rbx1 and Rbx2 with a number of conserved Cysteine residues for coordination of 3 Zinc ions. Therefore the $\mathrm{APC} / \mathrm{C}$ is speculated to utilize a Cullin-RING type mechanism, as discussed previously. 

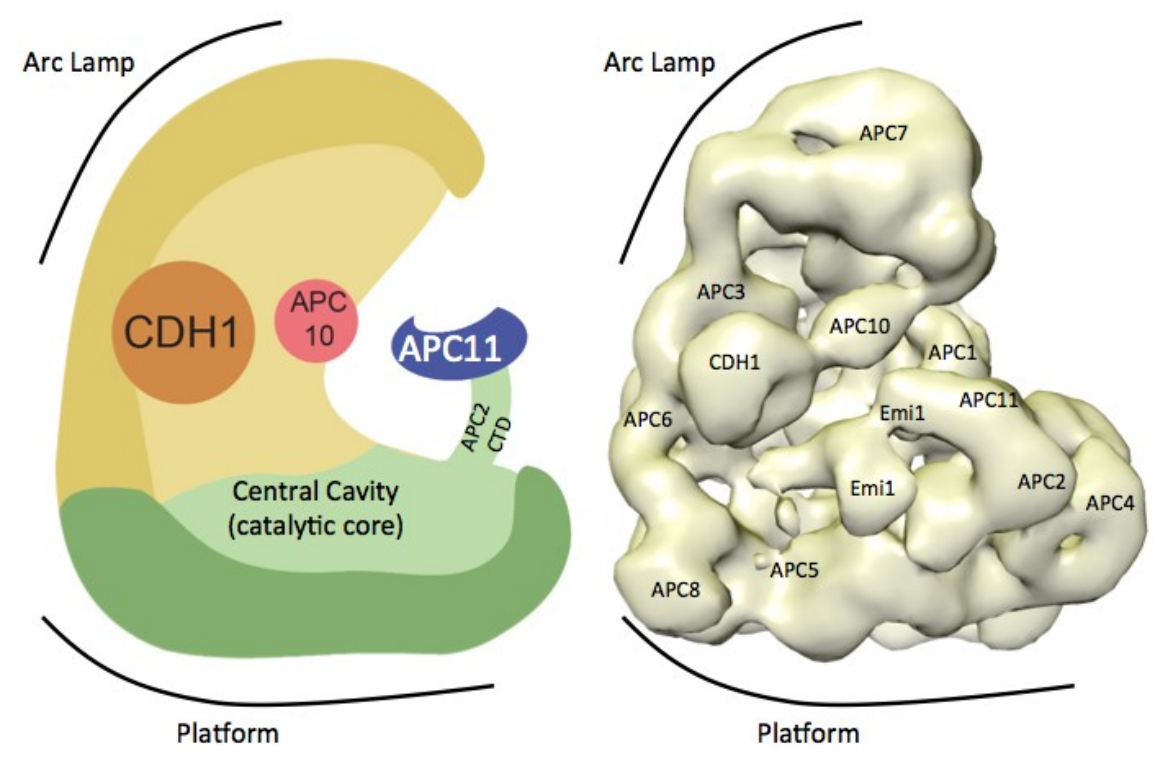

Figure 1-4. Overall Architecture of the APC/C.

Left, Schematic representation of the APC/C with Cdh1 and APC10 poised to corecruit substrate D-boxes, and APC11 positioned to perform catalysis. Right, EMDB-2354 shows APC/C-Cdh1-Emil-Skp1 with labels for subunits contributing to density. 


\section{The APC/C Coordinates with Coactivator Proteins Cdc20 and Cdh1 to Recruit Substrates and Activate the Platform for Catalysis}

Cdc20 (Cell Division Cycle 20) and its homolog Cdh1 (for Cdc20 Homolog 1) were discovered for their role in maintenance of cell division in Saccharomyces cerevisiae (Visintin, Prinz et al. 1997). Both of these proteins binds to the APC/C at the same position, and therefore compete for binding (Nagai and Ushimaru 2014). Levels of Cdc20-bound and Cdh1-bound APC/C are distinct throughout the cell cycle, as pools of these proteins are not constant and binding is competitive. Early in mitosis, Cdh1 levels are decreased and APC/C-Cdc20 exists predominantly. Following the metaphase to anaphase transition, $\mathrm{Cdc} 20$ becomes a target of $\mathrm{APC} / \mathrm{C}$-mediated degradation and APC/C-Cdh1 is the dominant complex throughout the rest of the cell cycle (Morgan 2007). The APC/C collaborates with $\mathrm{Cdc} 20$ and $\mathrm{Cdh} 1$ for two primary reasons; substrate recruitment and platform activation. The 7-bladed WD40 B-propeller domain common to both $\mathrm{Cdc} 20$ and $\mathrm{Cdh} 1$ provides a single, well-studied docking surface for recruitment of a "degron-motif" common to APC/C substrates, as well as other surfaces that aid in recruitment of secondary motifs. Substrates present an exposed RxxLxxx(x)N motif which is recruited by bipartite mechanism to both the coactivator and a nearby subunit called APC10 (da Fonseca, Kong et al. 2011). Secondary substrate motifs such as the ABBA (first characterized in Cyclin A, Bub3, BubR1, and Acm1) motif and KEN-box (Lys-Glu-Asn) are further coordinated by the coactivator (Tian, Li et al. 2012, He, Chao et al. 2013). APC/C recognition of substrates by multiple motifs of varying affinity is thought to be a mechanism for coordinating specificity and timing of substrate turnover. In more recent studies (Chang, Zhang et al. 2015) it has been shown that an N-terminal $\mathrm{C}$-box motif of Cdc20 and Cdh1 enhances coactivator binding and $\mathrm{APC} / \mathrm{C}$ activation independent of substrate recruitment.

\section{Many Substrates Are Targeted for Destruction by the APC/C}

The APC/C ubiquitinates a large number of proteins involved in cell cycle regulation. In one example, Cyclins are a group of proteins that were named for the cyclic fluctuation of their expression levels throughout the lifetime of $S$. cerevisiae cells. The characterization of these proteins, of which there are several, to be found in repeating cycles of high and low concentration was the first evidence for what is known today as the cell cycle (Evans, Rosenthal et al. 1983). Cyclins are regulatory proteins for Cyclindependent Kinases (CDKs), a group of kinases with critical functions throughout the cell cycle. Therefore cyclic levels of Cyclin proteins leads to fluctuations in CDK activity, and drives the cell cycle forward. A- and B-type Cyclins are bonafide substrates of the $\mathrm{APC} / \mathrm{C}$, and this underscores the role of the $\mathrm{APC} / \mathrm{C}$ in regulating cell-cycle progression. The APC/C also targets many other mitotic proteins including Aurora, Polo-like Kinase 1 (PLK1), Nek2a, Securin, and parts of the APC/C machinery itself including the Cdh1 and Ubch10 (Ostapenko, Burton et al. 2012, Lu, Hsiao et al. 2014, Lu, Girard et al. 2015). Degradation of this large group of cell-cycle regulatory proteins in an ordered and specific way allows the APC/C to orchestrate and direct progression through mitosis and then regulate its own activity in trans following completion of anaphase. Detailed 
information about substrate selection and temporal regulation of ubiquitination surrounding the cell cycle represents an active area of research.

\section{Primarily Two E2 Enzymes Work in Conjunction with the APC/C to Deliver Ubiquitin}

The APC/C is a Cullin-RING E3 ligase. As such, it brings together a substrate and a Ub-loaded E2 to catalyze direct ubiquitination of the substrate. The APC/C has two dedicated E2 enzymes called Ubch10 (sometimes called Ube2c), and Ube2s. Ubch10 utilizes canonical activating residues on the APC11 RING domain, and thus participates in a relatively standard Ubiquitination process. It has been shown that Ubch 10 prefers to modify lysines on substrates rather than on Ubiquitin itself, and therefore builds only very short chains and many single Ubiquitins decorated on the substrate surface (Yu, King et al. 1996, Lin, Hwang et al. 2002). Ube2s, however, is a chain-elongation enzyme similar in function to Cdc34 for other CRLs. Ube2s can only attach a Ubiquitin to the Lysine (typically K11) of another Ubiquitin and has essentially no capacity to modify APC/C substrate Lysines directly (Garnett, Mansfeld et al. 2009, $\mathrm{Wu}, \mathrm{Merbl}$ et al. 2010). Though the Ube2s reaction is simplified to a single modification, it occurs rapidly and repeatedly, building long K11-linked homotypic chains, which have been shown to be essential for mitotic progression (Min, Mevissen et al. 2015).

Interestingly, mutations of RING residues within APC11 that are deficient for canonical E2 enzyme activities have no profound effect on Ube2s activity, suggesting a novel, yet undiscovered mechanism of ubiquitination (Brown, Watson et al. 2014).

\section{The Mitotic Checkpoint Complex Binds to the Core of $\mathrm{APC} / \mathrm{C}$ and Inhibits Function}

The APC/C is engaged not only by E2 enzymes, coactivators, and substrates for activity, but also by inhibitors such as the Mitotic Checkpoint Complex (MCC) and Emi1. In the early stages of mitosis, an MCC comprised of four proteins (Mad2, Bub3, BubR1, Cdc20) binds directly to the APC/C and inactivates destruction of several substrates. Interestingly, certain APC/C substrates like Nek2a and Cyclin A are still targeted, presumably by an MCC-bound $\mathrm{APC} / \mathrm{C}$ through unknown mechanisms. Following cell cycle progress cues, the $\mathrm{APC} / \mathrm{C}$ is released from $\mathrm{MCC}$, and causes destruction of its full suite of substrates, including Cyclin B and Securin - factors responsible for promotion to Anaphase. A low-resolution electron microscopy structure of an MCC-bound APC/C reveals a probable model for how the MCC blocks APC/C activity (Herzog, Primorac et al. 2009, Chao, Kulkarni et al. 2012). The structural data, when analyzed both as Apo-APC/C and MCC-APC/C, shows substantial electron density within the central cavity of APC/C only when bound by the large MCC. The MCC likely binds to and blocks APC/C catalytic functions as a competitive inhibitor through direct binding of the catalytic core of $\mathrm{APC} / \mathrm{C}$, 


\section{Emi1 Is Responsible for Inhibition of the APC/C Throughout Interphase}

Another protein called Emi1, for Early Mitotic Inhibitor 1, is also thought to directly bind and inhibit the APC, albeit through unknown mechanisms. In stark contrast to the multi-protein, $\sim 300 \mathrm{kDa}$ checkpoint complex and the $\sim 1,200 \mathrm{kDa} \mathrm{APC} / \mathrm{C}, \mathrm{Emil}$ is relatively small at only $50 \mathrm{kDa}$. Unlike the $\mathrm{MCC}$, Emil has not been structurally characterized in complex with the $\mathrm{APC} / \mathrm{C}$, and its mechanism is presumed to be unique due to the massive difference in size.

\section{Emi1 - The Interphase Inhibitor of APC/C Polyubiquitination}

Emil was first discovered as Rcal in fruit fly genetic screens in 1997 (Dong, Zavitz et al. 1997), and was introduced as Fbxo5 in 1999 from a yeast two-hybrid screen for proteins that bind to Skp1, a well-known substrate-adaptor for the Cullin-RING family of E3 ligases (Cenciarelli, Chiaur et al. 1999, Latres, Chiaur et al. 1999). It was then rediscovered in Xenopus laevis in 2001 using similar methodology, and characterized as an inhibitor of APC/C activity early in mitosis (Reimann, Gardner et al. 2001). A closely related homolog, Emi2, shares similar domain architecture with Emi1, and plays a similar role in the Xenopus meiotic cycle, so for the sake of simplicity, I will highlight only the features of Emi1. In addition to cycles of expression and assembly of the APC/C, Emil association and inhibition also occurs cyclically. Throughout interphase the $\mathrm{APC} / \mathrm{C}$ is found in its inhibited state and only at the onset of mitosis is Emil removed and degraded, allowing the cell to precisely control both the timing and order of substrate degradation, targeted by the $\mathrm{APC} / \mathrm{C}$, which is an important prerequisite for maintenance of the cell cycle.

\section{Multiple Domains of Emi1 Are Suggested to Participate in APC/C Inhibition}

At the onset of our investigation, putative domains of Emil had been discovered, but had not been thoroughly characterized for APC/C-specific function (Figure 1-5). Emil residues $\sim 250-300$ contain an F-box motif (named for its discovery first in Cyclin F) by which Emi1 was discovered. F-box domains are structural motifs that mediate protein-protein interactions, and are usually involved in Cullin-mediated ubiquitination pathways. The F-box fold interacts with other motifs such as the Leucine-Rich Repeat (LRR) and WD-40 motifs that are often involved in CRL substrate presentation (Cenciarelli, Chiaur et al. 1999). Residues 360-420 of Emil contain primary sequence hallmarks that are conserved in a structural motif called a Zinc-Binding Region (ZBR). Zinc ions are coordinated by regularly spaced Cysteine and Histidine residues and are necessary for maintaining tertiary structure of this motif. Indeed, mutation of Cysteine residues thought to coordinate Zinc abrogates Emi1 function (Reimann, Freed et al. 2001, Tang, Wu et al. 2010). An extreme C-terminal Arginine-Leucine (RL) motif, called the 


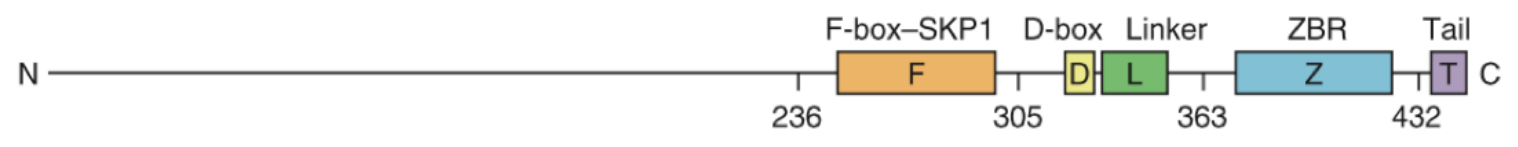

Figure 1-5. Domain Orientation of Emi1 to Scale.

Emil has a large N-terminal domain unimportant for APC/C association, a folded F-box domain that associates with Skp1, a small D-box motif, Linker Region, Zinc-BindingRegion, and C-terminal LRRL tail. 
RL-tail, has been proposed to aid in recruitment of both Emi1 and Emi2 to APC/C through direct binding (Ohe, Kawamura et al. 2010). Deletion of these residues of Emi2 ablates binding to endogenous $\mathrm{APC} / \mathrm{C}$, as evidenced by an inability to co-IP APC/C from Xenopus oocytes.

\section{Emi1 Itself Is Regulated by Phosphorylation and Ubiquitination by SCF}

Emi1 itself is a substrate of CRL-mediated ubiqutination and subsequent proteasomal degradation. The N-terminal domain of Emil contains a variety of motifs which are recognized by both kinases and CRL machinery to provide controlled mechanisms of Emil destruction. First, a pair of Serines at residues 145 and 149 within Emi1 are phosphorylated by Polo-like Kinase 1 (PLK1) in an Evi5-dependent manner. When Evi5 is not associated with Emi1, PLK1-mediated phosphorylation creates a wellcharacterized phospho-degron DSGxxS (Residues 144-149) motif for SCF recruitment. $\boldsymbol{\beta}$-TrCp, an SCF substrate adaptor protein, binds Emi1's phospho-degron and promotes SCF-dependent Emil turnover (Margottin-Goguet, Hsu et al. 2003, Hansen, Loktev et al. 2004). Despite knowledge of these mechanisms of Emil destruction, the context of its regulation is not known. Two possible scenarios could describe the relationship between Emil's own regulation and its inhibition of APC/C. In one scenario, Emil's N-terminus could be protected from recognition by interaction with the $\mathrm{APC} / \mathrm{C}$. Alternatively, Emil $\mathrm{N}$-terminus may be only flexibly tethered to the APC/C through $\mathrm{C}$-terminal contacts, allowing constant phosphorylation, ubiquitination, and degradation. In the second scenario, it is also conceivable that phosphorylation or ubiquitination of Emi1 could either enhance $\mathrm{APC} / \mathrm{C}$ binding, or provide a mechanism for liberation of $\mathrm{APC} / \mathrm{C}$.

However, there is no direct evidence for regulation of Emil while associated with $\mathrm{APC} / \mathrm{C}$ yet, and the mechanism of dissociation is not well understood. Emil is also regulated at the transcriptional level by a transcription factor called E2F. Its transcription is induced at the G1/S-phase transition, enhancing APC/C inhibition and substrate stabilization (Hsu, Reimann et al. 2002, Verschuren, Ban et al. 2007).

\section{Specific Timing and Localization of APC/C Inhibition Within the Cell Cycle}

Emil's inhibition of the $\mathrm{APC} / \mathrm{C}$ is critical to prevent premature degradation of Cyclins and other cell cycle kinases. Emil levels increase following mitosis and APC/C remains in an inhibited state throughout interphase. Even during the early stages of mitosis, while Cyclin B activates Cdk1 to drive spindle assembly, APC/C must be inhibited. To inhibit APC/C specifically at the location of spindle assembly, Emi1 is recruited through an interaction with a $\mathrm{NuMa}$ /Dynein-dynactin complex. This localizes Emil to the spindle poles and therefore any APC/C at the poles is efficiently inhibited, and Cyclin B is not degraded (Ban, Torres et al. 2007). Following phosphorylation and degradation of Emil, the $\mathrm{APC} / \mathrm{C}$ is bound by $\mathrm{MCC}$ until completion of the Spindle Assembly Checkpoint (SAC). By unknown mechanisms, MCC disassembles from the $\mathrm{APC} / \mathrm{C}$, which is finally able to rapidly degrade a number of cell cycle regulatory proteins and drives the cell cycle forward. 


\begin{abstract}
Aims of This Study
In the present study, I aim to characterize how Emi1, a protein dwarfed in size by its target, is capable of reducing the activity of $\mathrm{APC} / \mathrm{C}$ to negligible levels throughout most of the cell cycle; this allows a functional $\mathrm{APC} / \mathrm{C}$ to be assembled and ready to efficiently degrade cell cycle regulatory components only when the cellular environment is ready. Protein-protein interactions often mediate the activity or accessibility of enzymes and thus change the outcome. As mentioned above, the Anaphase Promoting Complex utilizes these interactions to attract its substrates and cofactors and catalyze the degradation of these substrates. As a form of regulation, the cell has also developed another protein that potently inhibits the $\mathrm{APC} / \mathrm{C}$ by unknown mechanisms, and it is speculated that this inhibition is also mediated through protein-protein interactions..
\end{abstract}

To characterize Emil function, I will establish protocols for expression and purification of many constructs of the Emil gene. With sufficient quantity of pure Emi1 proteins, and the capacity to make mutations, we can begin to probe the functionality of Emi1 in APC/C-dependent ubiquitination assays. Using established in vitro enzyme assays designed to monitor APC/C ubiquitination efficiency, we can saturate with Emi1 preemptively to counteract the activity of APC/C. I will utilize this system to establish baselines for how effectively mutants of Emil inhibit these reactions.

In parallel, Emil will be used both as the subject and critical tool for electronmicroscopy studies with APC/C-Cdh1. EM density calculations systematically exclude mobile elements within protein complexes. Further micro-fluctuations of the metastructure of large complexes limits the resolution obtainable by this method. Emil will therefore be used in EM studies not only in attempt to characterize its location and function, but also in attempt to stabilize the $\mathrm{APC} / \mathrm{C}$ and therefore improve the structure determination processes.

Following a comprehensive analysis of Emil interactions with $\mathrm{APC} / \mathrm{C}$, the interaction will be further exploited to develop methods by which other $\mathrm{APC} / \mathrm{C}$ interactions can be studied. With Emil as a positive control for APC/C association, protocols will be developed for incorporation of a photoactivatable crosslinking reagent designed to inform on site-specific localization of protein-protein interactions. In brief, an unnatural amino acid called $p$-BPA will be incorporated to a single site within Emi1. Following association with $\mathrm{APC} / \mathrm{C}$, crosslinking will be activated and information about the interaction is revealed. This technique is both complementary to other biochemical and structural studies of Emil-APC/C, and also provides a framework to study less tractable APC/C interacting partners. For instance, Ube2s interacts with the APC/C only transiently, and cannot be visualized through electron microscopy. Following optimization and confirmation of Emil crosslinking, analagous experiments can be performed with Ube2s to stabilize and characterize otherwise unobservable interactions. 


\title{
CHAPTER 2. EXPRESSION AND PURIFICATION OF EMI1 AND UBE2S FOR BIOCHEMICAL AND STRUCTURAL STUDIES
}

\author{
Emi1 Expression and Purification
}

Initial characterization of Emi1 includes describing which of the known or yet undiscovered motifs are contributing to the functionality of Emi1. To this end, we designed expression constructs systematically isolating or deleting a number of domains of Emil for functional testing against APC/C-mediated ubiquitination in vitro. Utilizing recombinantly expressed $\mathrm{APC} / \mathrm{C}$ and its bona-fide cell cycle substrates, we can recapitulate the activities of cellular $\mathrm{APC} / \mathrm{C}$ and analyze loss or gain of function variants of Emil in in vitro ubiquitination assays.

\section{Expression of Recombinant Emi1-Skp1 Protein Complex in E. coli Cells}

With rough approximations of a regulatory N-terminus, an F-box, a D-box, a linker sequence spanning between the D-box and a folded ZBR, and the extreme Cterminal tail, we made whole domain truncations as described in Table 2-1. For the sake of simplicity, I establish and hereafter utilize motif-specific nomenclature for constructs of Emil, namely N, F, D, L, Z, and T for N-terminus, F-box, D-box, Linker region, ZBR, and Tail, respectively. Therefore Emil DLZT contains the latter four domains and does not contain the N-terminus or F-box, and so on.

Bacterial expression in Escherichia coli has long been a standard technique for promoter-driven protein over-expression due in part to the ease of culture maintenance, relative affordability, and robustness of expression. Therefore all gene constructs were initially cloned into a robust expression vector with an N-terminal GST affinity tag. A modified version of pGEX-4T1 (GE Healthcare), with a TEV protease recognition site replacement of the Thrombin protease recognition site, was an ideal choice for initial protein expression for several reasons. First, the genetic linkage of Emil to a GST tag allows for significant improvement in purity from affinity chromatography over the more widely use hexa-Histidine tag, and subsequent TEV-mediated liberation of the GST tag yields high-quality protein with nearly native amino acid sequence. This also subverts the need for immobilized metal affinity chromatography, which may interfere with Emil's Zinc-binding region. Second, the pGEX vector is under control of the Lac operon and therefore protein expression is directly induced with a relatively inexpensive chemical called isopropyl-thiogalactopyranoside, IPTG. As such, this vector has been widely used to produce high quantities of well-purified protein samples.

For Emil constructs that contain the folded F-box motif, dual-plasmid coexpression with a Skp1 clone was found to be necessary, as uncomplexed Emi1 F-box yields very little protein. Following standard expression and induction protocols, the initial quantity and quality of GST-Emil produced for these constructs was widely 
Table 2-1. Emi1 Constructs Are Named According to Their Inclusive Domains.

\begin{tabular}{lccc}
\hline \multicolumn{1}{c}{ Construct } & Residues & $\begin{array}{c}\text { Skp1 } \\
\text { Coexpression }\end{array}$ & $\begin{array}{c}\text { Expression } \\
\text { System }\end{array}$ \\
\hline $\begin{array}{l}\text { Emil-NFDLZT } \\
\text { (full-length) }\end{array}$ & $1-447$ & Yes & High-five \\
Emil-NFDLZ & $1-432$ & Yes & High-five \\
Emil-NFDL & $1-362$ & Yes & High-five \\
Emil-FDLZT & $236-447$ & Yes & BL21 Gold \\
Emil-DLZT & $305-447$ & No & BL21 Gold \\
Emil-ZT & $363-447$ & No & BL21 Gold \\
Emil-T & & No & Synthesized \\
\hline
\end{tabular}

Emi1-NFDLZT contains the N-terminus, F-box with Skp1 bound, D-box, Linker Domain, Zinc-Binding-Region, and essential Tail residues. Smaller constructs lack one or more of these domains and are named accordingly. 
variable. Whereas milligram quantities of pure Emi1-DLZT or ZT are obtained per liter of expression, only microgram quantities of relatively impure Emil-NFDLZT are expressed in E. coli, even when co-expressed with Skp1.

\section{Expression of Emi1-Skp1 in High-Five Insect Cells}

Notably, constructs containing sequence more N-terminal than the F-box were unable to be expressed in bacteria in sufficient quantity for purification. These clones were transferred to a baculovirus-containing plasmid for transfer to an insect cell expression system (Philipps, Forstner et al. 2005). The Bac-to-Bac vector system (Invitrogen) allows for viral incorporation of Emi1 genes, and subsequent transfection into insect cells in a number of steps. A plasmid called a Fastbac is first transformed to chemically competent cells harboring baculovirus DNA and incorporates the viral DNA in a process termed transposition. Bacmid DNA is then purified from these cells, which harbors the Emil gene, a reporter GFP, and necessary components to produce live virus. Transfection of this bacmid DNA to adherent SF9 insect cells initiates the viral life cycle and virus can be harvested in the extracellular medium 3 days post-infection (d.p.i.). This process can be repeated to increase viral titers until mature, concentrated viral media can be used to infect large-scale suspension cultures of another insect cell line, High-five (Hi5). Using this expression system, N-terminal Emil constructs could be generated in sufficient quantity and quality for purification and use in assays (Figure 2-1). With the combination of these two expression systems, high-level overexpression of all Emi1 constructs is possible, and procedures for purification of these proteins can be developed.

\section{Individualized Purification of Emi1 Constructs}

A single, standard purification protocol was applied en bloc to all of these constructs, with various outcomes. While some constructs behaved quite well and were readily purified through affinity, ion-exchange (IEX), and size-exclusion (SEC) chromatographies, others were unable to be purified in this way for varied reasons. This section will highlight some of the most important observations and the protocols that were developed to produce large quantities of optimally pure protein in the most timeand cost-effective way for the variety of Emil constructs.

\section{N-terminal Constructs of Emi1 Are Unstable and Require High Ionic Strength}

Full-length Emi1-NFDLZT as well as constructs containing the N-terminus through residue 432 (NFDLZ), or residue 362 (NFDL), were expressed in high-five cells as previously described. These protein complexes (each are co-expressed with Skp1) are observed to be relatively unstable and require high ionic strength for solubility.

Following GST immobilization chromatography, or GST pulldown, overnight dialysis to $50 \mathrm{mM}$ Tris $\mathrm{pH} 7.6,50 \mathrm{mM} \mathrm{NaCl}, 5 \mathrm{mM}$ DTT resulted in significant precipitation present 


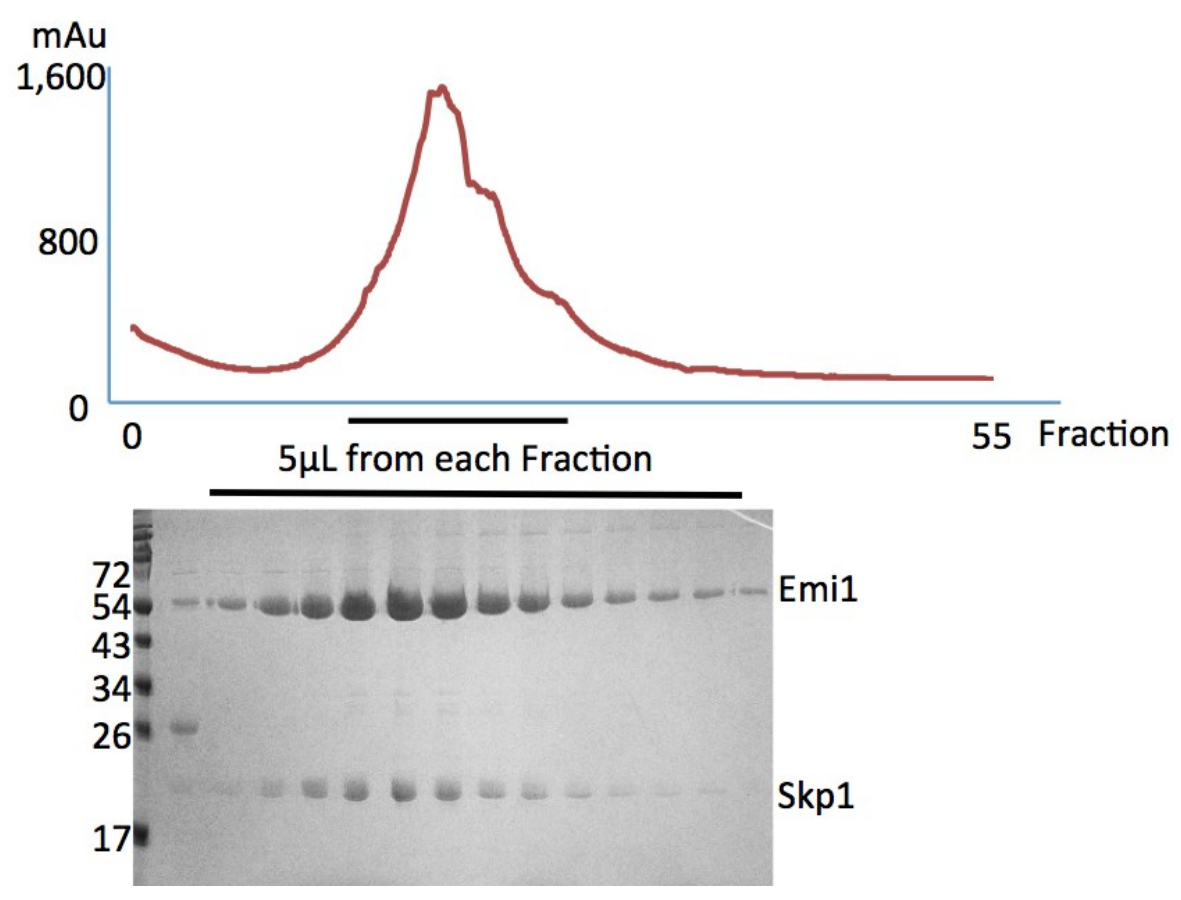

Figure 2-1. Emi1-NFDLZT Purification on Cation Exchange.

Above, representative gradient elution from Cation Exchange collected in several $5 \mathrm{~mL}$ fractions. Below, $5 \mu \mathrm{L}$ each fraction under the peak is analyzed for purity and concentration on SDS-PAGE. 
inside the protein-containing dialysis tubing, and insignificant Emil protein remaining in the soluble fraction. To overcome this issue, following affinity chromatography these constructs are dialyzed and cleaved in a buffer containing $50 \mathrm{mM}$ MES pH $6.0,200 \mathrm{mM}$ $\mathrm{NaCl}$, and 5mM DTT. By maintaining physiological $\mathrm{NaCl}$ concentration, no precipitation is observed, and the slightly basic $\mathrm{pH}$ of the MES buffer affords tighter binding to cation exchange resin in the next step. To further enhance the affinity with cation exchange resin, gradual dilution to $100 \mathrm{mM} \mathrm{NaCl}$ while mixing is required and immediate cation exchange is used to remove all liberated GST and several other impurities. Protein precipitation is observed at this dilution step on a time-course and $\mathrm{NaCl}$ dilution titration, necessitating immediate loading to the IEX resin. Elution with a shallow $\mathrm{NaCl}$ gradient yields a strong protein peak that correlates with fractions containing Emil (Figure 2-1). Following IEX, the protein is further purified and buffer exchanged to $20 \mathrm{mM}$ Tris $\mathrm{pH} 7.6,150 \mathrm{mM} \mathrm{NaCl}$ through SEC on a 10/300 superdex column.

\section{Emi1 FDLZT Is Easily Purified in Complex with Skp1}

Despite containing the F-box and Skp1 co-expression like other N-terminal constructs, FDLZT (residues 236-447) gives moderately good yield from bacterial cultures, and is purified without precipitation or loss of activity using a standardized protocol. Following GST pulldown and glutathione-mediated elution, FDLZT constructs are treated with $\sim 1 \% \mathrm{w} / \mathrm{w}$ TEV protease in elution buffer at $16^{\circ} \mathrm{C}$. To enhance binding to IEX resin, the protein is diluted four-fold in buffer absent of salt, bringing the concentration of $\mathrm{NaCl}$ to $50 \mathrm{mM}$. No precipitation is observed at low $\mathrm{NaCl}$, perhaps implicating the N-terminal 235 residues of Emil in NaCl-dependent solubility. Following elution from cation exchange by a $\mathrm{NaCl}$ concentration gradient, the protein is further purified through SEC, concentrated to $\sim 100 \mu \mathrm{M}$ and flash-frozen in liquid nitrogen for storage at $-80^{\circ} \mathrm{C}$.

\section{The C-terminal Inhibitory Region of Emi1 Requires Optimization of Purification Protocols}

Emil-DLZT and ZT protein purification are performed similarly to FDLZT through GST-affinity chromatography. However, glutathione-mediated elution is inefficient and requires up to $20 \mathrm{CV}$ before Emil is fully removed from the column. The massive volume of eluent is problematic for downstream purification procedures, and is unable to be concentrated despite several hours of centrifugal pressure in a centrifugal concentrator. To first identify the underlying biophysical events causing these problems, glutathione eluent protein samples were loaded to an Ethidium Bromide (EtBr) agarose gel typically used for purification of nucleotide products. Indeed, Emil DLZT purified from BL21 cells and purified through GST affinity is visible through EtBr staining suggesting the protein sample forms intermolecular crosslinks with nucleotides. Due to these non-specific crosslinks, elution from all types of sepharose columns is impractical

and leads to damage and clogging of columns and concentrating membranes. Following 
subsequent cation exchange, fractions from the IEX unbound and wash pools contain nucleotides, whereas protein eluate does not stain with EtBr (Figure 2-2).

To overcome this, multiple approaches were attempted simultaneously. Inclusion of DNAse had negligible effect when added either to the lysis or elution buffers, and purifications performed in $1 \mathrm{M} \mathrm{NaCl}$ yield half the protein but do not positively affect the glutathione elution profile (Figure 2-3). Though on-column cleavage is typically avoided to prevent enzymatic contamination of resins and columns used in future purifications, it was tested as an alternative to glutathione elution for these constructs. An improvement in elution was not expected, as the GST-tag itself is not implicated as the problem and Emil would still be capable of association with nucleotides as before. Much to our surprise, on-column cleavage with TEV allowed for liberated Emil to elute from the column in only 2 column volumes, making four-fold dilution of $\mathrm{NaCl}$ in downstream steps non-prohibitive. Furthermore, by leaving the liberated GST tag on the column, the eluent of on-column cleavage is nearly full-purity Emi1 (Figure 2-4). To remove the small amount of remaining impurities, we further purify by cation exchange using free resin in batch and transferring to gravity columns.

A combination of factors makes this purification protocol scalable to both high and low number of constructs, at high or low culture volume; a single construct of 24 Liters of cells yields protein of similar quality to multiple constructs at 1 Liter scale with similar demands on time and technical performance. By performing purification steps manually in plastic columns instead of through automated FPLC runs, many constructs are simultaneously purified, and eluted samples do not require time-consuming centrifugal concentration steps prior to IEX as they are robustly expressed and eluted at small volumes. This protocol makes it possible to purify upwards of 60 different constructs of Emi1-DLZT, Emi1-FDLZT or full-length Ube2s at 1 Liter scale within 48 hours by a single person (Figure 2-5). This provides the framework for development of mutagenesis experiments that require multiple variants of a single Emil construct at approximately equal purity. Following functional assay screens of the many mutants purified this way, protein constructs with desired behaviors can be followed up by larger scale purification ending in SEC for final polishing and full purification.

\section{Utilizing Assays That Segregate the Functions of the APC/C-specific E2s Ubch10 and Ube2s}

In order to be able to test Emil function, we utilize established in vitro ubiquitination assays in a variety of ways. By modifying pure proteins with fluorescent markers, we can monitor the ubiquitination of APC/C substrates in fluorescent scans of SDS-PAGE gels as slower-migrating (and therefore more modified) species. For the majority of assays presented in this work, we have chosen an $\mathrm{N}$-terminal fragment containing the N-terminal 95 residues of Cyclin B. This construct contains several lysines for modification with Ubiquitin, and behaves well as an in vitro substrate in published studies (Dimova, Hathaway et al. 2012). Ubiquitination assays are performed 


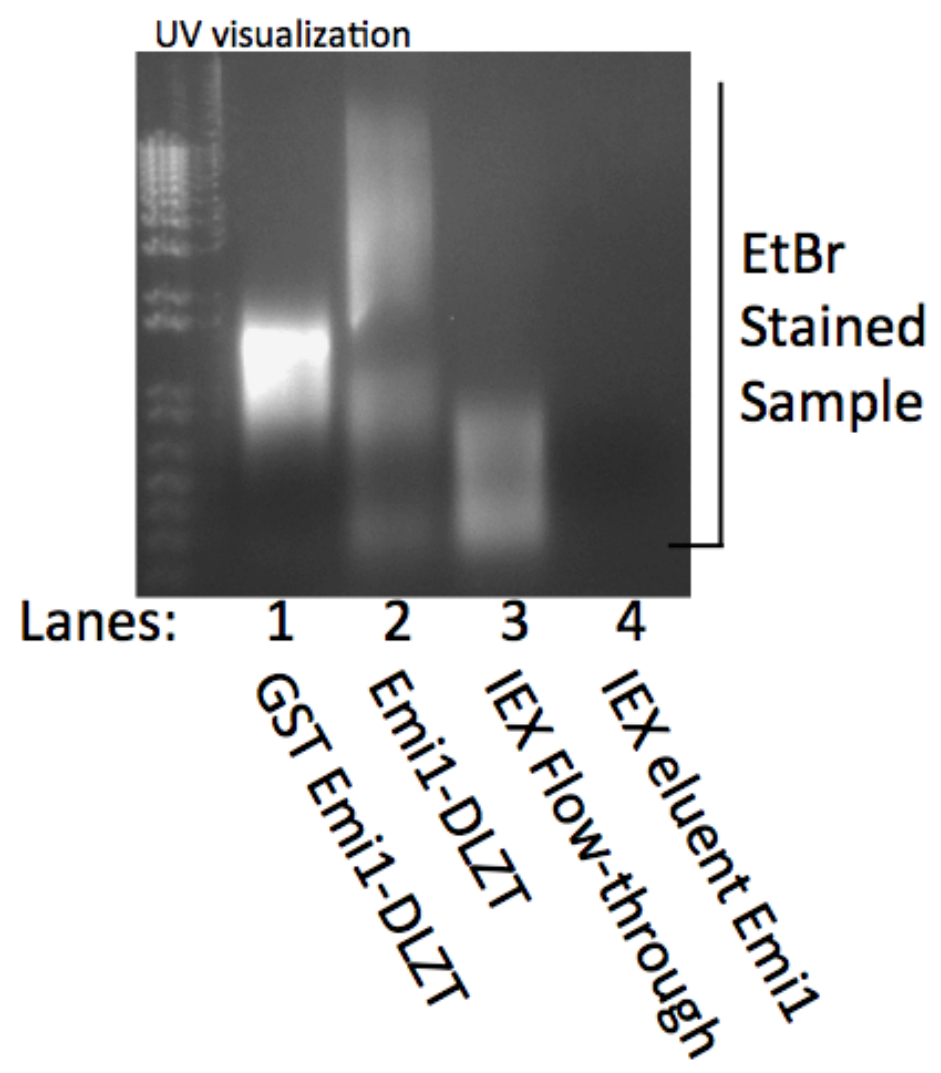

Figure 2-2. Emi1-DLZT Dissociates from Nucleotides during IEX.

Protein samples are loaded to $0.8 \%$ agarose gel and stained with EtBr. Lane 1 contains GST-Emi1-DLZT elution from GST-pulldown, Lane 2 contains product of TEV cleavage, Lane 3 shows the unbound fraction from ion exchange, and Lane 4 shows pure Emil protein eluent from ion exchange. 


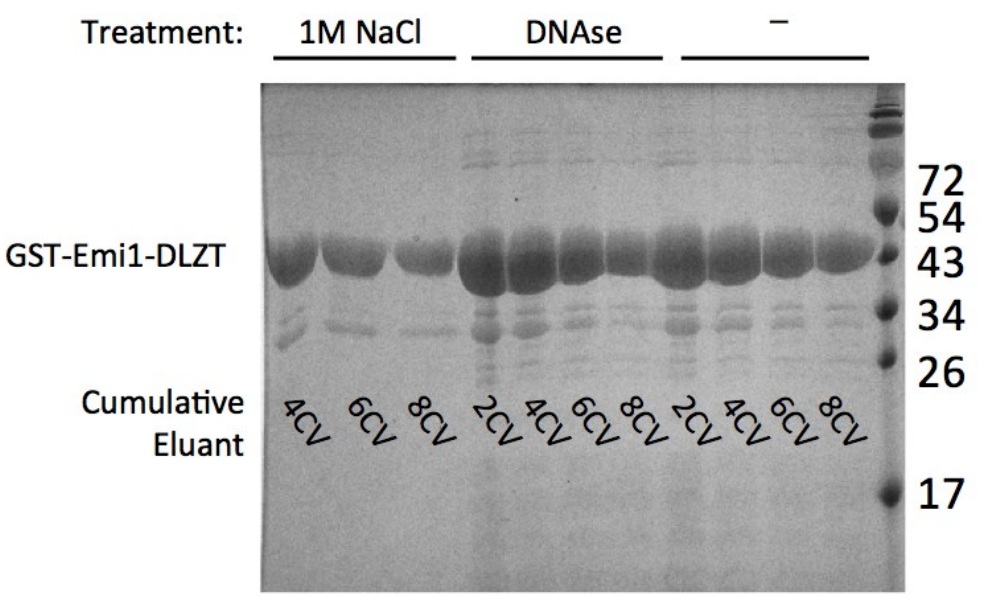

Figure 2-3. Increased Ionic Strength and DNAse Treatment Do Not Prevent Nucleotide Binding.

DNAse and $1 \mathrm{M} \mathrm{NaCl}$ concentration each fail to clear nucleotides from Emi1-DLZT protein preps. With protein elution requiring many column-volumes $(\mathrm{CV})$, downstream purification steps are impossible. 


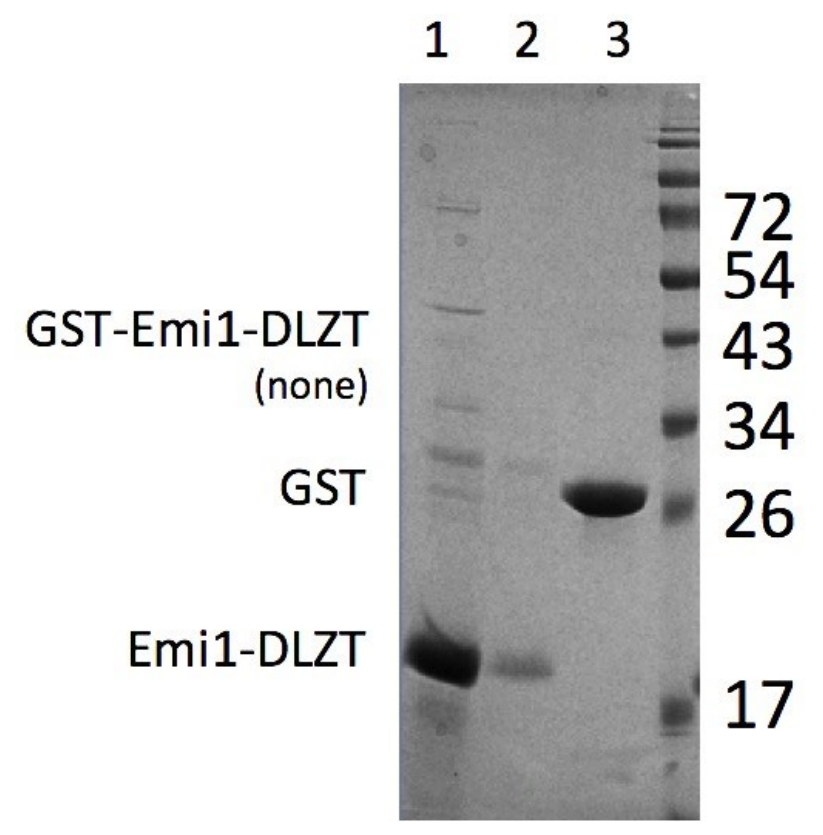

Figure 2-4. On-column Cleavage Effectively Purifies Emi1-DLZT from GST in Small Volumes.

On-column cleavage is performed for Emi1-DLZT and protein products are visualized by SDS-PAGE. Lane 1 contains the first column-volume elution using wash-buffer, Lane 2 contains the fifth column-volume elution using wash-buffer, and Lane 3 contains the first column-volume elution with Glutathione. This suggests Emil is completely liberated from GST, is eluted in low volume, and is well-purified from GST or contaminants following wash-buffer elution. Wash-buffer contains 50mM Tris $\mathrm{pH} 7.6,200 \mathrm{mM} \mathrm{NaCl}$, 5mM DTT, and no Glutathione. 


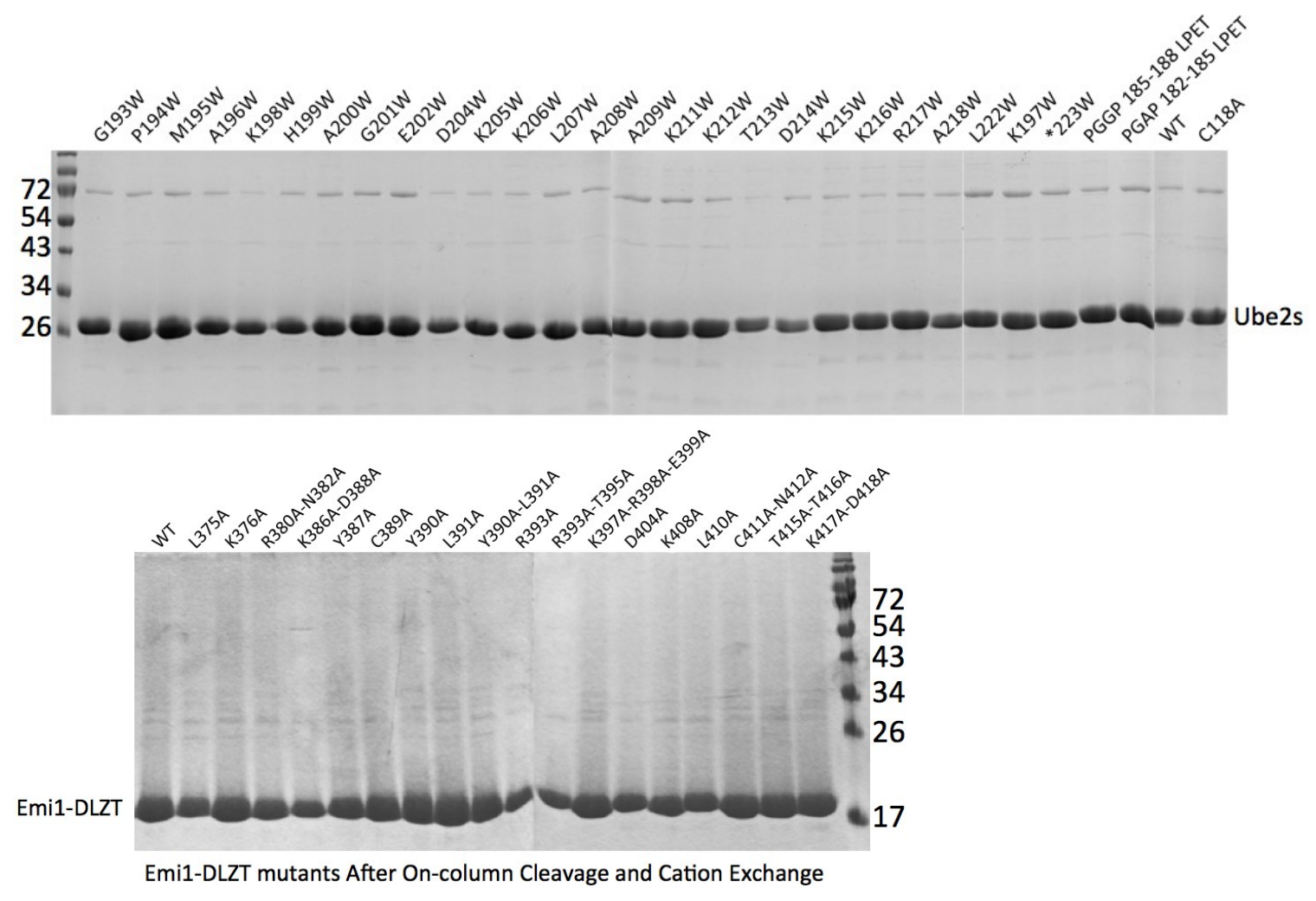

Figure 2-5. Optimized Purification Strategy Yields Pure Ube2s and Emi1.

Optimized purification of Ube2s (Top), Emi1-DLZT, (Bottom), or Emi1-FDLZT-Skp1 enables preparation of 60 constructs purified to high quality at the same time. This purification strategy makes Tryptophan-, Alanine-, and Amber-Scanning Mutagenesis experiments possible at large scale. 
by combining two independent mixtures: one contains $\mathrm{APC} / \mathrm{C}, 5 \mathrm{mM} \mathrm{MgCl} 2,5 \mathrm{mM}$ ATP, $0.25 \mathrm{mg} / \mathrm{mL}$ BSA, $1 \mu \mathrm{M}$ Cdh1, and $100 \mathrm{nM} \mathrm{UBA} 1$, and the second mixture contains $\mathrm{E} 2,125 \mu \mathrm{M}$ bovine Ubiquitin (Sigma) and fluorescent substrate. APC/C in the first mixture is incubated with $\mathrm{Cdh} 1$ on ice for at least $30 \mathrm{~min}$ prior to mixing. This combination prevents autoubiquitination of the E2 enzyme, which occurs when the E2 is capable of loading but does not have a substrate to target (Jarvis, Brown et al. 2016).

The APC/C works with two distinct $\mathrm{E} 2 \mathrm{~s}$ in a sequential manner. The requirement for the substrate to be ubiquitinated before Ube2s can function makes it difficult to segregate any E2-specific functions of Emil inhibition. To circumvent this problem, a Ubiquitin protein is genetically fused to the N-terminus of Cyclin B 1-95 (UbCyclin B) that is labeled and purified as before. This mimic of ubiquitinated Cyclin B bypasses the requirement for the initiating E2, Ubch10. Therefore assays separating the functions of each E2 can be tested in Emi1 inhibition assays.

After establishing baselines for APC/C activity along a timecourse, Emil can be tested as an inhibitor of $\mathrm{APC} / \mathrm{C}$ function. Emil is added to the mixture containing APC/C-Cdh1 and allowed to incubate 1 hour before starting the reaction with E2 and substrate. This allows complexes of APC/C-Cdh1-Emi1 to form at equilibrium regardless of the affinity of mutant versions of Emil. Emil is a potent inhibitor of APC/C-Cdh1 mediated ubiquitination of the fluorescent Cyclin B 1-95 either with Ubch 10 or Ube2s alone (Figure 2-6). This provides the first evidence that Emil may be acting as a general APC/C inhibitor and not targeting the individual functions of the E2s. 

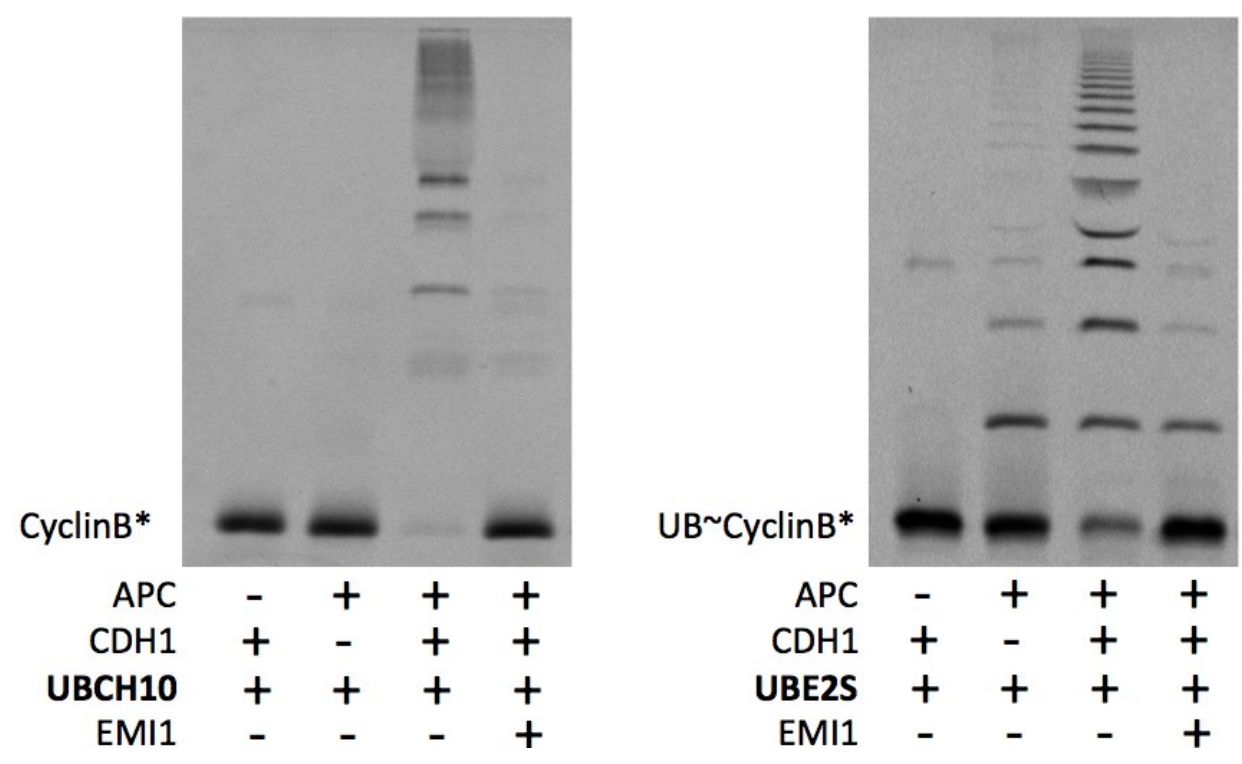

Figure 2-6. Emi1 Is a Potent Inhibitor of APC/C Mechanism in Assays That Segregate Both E2 Enzymes.

Fluorescent scan of SDS-PAGE results of ubiquitination assays monitoring fluorescent substrate modification by APC/C in presence or absence of Emi1-FDLZT.

Ubiquitination of Cyclin B 1-95* by Ubch10, Left, and Ub Cyclin B 1-95* by Ube2s, Right, are both inhibited by $50 \mathrm{nM}$ Emi1-FDLZT in a 12-minute reaction containing $12.5 \mathrm{nM}$ APC/C-Cdh1. 


\section{CHAPTER 3. MAPPING THE DOMAINS WITHIN EMI1 THAT CONTRIBUTE TO APC/C INHIBITION}

\section{Introduction to Emi1 as a Multi-Modal Inhibitor}

Three essential motifs and domains of the Emil protein have been discovered prior to this study, and provide a basis for understanding Emil activity and for our thorough biochemical characterization. Critical to Emil's proposed mechanism is a canonical D-box degron motif. This motif is commonly found in APC/C substrates and represents the major mode of substrate recruitment and targeting. The relative simplicity and disordered nature of the D-box motif presents a conundrum for APC/C substrate recruitment: conceivably many proteins contain Arginine-X-x-Leucine (RxxL) sequences, but are not intended APC/C targets. Indeed, Emil itself has two such sequence motifs and is predicted to be largely intrinsically disordered, fulfilling the two requirements for D-box binding. In preliminary studies, mutation of the conserved D-box of recombinant human Emi1 (Ala322-X-X-Ala 325 ) reduces immunoprecipitation of APC/C from HeLa extracts (Reimann, Gardner et al. 2001) and does not sustain M-phase arrest in the Xenopus laevis meiotic homolog Erp1 (Ohe, Inoue et al. 2007, Tischer, Hormanseder et al. 2012).

The same studies introduce a Zinc-dependent folded domain which is similarly conserved in Emil and Emi2. This domain, called the Zinc-Binding Region (ZBR) coordinates two zinc ions using 8 conserved Cysteine and Histidine residues. Metal ion coordination is often a requirement for structural integrity within these types of domains, and this is evidenced for Emil by loss of function in Emi1 proteins mutated for one of the conserved zinc-coordinating Cysteine residues (Miller, Summers et al. 2006). Similarly, removal of Zinc itself with a specific chelator, TPEN, abrogates Emil function, which can be rescued by addition of excess Zinc (Reimann, Gardner et al. 2001). These results suggest that Emil's ZBR domain is either capable of a folding-unfolding transition that is dependent on Zinc, or participates in metal-dependent catalytic mechanism. Either may provide a mechanism for sensing cellular cues or localization-dependent regulation of Emil function.

Emi1 D-box and ZBR domains were its first functional elements to be discovered, and are both evolutionarily conserved and retained within functional homologs of Emil. Closer inspection of the data characterizing these regions does not account for the full capacity of Emi1, however. A third conserved, functional element was later speculated to account for these discrepancies. At the extreme C-terminus of Emil and homologs is a so-called RL tail consisting of a penultimate Arginine and C-terminal Leucine. In studies of both Emi1 and Emi2, deletion or Alanine substitution of these residues prohibits association with $\mathrm{APC} / \mathrm{C}$ as detected in immunoprecipitation experiments in human embryonic kidney cells (Ohe, Kawamura et al. 2010).

The preliminary data generated in these studies suggest that Emi1 requires a variety of motifs for function, but the mechanism of inhibition is still unknown. 
Wholesale deletion or mutation of critical domains in Emil makes it a defunct inhibitor, but neither the loss-of-function nor the wild-type mechanism is convincingly explained. Having overcome the technical hurdles of expressing both active APC/C-Cdh1 and a variety of Emil constructs recombinantly, and with ubiquitination assays that segregate the functions of the APC/C's E2 enzymes, studies characterizing and ranking the diverse modalities of Emil's domains can be performed. Our in vitro ubiquitination system does not have the limitations associated with experiments performed in cells or lysates. The purified system both increases the capacity for experimentation and reduces the complexity of result analysis. With this toolbox of techniques and knowledge, we are well equipped to study mechanism and structure of Emil inhibition of the APC/C.

The N-terminus of Emil has been implicated in Emil's own regulation through phosphorylation, association with CRLs, and subsequent destruction, though it is not clear whether it is required for APC/C-specific activity. To isolate regions of Emil that are critical for $\mathrm{APC} / \mathrm{C}$ inhibition, constructs are designed with wholesale deletion of a variety of Emil domains. We first establish that constructs that delete either 235 residues or 304 residues (FDLZT, DLZT) from the N-terminus are equally potent inhibitors to full-length Emil-Skp1 in qualitative assays. In agreement with previous studies, constructs which impinge on either the Dbox (residues 322-325) or the extreme Cterminus (residues 444-447) are deficient suggesting that approximately residues 300-447 represent the minimal Emil construct that exhibits wild-type activity (Frye, Brown et al. 2013).

\section{Alanine Scanning Mutagenesis of the Conserved Zinc-binding Region of Emi1}

As the name suggests, Emil's ZBR domain has been shown to bind Zinc and this metal coordination is in some way important for Emil's function. To further characterize the structural requirement for this domain, I developed an alanine scanning mutagenesis experiment. Many clones harboring single, double, or triple amino acid substitutions were prepared by site-directed mutagenesis. The structure of the folded ZBR was recently determined in our lab through NMR experiments, allowing selective mutation of only surface-exposed residues which would be candidates for intermolecular interactions. By mutating surface residues that are presumed not to be necessary for the overall fold of the ZBR, we can determine if any one residue or set of residues are important for binding and inhibiting the $\mathrm{APC} / \mathrm{C}$.

\section{Selective Mutant Emi1 Proteins Exhibit Deficiency for APC/C Inhibition in an E2- independent Manner}

To be thorough our mutational analysis includes 27 mutations covering the entire surface of the ZBR, a 45-residue domain, and these mutations were cloned in duplicate to Emi1-FDLZT and Emi1-DLZT to eliminate spurious effects and false-positives. We first utilize assays with Ubch10 and APC/C catalyzing ubiquitination of Cyclin B with titrations of WT Emil inhibitor to determine a sensitive range for inhibition. Within this 
range, Emil concentrations allow near-complete inhibition of $\mathrm{APC} / \mathrm{C}$ activity, but are not in excess such that subtle defects are compensated for. Many features of ubiquitination assays are malleable, especially timecourses and relative enzyme/substrate concentrations. These parameters are systematically altered to find the optimal conditions to visualize real defects in Emil inhibition.

Following assay optimization, purified Emi1-DLZT mutant proteins are screened for potency at two concentrations, $300 \mathrm{nM}$ and $60 \mathrm{nM}$. Although the majority of mutant Emi1 proteins are efficient inhibitors, defects are observable for 9 clones and are colored according to rank-order (Figure 3-1). Prompted by these results, we designed experiments to test whether the defects observed for Emi1 inhibition of this Ubch10 assay would persist for Ube2s. It is conceivable that the Emi1 ZBR somehow blocks Ubch10 activity or association with the APC/C, but does not affect Ube2s. This hypothesis is supported by unpublished data suggesting that Ube2s utilizes distinct surfaces of the Cullin-RING machinery within APC/C for its function. In this scenario, it is also possible that the mutations causing defects for Ubch10 would be benign in a Ube2s assay, read out as wild-type inhibition capacity. To test this directly, we utilize UbCyclin B which bypasses Ubch10 as previously described, and monitor Ube $2 \mathrm{~s}-\mathrm{APC} / \mathrm{C}$ mediated ubiquitination. As before, the assay is optimized with wild-type Emil to establish the same sensitive range for inhibition.

Surprisingly, Emil surface mutations that render it inefficient at inhibiting Ubch10 have the same effect for Ube2s. There are two logical explanations for this result: either the mutations disrupt the folding of the ZBR domain, or they suggest that Emil's ZBR contributes globally to inhibition of the catalytic mechanism of the APC/C, not necessarily interrupting either E2 interaction specifically. To gain insights about the ZBR fold respective to these deleterious mutations, HSQC NMR experiments were performed on purified Emil-ZT wild-type and mutant proteins. We were able to disavow mutation R393/T395 in the middle of a hydrophobic Beta-sheet through this screen, but other defective mutants exhibit the hallmarks of native ZBR folding, namely L375A and K376A (data not shown). This affirms that surface residues of Emi1 ZBR that are not required for native tertiary structure formation are important for APC/C inhibition.

\section{Discovering a Single Surface of the Emi1 ZBR That Mediates Activity}

The residues defective in our ZBR Alanine scan are distant in primary sequence space, ranging from L375 to L410. However, when studying the NMR structure, these residues localize to a single surface within the folded domain. This provides evidence that one surface of Emil's ZBR domain mediates contact with the APC/C either through inter- or intra-molecular interactions (Figure 3-2). Performing the entire screen again using Emi1-FDLZT-Skp1 further validated these results. The same ZBR mutant residues perturb Emil activity in proteins from a different construct and clonal source, confirming there is no experimental or systematic error with the proteins or the assays. 


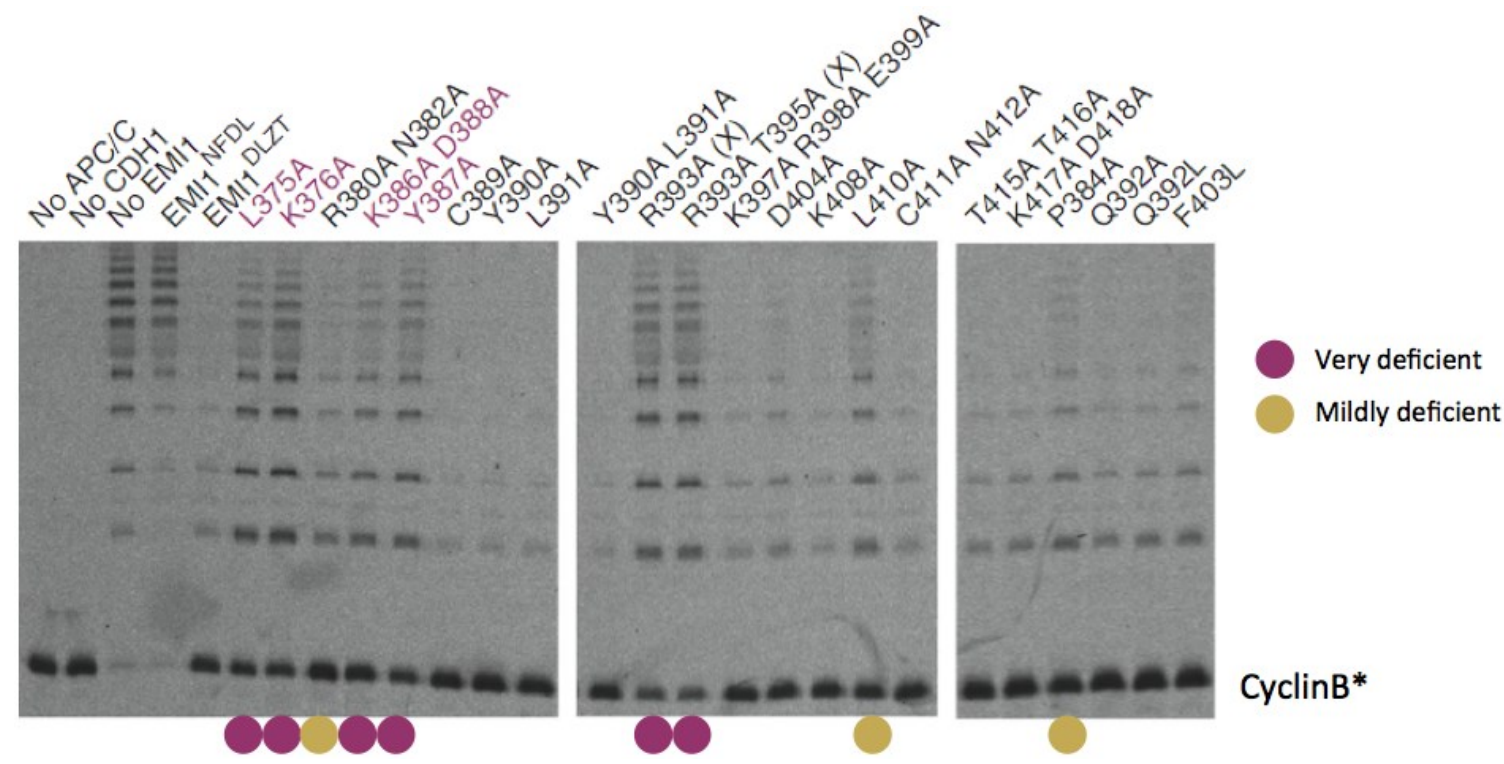

Figure 3-1. Alanine Scan of Emi1's ZBR Reveals Amino-acids Required for Function.

Ubch10-mediated ubiquitination of Cyclin B 1-95* is inhibited by 60nM Emi1-DLZT. Some mutations of Emil at the indicated positions hinder this function. Magenta circles indicate strongly deficient mutations, and orange circles indicate mildly-deficient mutations. 


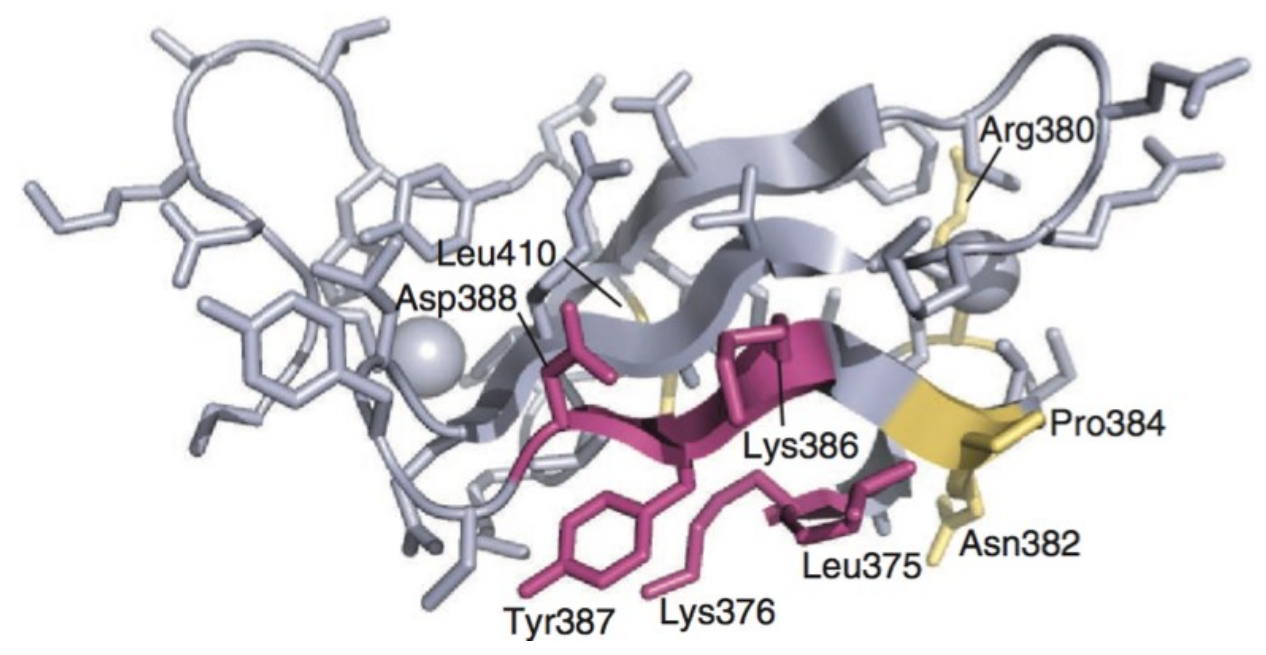

Figure 3-2. Alanine Scanning Mutagenesis Reveals a Single Surface Required for Inhibition.

Cartoon representation of the ZBR domain of Emil with results from Alanine scanning mutagenesis experiments highlighted in magenta (very deficient), or orange (mildly deficient). Mutants containing R393A have not been colored magenta, as they do not report on APC/C inhibition. Side-chains are shown in gray for all mutations in the screen that were not deficient in $\mathrm{APC} / \mathrm{C}$ assays. 


\section{Discovery of an Essential Linker Domain Between Emi1's D-box and ZBR Domains}

Both the ZBR and the D-box were implicated in previous studies as functionally relevant motifs of Emi1, described above. Again utilizing our in vitro expression and assay system, mutations of Emil's D-box can be tested in the context of Emil's inhibitory C-terminus. The $\mathrm{Arg}_{322}-\mathrm{X}-\mathrm{X}-\mathrm{Leu}_{325}$ mutation to Ala-X-X-Ala characterized as D-box dead is in fact required for Emil function, but not to the extent suggested from immune-precipitation experiments found in literature (Reimann, Gardner et al. 2001, Miller, Summers et al. 2006). This mutant, hereafter $\mathrm{D}^{\mathrm{mut}}$ is less harmful than mutation of the ZBR in a single assay (Figure 3-3, lanes 2, 3, 4, 13). A wholesale deletion of the D-box in a construct retaining both wild-type ZBR and the RL tail (Emil-ZT) does not, however, mimic the simple D-box mutation. This completely unexpected result leads us to consider other differences between Emil-D ${ }^{\text {mut }}$ LZT and Emi1 ZT. We hypothesize that there may be a functional motif in the linker domain which connects Emil's D-box to the ZBR. Functionality of this previously undiscovered region would rectify the disparity in Emi1 activity between our mutants, as it is left intact in Emi1-D ${ }^{\text {mut }}$ LZT, and deleted in Emil-ZT.

\section{Wholesale Deletion of a Linker Region of Emi1 Reveals a Functional Requirement for This Region}

To test this hypothesis, systematic deletion mutants targeting neither the D-box nor ZBR, but specifically the previously benign Linker domain between them were designed and prepared. We begin with a relatively mild deletion of 5 residues in the approximate center of this Linker domain, and further extend deletions in both directions to a total deletion of 10, 20, or 30 residues of this 50-residue sequence (Figure 3-3, top). Both Ubch10 and Ube2s-specific assays present identical functional consequence of Emil Linker deletion: 10-residue deletions are tolerated well in these assays, while 20and 30-residue deletions render Emi1 functionally incompetent. Importantly, both the Dbox and ZBR domains are intact in these constructs, pointing to a novel functional requirement for Emil inhibition.

\section{Residues Within Emi1's Linker Region Are Required for Inhibition}

Two possible scenarios account for this unexpected but striking result: either there are specific amino acids in this Linker region which are mediating contact with $\mathrm{APC} / \mathrm{C}$, or the distance spanned by these $\sim 40-50$ amino-acids is important to allow simultaneous D-box recruitment and ZBR engagement. Much of Emi1 is predicted to be intrinsically disordered, potentially to maximize the distance achievable with limiting sequence space. To test first whether only distance is required, I supplant the defective 20-residue deletion with 20 inherently flexible and extended Glycine, Serine, and Threonine residues. This full-length but mutant sequence of Emil does not robustly compensate for the 20-residue deletion, suggesting a functional role of specific amino- 


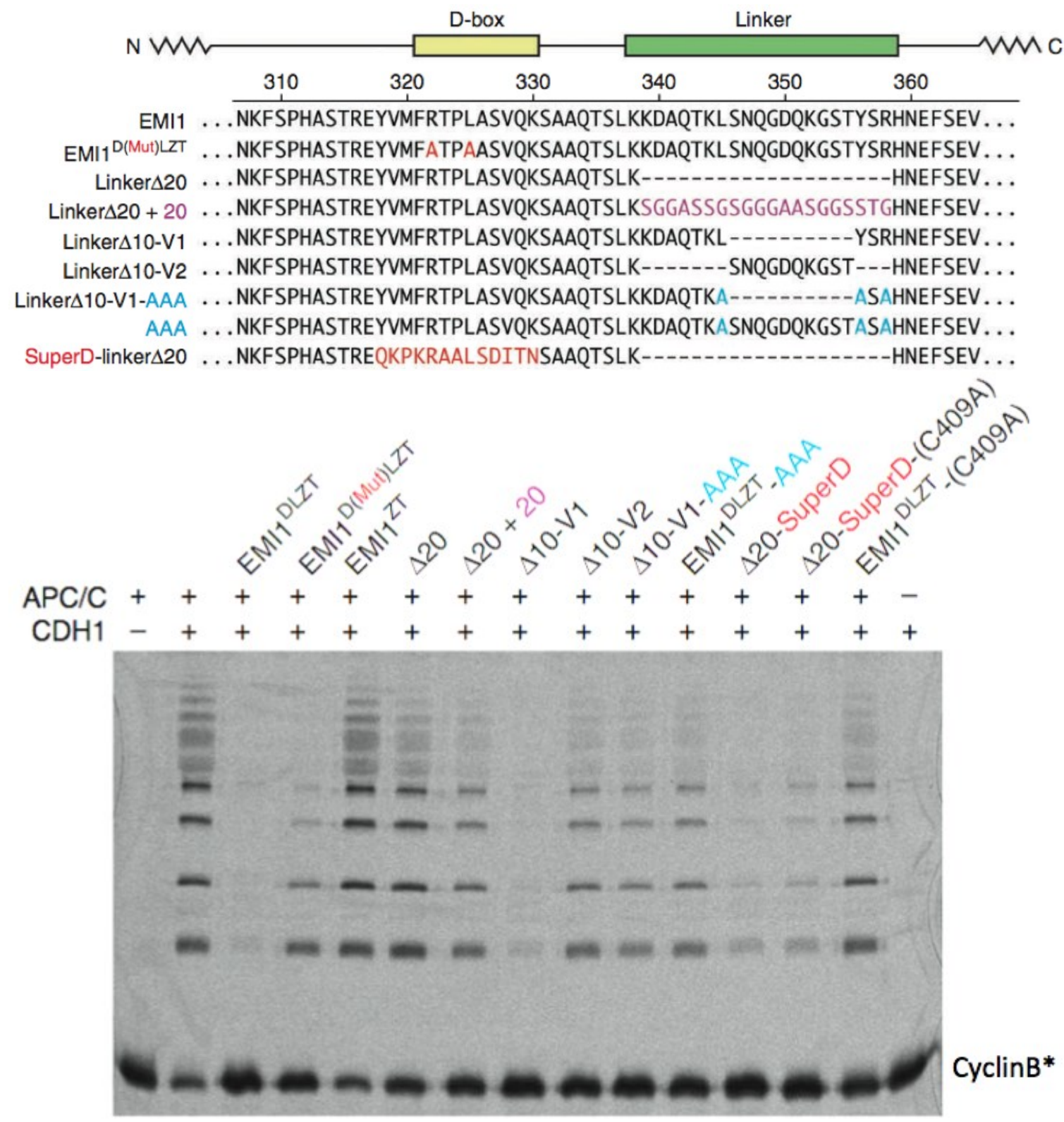

Figure 3-3. Relative Analysis for Mutations of Emi1 D-box, ZBR, and Functional Linker Domain Between Them.

Top, protein sequence and domain representation for Emi1 D-box and Functional Linker domain. Mutations in this region are annotated on the left, and color-coded for clarity. Bottom, fluorescent scan of SDS-PAGE results from inhibition of APC/C-Ubch10mediated ubiquitination. Emil-DLZT mutant proteins, as ascribed, are tested for their ability to inhibit Cyclin B 1-95* ubiquitination by APC/C. 
acid side-chains in this region. In other words, since the distance can be spanned again, but the defect still exists, it is likely that the amino-acid side-chains in this region are important. Multiple lines of evidence further support this hypothesis. Firstly, knowing that a 10 -residue deletion behaves normally where a 20 -residue deletion is severely deficient, I hypothesize that any sequence-specific functionality would derive from the opposite 10 residues (termed V2 for version 2) which are further deleted to form the 20residue deletion construct. In the same assay, the first 10-residue deletion behaves normally, where an orthogonal 10-residue deletion is severely deficient. Secondly, we locate specific residues within the linker that contribute to Emil activity. In the context of both the full-length-native, and benign 10-residue mutations, I make substitutions for patches of residues in the offending 10-residue Linker sequence. Triply mutating conserved Leu345, Tyr356 and Arg358 to Alanine residues was sufficient to substantially impair inhibition. Upon closer inspection of the data, mutation of these three residues alone, in otherwise wild-type Emil-DLZT, prevents Emil inhibition to a similar degree as Emi1-D ${ }^{\text {mut }}$ LZT and the Emi1-DLZT ZBR mutant (C409A, Figure 3-3, bottom). Therefore in these experiments, the contribution towards Emil's mechanism is approximately equal for each of these 3 domains.

\section{Emi1 Contains a Relatively Weak D-box and an Essential RL-Tail}

\section{Strengthening Emi1's Pseudosubstrate Activity Through Fusion with the D-box Region of Hsl1}

At least four domains, then, contribute to Emil activity: a D-box, a folded ZBR, a functional Linker between them, and a conserved RL Tail. To further characterize the relationship between these domains, and describe if they work competitively or cooperatively, we design constructs to enhance one domain and look for compensation of mutations in other domains. Emil's D-box contributes the least to inhibition, evidenced by the relatively good inhibition of Emil-D ${ }^{\text {mut }}$ LZT in Figure 3-3, lane 4. We tested this directly by generating peptides corresponding to the isolated D-box of both Emil and another D-box containing protein, the yeast APC/C substrate Hs11. In isolation, Emil's D-box is inefficient at blocking substrate ubiquitination, whereas an isolated peptide of Hsl1 potently blocks Cyclin B recruitment to the $\mathrm{APC} / \mathrm{C}$, presumably as a competitive inhibitor of the D-box binding site between Cdh1 and APC10 (Figure 3-4). Based on this information, a chimeric Emil Hsl1 fusion protein is generated that replaces the relatively poor sequence flanking and including the Emi1 D-box with the analogous region from Hsl1. This enhanced D-box version of Emi1, hereafter Super D-box or SuperD, is a much more potent inhibitor and nearly overcomes Emil's requirement for either a Linker or a ZBR (Figure 3-3, lanes 12, 13). Though we can only explain the mechanism but not the purpose for an avidity requirement, our analysis reveals that Emi 1 has evolved to utilize multiple weak motifs throughout the span of its $\mathrm{C}$-terminus, which are each essential but not sufficient for inhibition. 


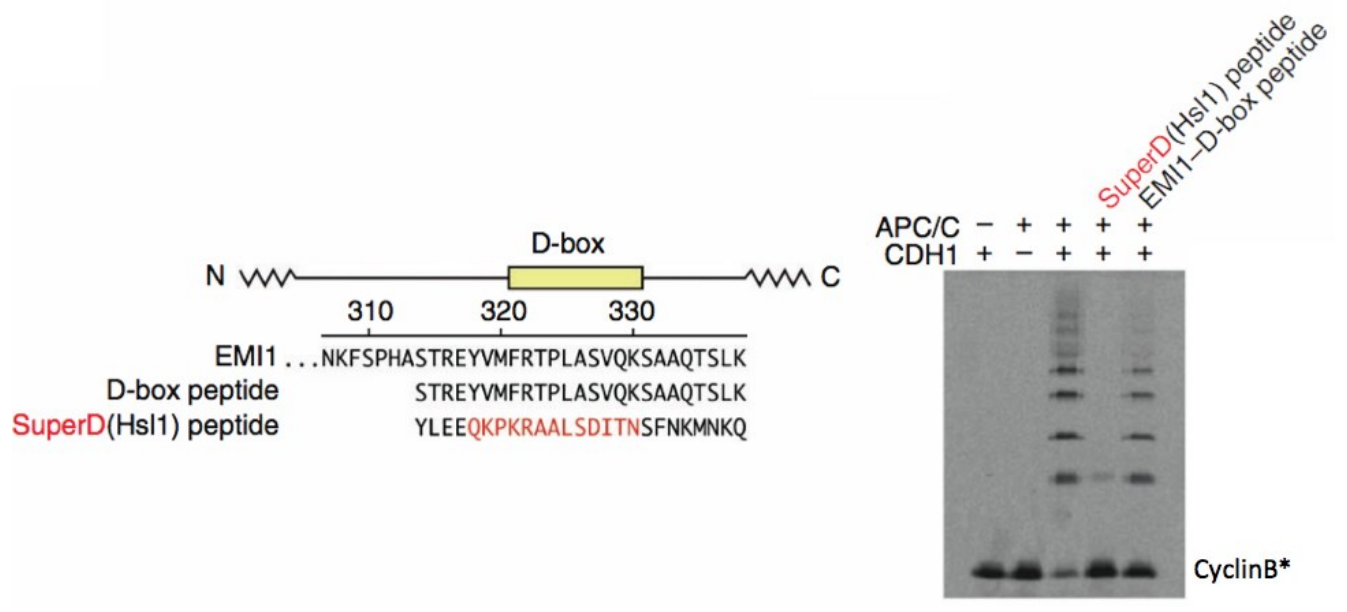

Figure 3-4. Emi1 D-box in Isolation Is an Inefficient Inhibitor of APC/C.

Left, Schematic Diagram and Sequence Information for D-box peptides generated for Emil and Hsl1. Hsl1 sequence in red directly replaces analogous Emil sequence above it in SuperD constructs. Right, Emil D-box peptide is tested for inhibition of Cyclin B 1-95* ubiquitination by APC/C-Ubch10 alongside Hsl1 D-box peptide. 


\section{Emi1's C-terminal RL-Tail Inhibits Ube2s Specifically}

Emil terminates with a Leu-Arg-Arg-Leu Tail (LRRL, or RL-tail) that is conserved both throughout evolution and among homologs (Figure 3-5). Our analysis has so far characterized the contributions of Emil's D-box, Linker, and ZBR domains as weak but cooperative for binding and inhibiting APC/C activities. Constructs of Emil deleted for the $\mathrm{C}$-terminal Tail domain were inefficient inhibitors in data not shown, which is in accordance with published data suggesting a role for the Tail in APC/C recruitment (Ohe, Kawamura et al. 2010). To study this domain's contributions, then, we generate the Tail domain in isolation through peptide-synthetic chemistry. Despite the isolated Emi1-T being a significantly weaker inhibitor of the $\mathrm{APC} / \mathrm{C}$, at high concentrations this small peptide is capable of inhibiting specific $\mathrm{APC} / \mathrm{C}$ functions, described below.

Close inspection of the C-terminal extension of one of the E2 enzymes specific for $\mathrm{APC} / \mathrm{C}$ polyubiquitination, Ube2s, reveals similar distinguishing features. For instance, an extended, unique basic tail follows the structurally conserved globular core domain shared among E2s. This Lys-rich E2-tail also terminates with an identical LRRL motif (Figure 3-5) that is not found in Ubch10. We hypothesize that Emi1 could antagonizes the activity of Ube2s, but not Ubch10, through direct competition for APC/C binding sites. We test this in a battery of Ubch10 and Ube2s specific assays, as well as ubiquitination assays which utilize both E2s and more directly recapitulate the in vivo function of the APC/C. What is clear from our results is that Emi1-T is a specific inhibitor of Ube2s-directed polyubiquitination. In a representative assay incorporating the activity of Ubch10 and Ube2s together, a titration of Emi1-ZT selectively inhibits Ube2s's Ubiquitin-extension mode of action (Figure 3-6). Qualitatively, no decrease in Ubch10-derived ubiquitination is observed (visualized as lower molecular-weight conjugates of 1 to 4 Ubiquitin proteins). Higher molecular-weight species, which are produced by Ube2s modification of Ubch10's products, are specifically inhibited upon titration of Emi1's isolated Tail. Conceptually, if Emi1-ZT were a Ubch10-specific inhibitor, we would expect that any low-MW conjugates would be efficiently polyubiquitinated and the migration pattern observed would be significantly different. This discrete function of Emil is corroborated in other in vitro assays (Wang and Kirschner 2013) monitoring radiolabeled Securin modification in the presence of Emil containing or lacking the C-terminal RL tail.

\section{Visualizing an APC/C-Cdh1-Emi1 Complex Through Electron Microscopy}

Our biochemical studies provide a comprehensive understanding of how Emi1 interacts with the $\mathrm{APC} / \mathrm{C}$ through several domain contacts, utilizing a multimodal framework for inhibition. Evidence suggests that the Emil D-box engages the D-box coreceptor proteins Cdh1 and APC10 in the top of the catalytic core, in the same way that substrates have been visualized in previous studies (Passmore, McCormack et al. 2003, Carroll, Enquist-Newman et al. 2005, Buschhorn, Petzold et al. 2011). Our 


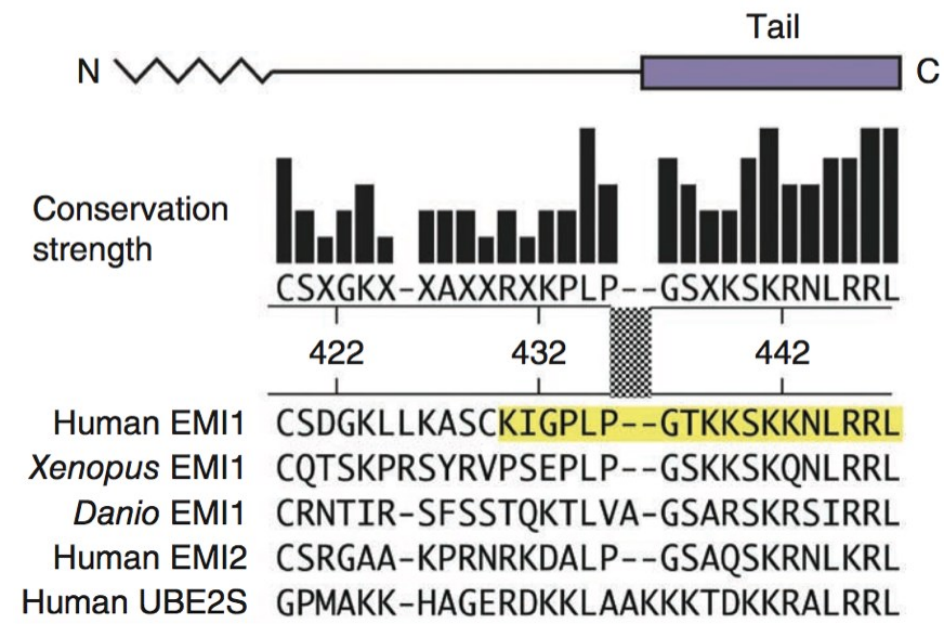

Figure 3-5. Emi1 C-terminal Tail Is Conserved Throughout Evolution, Among Homologs, and with Ube2s.

Schematic diagram and sequence information is shown for C-terminal tail of Emi1. Alignment of Emil from Humans, Frogs, and Zebrafish, Human Emi2, and Human Ube2s reveal a conserved LRRL tail. 


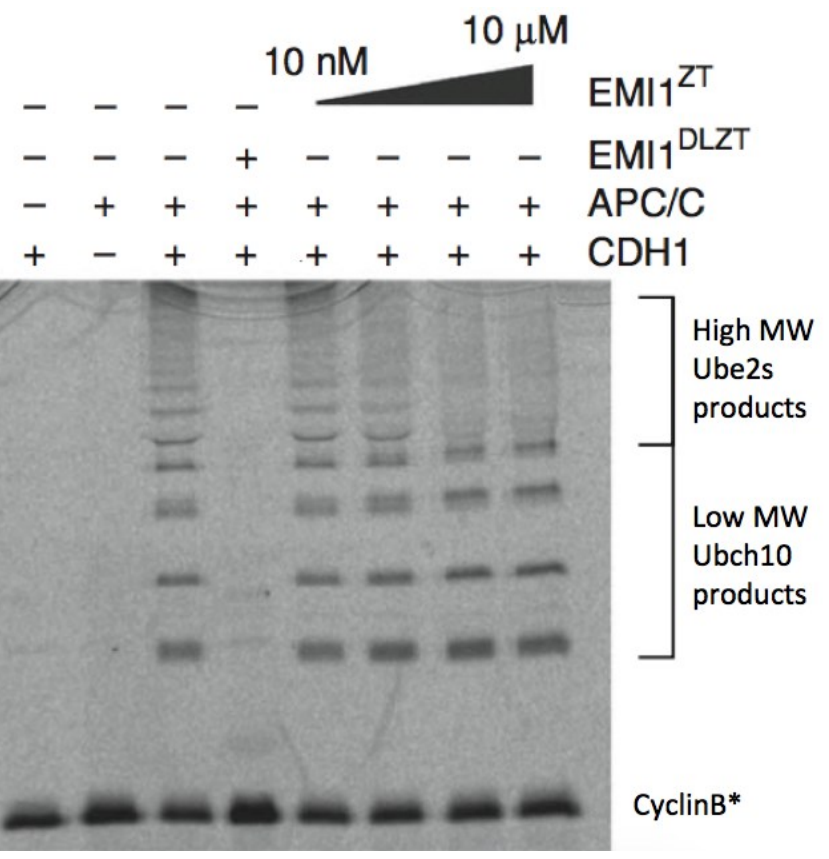

Figure 3-6. Emi1-ZT Inhibits Ube2s-generated High Molecular Weight Products.

Cyclin B 1-95* modification by APC/C with both Ubch10 and Ube2s is monitored in the presence of selected Emil variants. A titration of Emil-ZT reveals selective inhibition of high molecular weight products. 
characterization of a Linker and ZBR domain suggest that Emil is somewhat flexibly tethered to the APC/C through several important contacts, but is not spanning the maximal distance afforded by the sequence of Emi1. What is still entirely unknown, with the exception of the assumed D-box recruitment mechanism, is how and where these domains are binding to the APC/C. Though Emi1-T competes for Ube2s recruitment, and Emi1 ZBR affects catalytic efficiency, global placement of these domains is impossible with current structural information. Prior to this study, years of $\mathrm{APC} / \mathrm{C}$ structural characterization revealed the approximate locations of a majority of $\mathrm{APC} / \mathrm{C}$ proteins within the complex. Notably, the APC2-APC11 Cullin-RING proposed catalytic machineries have not been visualized as they are likely not rigidly attached to the body of the complex. If APC2 and APC11 behave similarly to other CRL family members, there are likely mobile elements that make their contributions to the averaged electron density map insignificant. It is believed that APC2 and APC11 function within the so-called catalytic core in the middle of the APC/C where the D-box co-receptors tether substrates. Studies of the MCC support this hypothesis, as the much larger inhibitory complex is shown to compete for the APC/C core and block APC/C activity through steric hindrance (Herzog, Primorac et al. 2009). We aim to visualize the structure of Emil bound to APC/C through electron microscopy to localize the sites of intermolecular contacts and understand more about the mechanism of inhibition. In collaboration with the Stark lab at the Max Planck Institute for Biochemistry in Göttingen, Germany, we perform EM studies to visualize our recombinant $\mathrm{APC} / \mathrm{C}$ as an apoenzyme or in complex with $\mathrm{Cdh} 1$ and Emil.

\section{Insertions of Globular Domains Reveal Emi1 Position and Orientation on the $\mathbf{A P C} / \mathbf{C}$}

EM analysis reveals that despite its small size, Emi1-DLZT spans much of the central core of the APC. In order to map the location of C-terminal elements of Emi1, we purify Emil-FDLZT-Skp1 proteins that have been engineered with large propeller insertions near specific domains within Emi1's C-terminal inhibitory region. These proteins were monitored closely throughout purification for behaviors either consistent with Emi1-NFDLZT, Emi1-FDLZT, or Emi1-DLZT so the purification strategy could be tailored to account for the insertions. Despite the large insertion nearly doubling the size of our GST-Emil-FDLZT construct, the purification protocol was indifferent and proteins were purified to high quality using the standard Emi1-FDLZT protocol (Figure 3-7).

APC/C samples with Emil bound were prepared by Georg Petzold in Jan-Michael Peters lab, and Holger Stark calculated single-particle EM reconstructions for all samples, including mutants in Emil-FDLZT-Skp1 with insertions between residues S354 and T355 in the Linker and following the C-terminal LRRL Tail. Since the C-terminal tail is required for maximal complex formation, the SuperD version of Emi1-FDLZTSkp1 was necessary. The insertions contained the Beta propeller from $S$. cerevisiae Doa1, (Pashkova, Gakhar et al. 2010) which is an ideal choice for two reasons. Doal's Beta propeller has its $\mathrm{N}$ and $\mathrm{C}$ termini in close proximity and therefore only minimally 


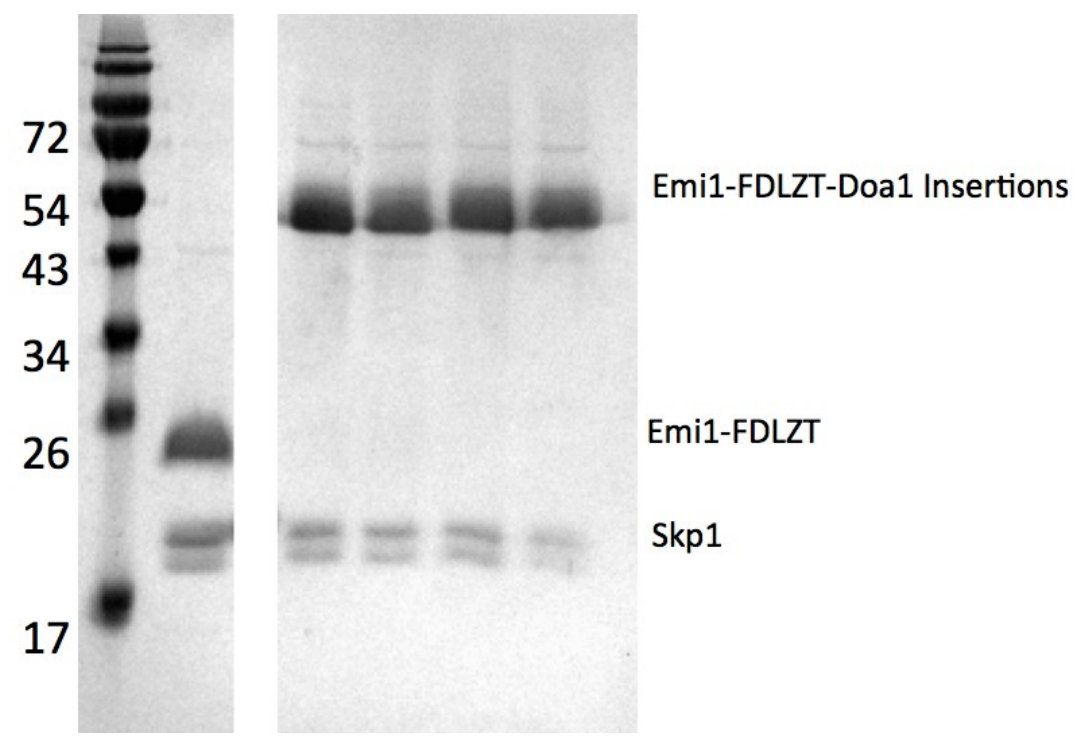

Figure 3-7. Emi1-FDLZT-Skp1 with Doa1 Insertions Are Purified Well Despite Their Relatively Large Size 
disrupts structural features of Emi1, and relatively large features such as Beta-propeller folds are easily visualized as prominent density in EM. Although we cannot be certain that the insertions do not alter native interactions, our resulting structures suggest an orientation of Emil that agrees with biochemical data. The data are consistent with the linker projecting away from the D-box bound to Cdh1 and APC10 and toward the APC/C platform and catalytic core and with the ZBR and tail extending across the platform to the base of the APC/C (Figure 3-8).

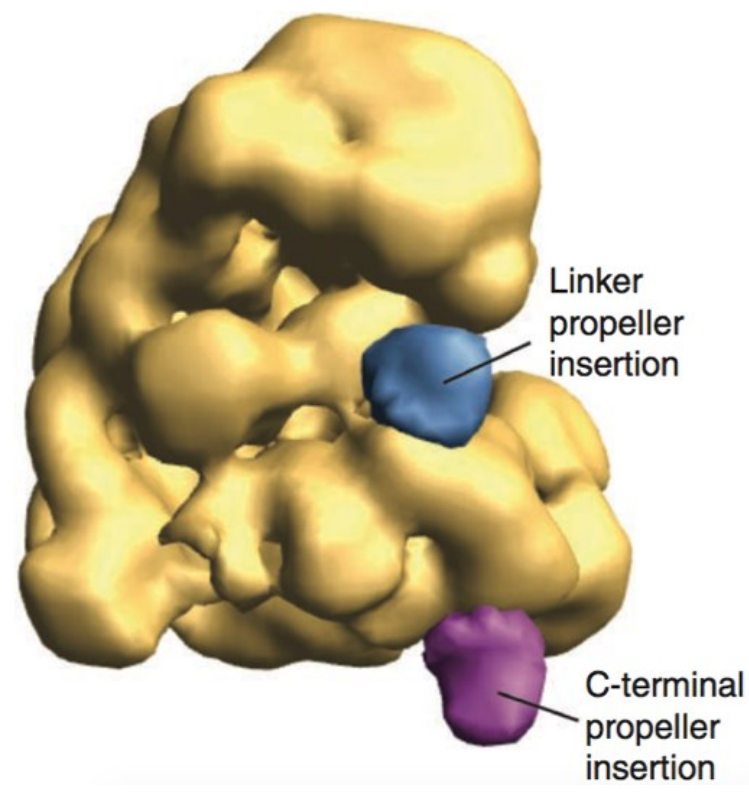

Figure 3-8. Difference Maps for Emi1-FDLZT-Skp1 Containing Beta-Propeller Insertions in the Linker Domain and C-terminus.

Density corresponding to the Doa1 Beta-propeller insertions is clear and are colored for reference. Difference density visible from insertion between residues S354 and T355 is colored blue, and C-terminal insertion density is colored magenta. 


\section{CHAPTER 4. MAPPING EMI1-APC/C AND UBE2S-APC/C INTERACTIONS THROUGH BPA PHOTOCROSSLINKING}

\section{Introduction to Photocrosslinking as a Strategy for Mapping Transient Protein- Protein Interactions}

In the previous sections we both revealed functionally important motifs and domains of Emil, and visualize Emil directly binding in the catalytic core of the APC/C through electron microscopy. Emil is tractable for EM studies with APC/C due to its high-affinity, avid binding. Studies of this nature are not possible for proteins that interact with $\mathrm{APC} / \mathrm{C}$ more transiently. Alternate methods must be developed to study the nature of this type of interacting protein, and for this we turned to photoactivatable crosslinking.

Prompted by new structural and biochemical information from our studies of Emil-bound APC/C, we asked a second related question: Where does the E2 enzyme Ube2s bind to the $\mathrm{APC} / \mathrm{C}$ ? Ube2s is speculated to behave in a unique way with the $\mathrm{APC} / \mathrm{C}$. It does not require the canonical E2-interacting surface of the APC11 RING, and does not require interaction with a RING at all to stimulate Ubiquitin transfer (Brown, Watson et al. 2014). How it coordinates with the APC/C to polyubiquitinate substrates, a process that is essential for proper mitotic progression (Garnett, Mansfeld et al. 2009, Bremm and Komander 2011), is unknown. We developed an orthogonal crosslinking approach to study the interaction of Ube2s with the APC/C. By allowing recombinant Ube2s to interact with $\mathrm{APC} / \mathrm{C}$ and snap-crosslinking, we can trap the native interactions as they occur, even if only transiently.

\section{para-Benzoyl-phenylalanine (BPA) Photo-crosslinker}

With the end-goal of locating Ube2s points of contact with the $\mathrm{APC} / \mathrm{C}$, thus giving the first glimpse at its location during ubiquitin chain-elongation, we selected a short-range, photoactivatable, non-specific crosslinker called para-Benzoylphenylalanine (hereafter BPA)(Chin, Martin et al. 2002). This benign crosslinker can be introduced to proteins in place of any standard amino acid using a variety of published methodologies (Chin, Santoro et al. 2002, Chin, Cropp et al. 2003, Chin, Cropp et al. 2003, Deiters, Cropp et al. 2003), and is called an Unnatural Amino Acid (UAA). Because the crosslinker is inactive until triggered with light, protein-protein interactions occur natively, allowing Emil or Ube2s to transiently associate with $\mathrm{APC} / \mathrm{C}$ through normal contacts. Upon excitation with intense UV light at a specific wavelength $(365 \mathrm{nM})$, the crosslinker's chemistry allows for short-range nucleophilic attack of incompletely identified chemical targets on contacting protein (Yeh, Tung et al. 2016) or DNA (Pendergrast, Chen et al. 1992) molecules. Its usefulness in capturing proteinprotein interactions has been demonstrated a number of times (Liu, Mack et al. 2008, Lee, Dimla et al. 2009, Chatterjee, Guo et al. 2013, Brown, Watson et al. 2014, Furman, Kang et al. 2014, Javahishvili, Manibusan et al. 2014), and we set out to develop 
strategies for incorporation of BPA to Emil and Ube2s and subsequent crosslinking to APC/C-Cdh1.

\section{Considerations for Substitution of a Photocrosslinker in Place of Native Amino Acids}

Some important considerations were made before deciding that BPA crosslinking is an appropriate strategy for our system. Firstly, by replacing a standard amino acid with a non-native residue, we might disrupt the overall fold of the target protein and therefore lose function. Secondly, by adding an exceptionally large amino acid analog to the proposed interface of a protein-protein interaction, it is possible that the interaction would be lost entirely. Therefore before expending a large amount of effort and time on incorporation protocols, we developed a simple screen to mimic the large size of the molecule and the effects it might have on our proteins and their intermolecular interactions.

\section{Development of Methods for Incorporation of BPA to Proteins}

\section{Tryptophan Scanning Mutagenesis}

Using the standard amino acid Tryptophan, which we consider is the best natural residue mimic of BPA's bulky size, we first test the effects of having a BPA molecule within proteins. Using site-directed mutagenesis, a number of desired positions of BPA (known or speculated interacting residues on Emi1 and Ube2s) were replaced by tryptophan, protein was prepared, and assays for fold or function were employed to remove any poorly designed positions.

As a representative assay, Emi1 C-terminal residues 440-447 were mutated to Tryptophan and purified as previously described. Some of these mutants are deficient in APC/C inhibition (Figure 4-1), due to disruption of necessary APC/C contacts. Residues that are not contributing to inhibition (Figure 4-1, green indicators) tolerate Tryptophan mutations, and are suitable targets for BPA incorporation. In our scan, residues K442, $\mathrm{N} 443$, and R445 and an additional residue past the C-terminus, $* 448$, are good candidates for replacement with a bulky BPA molecule. These mutants are in direct agreement with an Alanine scan performed in 2010 on Emi2 (Ohe, Kawamura et al. 2010). The analogous Emil residue for each of their mutants which are considered defective for $\mathrm{APC} / \mathrm{C}$ association by co-immunoprecipitation experiments is also found to be defective in our screen. 


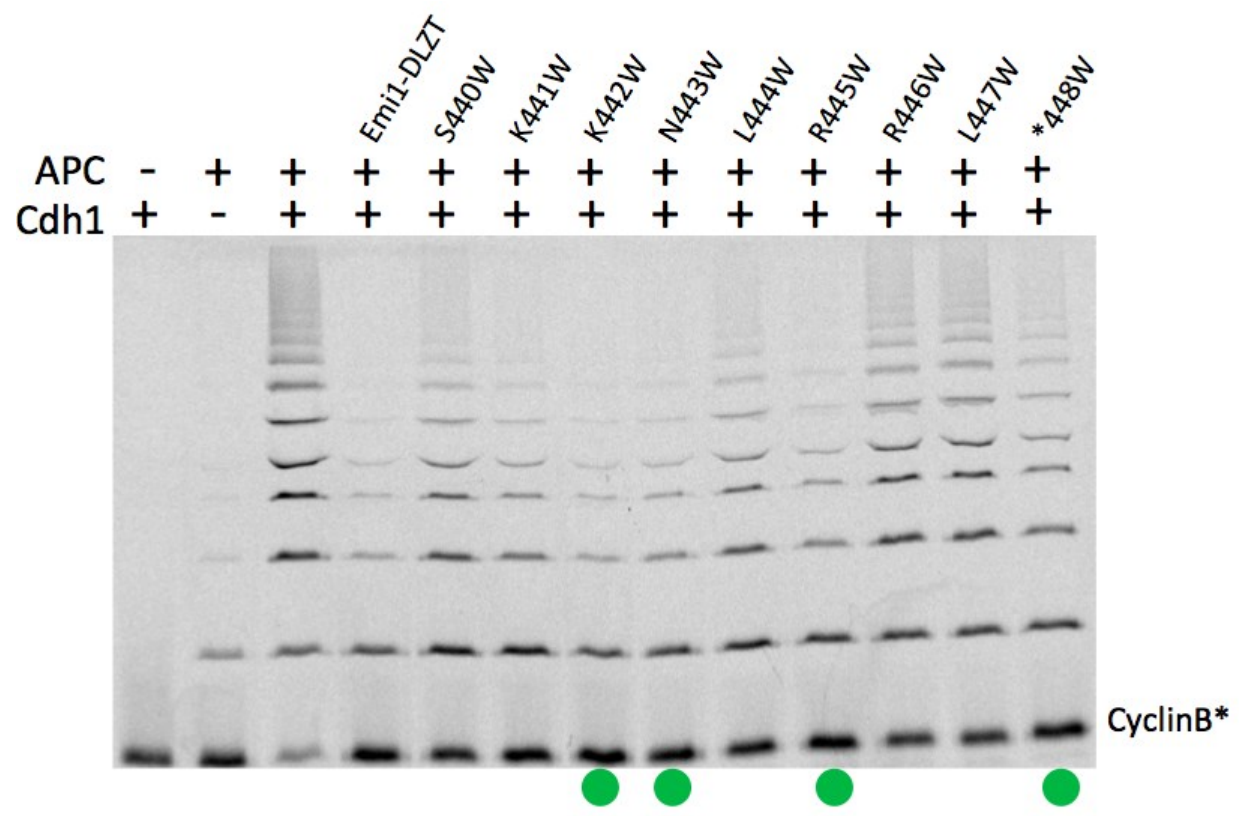

Figure 4-1. Emil C-terminal Tail Residues Are Mutated to Tryptophan to Mimic BPA Incorporation and Tested as Inhibitors in APC/C assays.

Cyclin B 1-95* ubiquitination is inhibited by Emil containing Tryptophan mutations in the C-terminal Tail. Mutants that are not defective for inhibition (shown by green spheres) are suitable positions for BPA incorporation. 


\section{in vivo Incorporation of BPA to Central Residues of Emi1 and Ube2s}

The most significant technical hurdle for UAA crosslinking is developing a protocol for incorporation of the chemical itself into the protein of interest. The first of two strategies we employ is amber suppression technology, which has been developed for a number of years by multiple groups (Wang, Brock et al. 2001, Wang and Schultz 2001, Wu, Deiters et al. 2004, Xie, Wang et al. 2004, Young, Ahmad et al. 2010). This in vivo incorporation methodology harnesses the native function of the host ribosomal translation machinery by supplying a new tRNA, an amino-acyl RNA synthetase, and a BPA amino acid precursor molecule. BPA can be translated with the protein at specific sites by including an amber stop codon at the desired UAA site. Relying on an evolved incorporation vector, amber codons do not exclusively recruit Release Factor 1 (RF1) to posit a translational "stop", but also provide a T-stem loop structure that recruits both the BPA molecule and the synthetase. At some ratio, BPA incorporation outcompetes stoppage and generates full-length protein to the next non-amber stop. For our future studies, we utilize the most recently optimized, high-efficiency system available publicly; a vector called pEVOL-pBpF developed by Dr. Peter Schultz (Young, Ahmad et al. 2010).

Despite years of progress and development, the efficiency of BPA incorporation is highly unpredictable for this system, and invariably protein expression yields are significantly reduced, even for proteins without an amber-stop incorporation burden. This is due in part to the reliance of $E$. coli host proteins utilization of amber stop codons. Throughout the bacterial genome, hundreds of genes require the TAG codon for termination of translation, and through amber suppression technology these are efficiently replaced with BPA. Presumably, this causes a decrease in the productivity of these cells during the cumbersome task of protein over-expression following chemical induction. Nutrient-rich media partially overcomes these prohibitively low protein yields, in part through the allowance of high cell density at induction. Following the published suggestions of the system's developers, we systematically optimize many steps of the expression protocol to increase production of purified BPA-containing protein. For Emi1 and Ube2s we find only a few factors that improve upon the previously optimized system. Auto-induction media (Studier 2005) produces approximately fourfold more protein than LB with identical incorporation efficiency, when accompanied by co-induction with previously optimized concentrations of arabinose and IPTG at an optical density of 1.6 instead of 0.8 , measured at $600 \mathrm{~nm}$. Changing expression temperatures between $16^{\circ} \mathrm{C}$ and $30^{\circ} \mathrm{C}$ for 16 hours did not have a drastic effect, whereas $37^{\circ}$ induction for 4 hours was insufficient. Concentration of BPA itself in the cultures was varied and found to be most effective at $0.2 \mathrm{mM}$, in agreement with published findings (Young, Ahmad et al. 2010). From our pGEX vector, this improved system is capable of yielding as much as $10 \mathrm{mg}$ per Liter, or amounts unsuitably low for purification.

Interestingly, expression and incorporation efficiencies are changed drastically within a single construct, solely dependent upon the relative location of the TAG codon for BPA incorporation. In Figure 4-2, Ube2s is expressed from a single construct using 


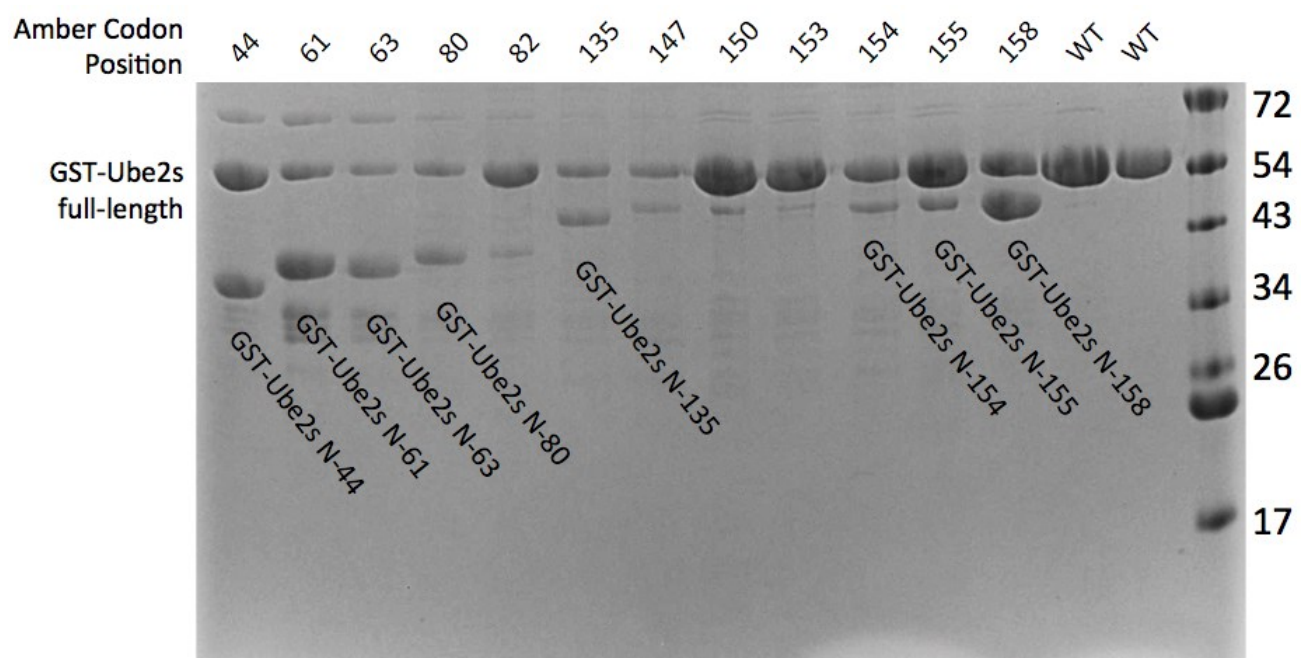

Figure 4-2. Incorporation Efficiencies Are Evident from GST-Ube2s Pulldowns Following in vivo BPA Incorporation.

BPA is introduced through amber suppression to several positions throughout Ube2s. At some ratio, incorporation failures are visualized as quicker migrating bands of truncated molecular weight. 
identical parameters but changing the amino-acid replaced with BPA for several mutants. BPA incorporation and overall expression are changed many-fold through a seemingly random mechanism that likely points to a poorly-understood mechanism of ribosomal incorporation reliant on either DNA or peptidyl sequences flanking the amber stop. This effect is not an artifact of a single experiment, as completely new clones purified with a C-terminal LRRL deletion exhibit the same trend of expression and incorporation variation (Figure 4-3). Through our optimized protocols and ability to perform expression at a large 24 liter scale for any low-level expression construct, we are able to produce BPA-containing proteins at essentially any position of Emil or Ube2s. Using this methodology, BPA has been incorporated to over 50 constructs of Emil and Ube2s.

\section{Purification of BPA-containing Emi1 or Ube2s Following in vivo Incorporation}

Incorporation of BPA site-specifically using amber suppression technology is only partially efficient, as described above, yielding both full-length protein with BPA and protein C-terminally truncated at the site of the amber stop-codon. A number of purification strategies are used to separate full-length proteins from truncations, including $\mathrm{C}$-terminal affinity tags and chromatographic separation based on size. However, Cterminal affinity tags are not optimal for Emil or Ube2s as both require a native Cterminal LRRL sequence for APC/C-dependent activity. Furthermore, though SEC is possible when the BPA replacement site is near the $\mathrm{N}$-terminus, any $\mathrm{C}$-terminal positions of BPA would create truncated proteins at nearly full-length, making separation by size impractical. Luckily, for Emil and Ube2s, a highly basic C-terminal $\sim 40$ amino acid stretch allows for separation from the neutral, uncharged $\mathrm{N}$-terminal region of these proteins more efficiently than SEC using cation exchange. This does not, however, provide a means for purification of near full-length incorporation failures. For this we develop an entirely new method for incorporation of BPA to C-terminal fragments of disordered proteins.

\section{Introduction of Fmoc BPA to C-terminal Residues of Emi1 and Ube2s}

To produce Emil or Ube2s with BPA near the C-terminus, we utilize a bacterial transpeptidase called sortase to covalently attach a preformed peptide with a purified protein. This method has been used in the past for a variety of reasons (Bolscher, Oudhoff et al. 2011, Popp, Dougan et al. 2011, Guimaraes, Witte et al. 2013, Swee, Guimaraes et al. 2013, Theile, Witte et al. 2013, Strijbis and Ploegh 2014), and has been a popular method within our lab for applying $\mathrm{N}$ - or C-terminal fluorescent tags to proteins. The sortase enzyme itself recognizes any exposed $\mathrm{LPET}^{\wedge} \mathrm{G}$ sequence $\left({ }^{\wedge}\right.$ denotes site of cleavage) within proteins or small polypeptides and catalyzes simultaneous cleavage and transpeptidation of substrates with N-terminal Glycine residues (Figure 4-4)(Popp, Antos et al. 2009).

Before attempting BPA incorporation, we first identify a site within the Cterminus of Emil capable of tolerating an $\mathrm{LPET}^{\wedge} \mathrm{G}$ motif as a final product. Assays 


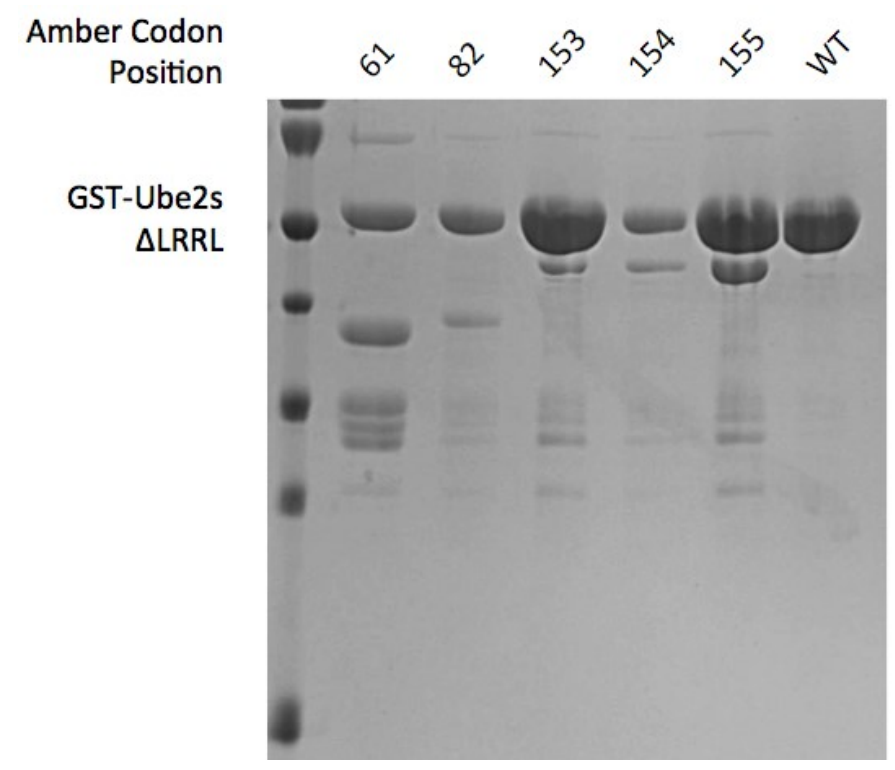

Figure 4-3. Ube2s BPA Using New Clones with C-terminal Deletion.

SDS-PAGE of samples from GST-affinity pulldown reveals identical expression and incorporation ratios for new clones with C-terminal LRRL tail deletion. 


\section{Protein-LPET/G + G-peptide}

$=$

Protein-LPETG-peptide

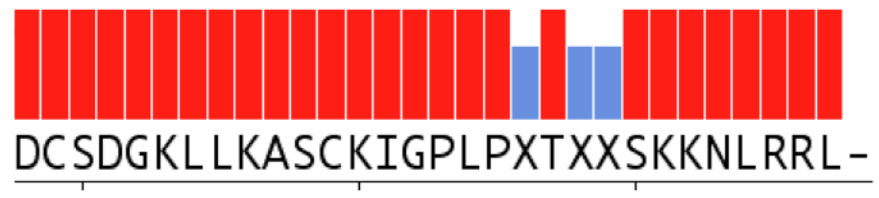

\begin{tabular}{ll}
420 & 430 \\
\hline DCSDGKLLKASCKIGPLPGTKKSKKNLRRL.
\end{tabular}

Figure 4-4. Sortase-mediated Transpeptidation Attaches an Emi1 Tail Peptide to Emi1 Protein.

Schematic Diagram and Sequence Information showing how Sortase fuses a C-terminal peptide of Emil sequence with purified Emil protein corresponding to $\mathrm{N}$-terminal sequence. This technique generates 3 mutations at the site of attachment, but yields otherwise wild-type full-length protein. 
designed to test these final product mimics validate a region 23 residues from the $\mathrm{C}$ terminus of Emil as benign. As proof of principle and in order to optimize sortase parameters for this system, peptides corresponding to these residues of Emil were synthesized, and Emil terminating in LPETGG is purified. Following enzymatic reaction, full-length Emil can again be separated from truncated products through cation exchange and SEC.

\section{Establishing Positive Controls for Capturing Protein-Protein Interactions with BPA}

To validate this relatively complicated strategy for mapping protein-protein interactions in our multi-protein system, we first develop the technique using a robust two-protein complex. In a previous study (Sato, Mimasu et al. 2011), Sato et.al were able to recapitulate a crystallizable (Nakamura, Nakano et al. 2007) interaction between mouse Gankyrin and a C-terminal domain of an AAA+ ATPase called S6 (S6C). The authors replaced residues at the crystallized interface between Gankyrin and S6C with BPA in a variety of combinations. Following extensive crosslinking and purification of the crosslinked product, the same crystals are formed and the structure is solved with a covalent BPA crosslink. The electron density map reveals the same molecular structure but with extra density corresponding to the crosslinked residues. These constructs and protocols serve as a strong positive control for many aspects of BPA crosslinking including functionality of the synthesized UAA chemical itself, correct UV activation protocols and machinery, proper incorporation of BPA to proteins and our ability to monitor native protein-protein interactions through SDS-PAGE.

As seen in Figure 4-5, we are able to reproduce the protein-protein interactions described in literature, and we can validate that our crosslinker is correctly incorporated, specifically replacing residue Arg85 of gankyrin, which is capable of co-purifying with S6C as predicted from the study. On a time-course of UV photoactivation, the covalently crosslinked product of Gankyrin-S6C is observed in denaturing SDS-PAGE experiments only in reactions containing the residues responsible for the interaction. Interestingly, replacement of the receiving Glutamate 356 of S6C to Aspartate, a theoretically mild mutation, is incapable of BPA crosslinking. These results are confirmatory that BPA incorporation and crosslinking behaves similarly to published results in a model system.

\section{Using Emi1 as a Positive Control for APC/C-specific Crosslinking and Detection}

With confidence that our BPA crosslinking methods report on direct proteinprotein interactions, and with the ability to generate and purify Emil and Ube2s proteins with BPA at any position, we aim to test site-specific crosslinking in the context of the $\mathrm{APC} / \mathrm{C}$. Due to the vanishingly small quantities of recombinant $\mathrm{APC} / \mathrm{C}$ we are able to generate, and to the transient nature of Ube2s-APC/C interactions, we first establish $\mathrm{APC} / \mathrm{C}$ crosslinking with Emil as a positive control. The tight-binding nature of Emil, and our prior domain characterization and structure determination make this an attractive system for validation of this approach. 


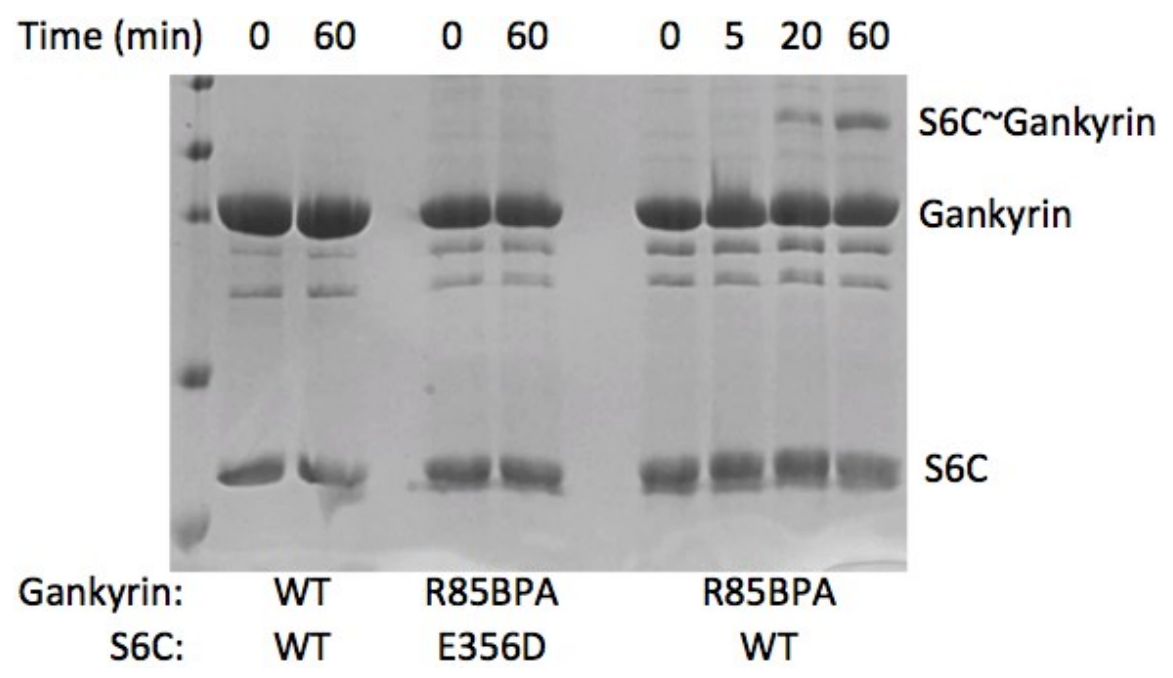

Figure 4-5. Gankyrin and S6C Are a Positive Control for BPA Crosslinking.

This coommassie-stained SDS-PAGE gel of BPA crosslinking recapitulates published crosslinking for the Gankyrin-S6 complex. Crosslinking is visualized as a higher molecular weight band appearing on a timecourse of UV photoactivation, and only in conditions where BPA within Gankyrin is expected to crosslink S6C. 
We incorporate BPA to 8 positions among Emil's D-box, Linker domain, and Cterminal tail as previously described. $1 \mu \mathrm{M}$ Emil-BPA is mixed with $1 \mu \mathrm{M}$ APC/C-Cdh1 and incubated for 30 minutes prior to photoactivation. Photo-crosslinking is performed for 60-minutes using our optimized protocol, and reaction products are loaded to SDSPAGE gels. Western blots with anti-His tag primary antibodies (Sigma) specific for a His-tagged Emi1 reveal high molecular-weight species indicative of APC/C crosslinking. Importantly, these crosslinks do not form when Emil-BPA is mixed only with Cdh1 absent of APC/C (Figure 4-6). Interestingly, residues near the D-box of Emil form crosslinked products of two sizes, whereas crosslinked Tail residues migrate to a single position, indicative of binding to only one protein.

\section{Ube2s Interactions with APC/C at Multiple Locations Are Captured Through BPA Crosslinking}

In the context of the multi-subunit APC/C, specific crosslinks are visualized for Emi1-BPA. This result validates this crosslinking approach as a means to capture and monitor binding events between specific residues of $\mathrm{APC} / \mathrm{C}$ associating proteins. We aim to highlight the usefulness of this tool not by recapitulating interactions that are well characterized, rather to report on previously unidentified contacts. Although from our electron microscopy studies we have information to trace Emil's path along the APC/C architecture, very little is known about the location of Ube2s in the context of APC/C. We therefore employ photocrosslinking as an orthogonal approach to electron microscopy to glean information about the transient structure of Ube2s-bound APC/C.

Residues surrounding E153 and I154 of Ube2s were chosen for crosslinking and are of general interest because they are kinetically implicated in an activation mechanism in experiments performed by Nick Brown at the onset of this part of the project. A double mutant E153A-I154A version of Ube2s is not activated by the APC/C, and is therefore considered severely deficient in APC/C-dependent assays. However, in APC/C independent reactions, where the inherent reactivity of Ube $2 \mathrm{~s}$ is tested in Ubiquitin transfer to an acceptor Ubiquitin, no defect is observed. These results suggest that residues E153 and I154 contact the APC/C to direct Ubiquitination of APC/C-bound substrate Ubiquitins. To visualize and characterize this interaction, I target residues along the pair of helices containing E153 and I154 for BPA incorporation. Crosslinking is performed similarly to the optimized protocol established for Emi1, and products of the reaction are loaded to SDS-PAGE and monitored by western-blot analysis of a FLAG-tag on Ube2s.

\section{C-terminal Helices C and D of Ube2s Crosslink Specifically to APC2 and APC4}

BPA substitutions of several residues within this targeted region of Ube $2 \mathrm{~s}$ are crosslinked to APC/C-Cdh1 by co-mixing $1 \mu \mathrm{M}$ Ube $2 \mathrm{~s}$ with $1 \mu \mathrm{M}$ APC/C-Cdh1 for 30 minutes prior to photoactivation. Reactions are performed at sufficiently large volumes

to allow the same reactions to be loaded many times to different gels, making it possible 


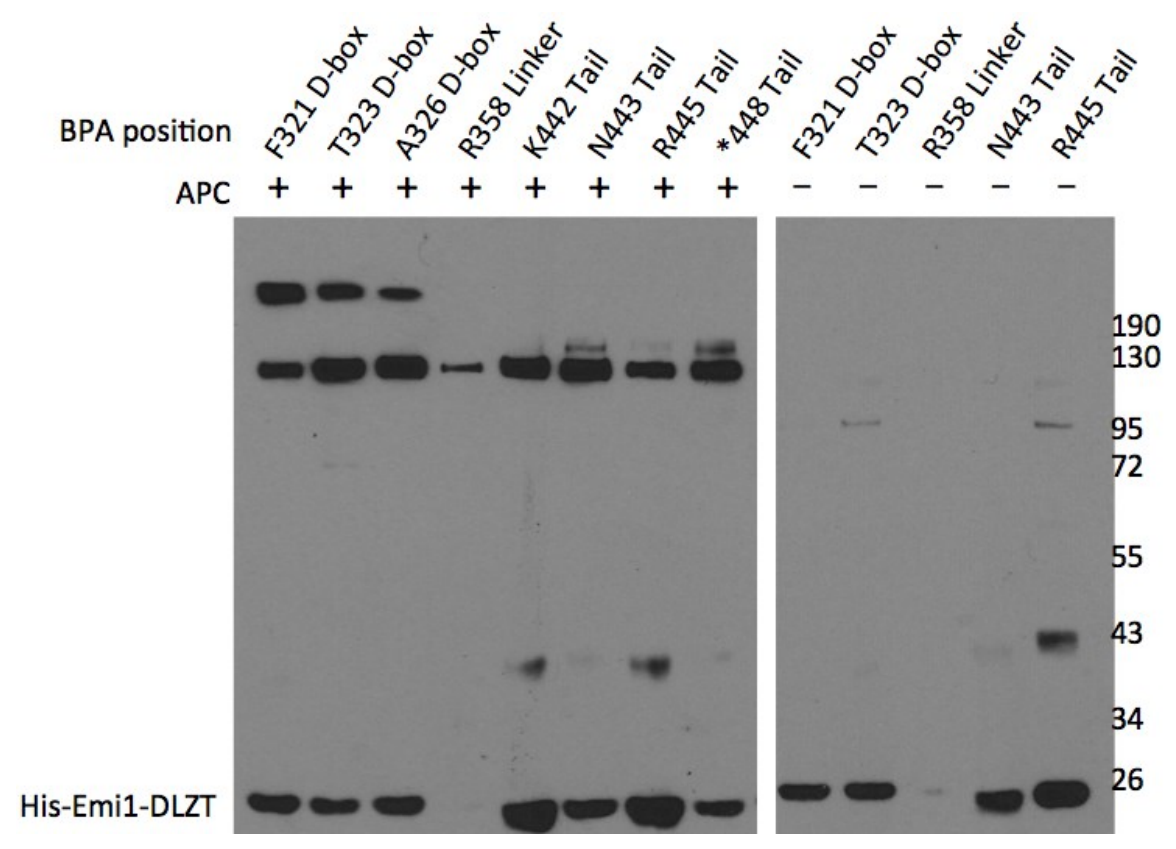

Figure 4-6. His-Emi1 with BPA Reporting on D-box, Linker, and Tail Interactions with $\mathrm{APC} / \mathrm{C}$.

This western blot of SDS-PAGE gel using anti-His antibodies specific for His-Emi1DLZT reveals APC/C dependent crosslinking. Crosslinks observed for BPA positions surrounding the D-box are different from those observed for Emil's Tail. 
to western blot for several of the proteins involved in the interaction without introducing the variability associated with performing several experiments.

Crosslinking is performed with a number of controls to validate the specificity of the reaction: UV exposure of Ube2s-BPA in the absence of APC/C reveals any nonspecific intramolecular crosslinking. Furthermore, Ube2s-BPA proteins lacking the Cterminal LRRL tail are tested to verify the crosslinking is dependent on specific recruitment of Ube $2 \mathrm{~s}$ to the $\mathrm{APC} / \mathrm{C}$, and does not report on non-specific, random interactions. Negative crosslinking results in these control experiments strengthen our confidence in the effectiveness of our system to recapitulate native interactions between Ube2s and the APC/C.

Only upon activation with UV light, significant crosslinking is observed between residues E153, I154, and A158 of Ube2s and specific subunits of the APC/C (Figure 4-7, Figure 4-8, Figure 4-9). Western blots specific for the FLAG-tag on Ube2s show migration patterns specific for two locations of Ube2s significantly larger than Ube $2 \mathrm{~s}$ protein itself. These two alternate migrations of Ube2s persist throughout crosslinking of the three different BPA positions in this helix. Further analysis of the same reactions reveals that only certain subunits of the APC/C are modified with Ube2s. Antibodies specific for APC4 protein and APC2 protein reveal that both of these subunits are modified with Ube2s in specific reactions. Furthermore, a second antibody for the Streptag on APC4 confirms there is not a problem with antibody specificity; rather the APC4 subunit is specifically crosslinked by Ube $2 \mathrm{~s}$ in these reactions. These results begin to explain the mechanism of Ube2s activation by the APC/C. The C-terminal helices of Ube2s that include residues E153, I154, and A158 make contact with the APC2/APC4 region of the platform, and this is likely responsible for either direct activation of the E2, or as a means for E2 positioning near its substrate, or both. Since the methodologies for residue-specific identification of the crosslinked protein side-chains are not fully developed, future studies will be required to elucidate what specific APC2 and APC4 contacts are being made, and how they facilitate Ube2s activity. 


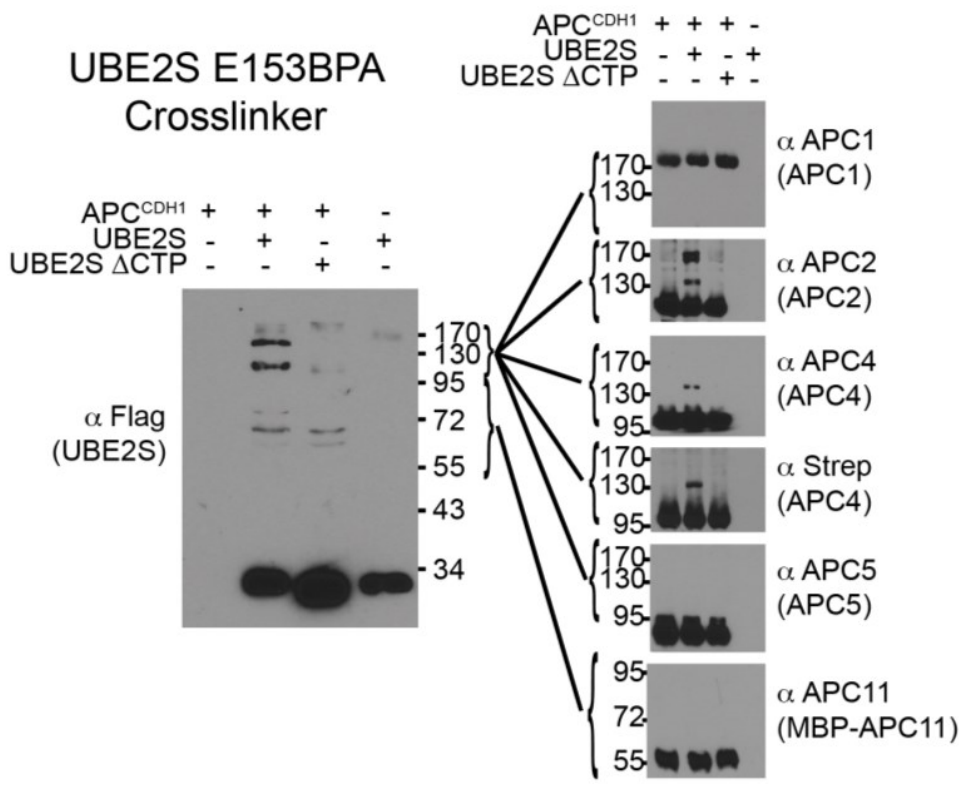

Figure 4-7. Crosslinking Between Residue E153 of Ube2s and APC/C-Cdh1.

Western blots of Ube2s-APC/C photocrosslinking reactions are performed with the indicated antibodies. Ube2s migration in SDS-PAGE gels is specifically slowed to two positions. These positions correlate with slower migration visualized for APC2 and APC4, suggesting specific crosslinking to these subunits. These results validate an RLtail recruitment dependency for these APC/C-Ube2s interactions, and an APC/C dependency for Ube2s crosslinking. 


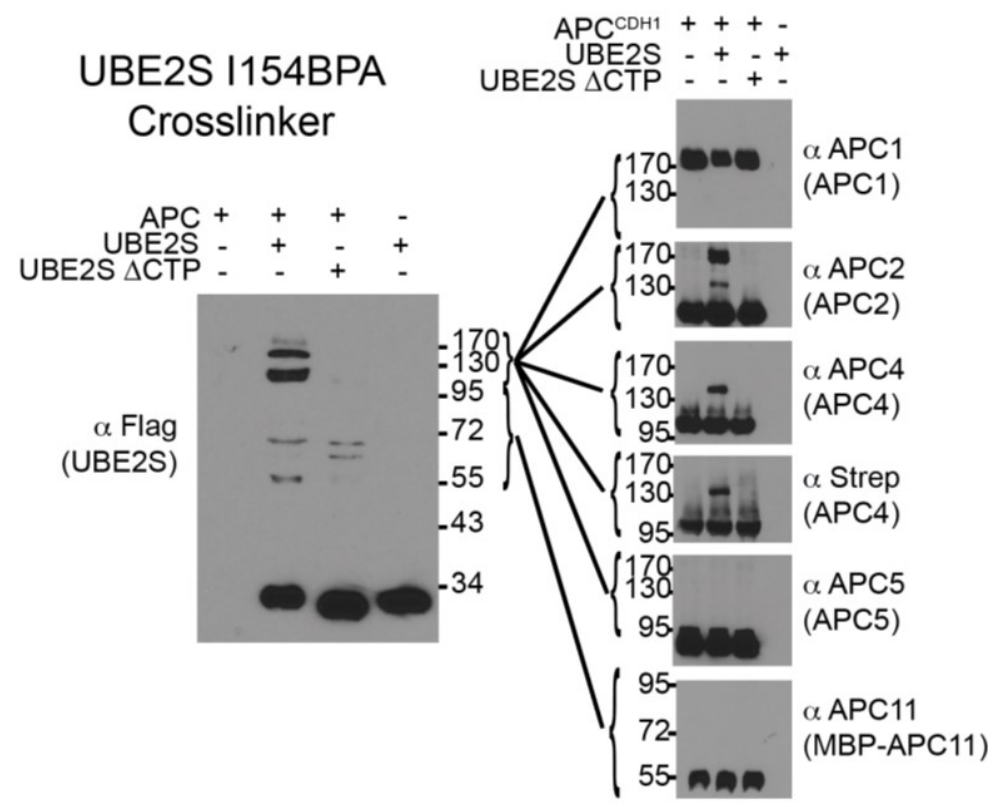

Figure 4-8. Crosslinking Between Residue I154 of Ube2s and APC/C-Cdh1.

Western blots of Ube2s-APC/C photocrosslinking reactions are performed with the indicated antibodies. Ube2s migration in SDS-PAGE gels is specifically slowed to two positions. These positions correlate with slower migration visualized for APC2 and APC4, suggesting specific crosslinking to these subunits. These results validate an RLtail recruitment dependency for these $\mathrm{APC} / \mathrm{C}$-Ube2s interactions, and an $\mathrm{APC} / \mathrm{C}$ dependency for Ube2s crosslinking. 


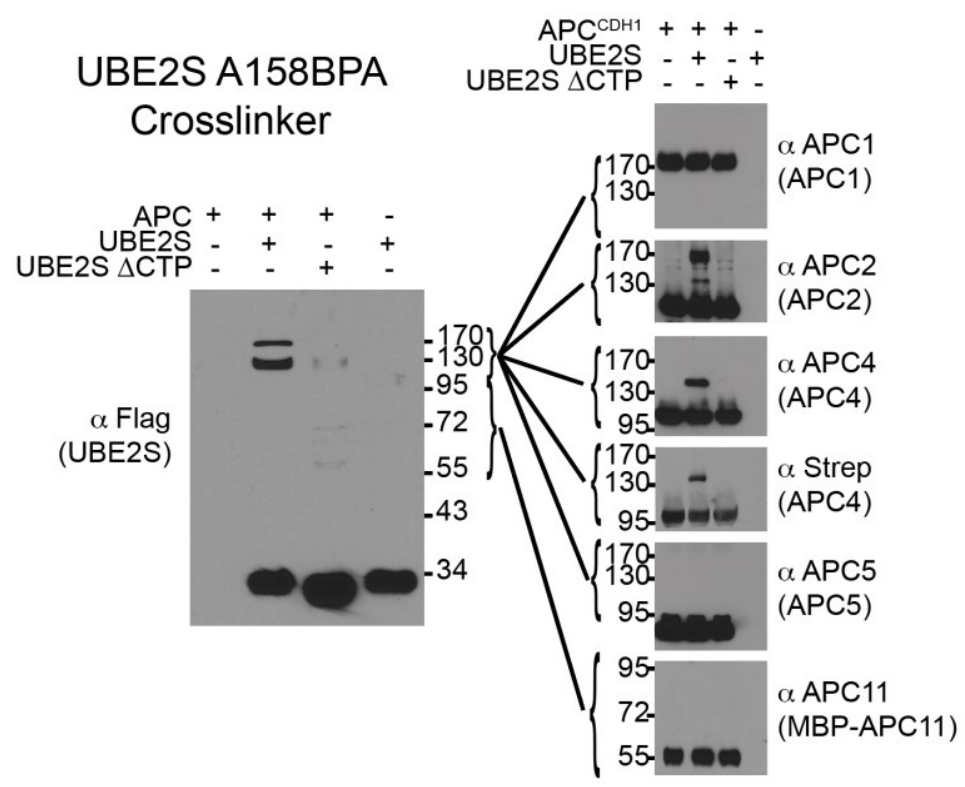

Figure 4-9. Crosslinking Between Residue A158 of Ube2s and APC/C-Cdh1.

Western blots of Ube2s-APC/C photocrosslinking reactions are performed with the indicated antibodies. Ube2s migration in SDS-PAGE gels is specifically slowed to two positions. These positions correlate with slower migration visualized for APC2 and APC4, suggesting specific crosslinking to these subunits. These results validate an RLtail recruitment dependency for these $\mathrm{APC} / \mathrm{C}-U b e 2 s$ interactions, and an $\mathrm{APC} / \mathrm{C}$ dependency for Ube2s crosslinking. 


\section{CHAPTER 5. DISCUSSION}

\section{APC/C-Cdh1-Emi1 Structure at High Resolution}

Two years after completion of the work described in this dissertation, a unique opportunity to analyze the high-resolution structure of $\mathrm{APC} / \mathrm{C}$ with Emil bound was made possible both by data generated by our lab and our collaborators, as well as by a journal article published by the Barford lab in Cambridge, UK (Chang, Zhang et al. 2015). Both high-resolution structures combined with the structural groundwork provided by our lab (Frye, Brown et al. 2013) yield similar information about the orientation of Emil on $\mathrm{APC} / \mathrm{C}$ and the interactions between them, and accordingly both are studied to provide insights into the results obtained prior to their discovery.

\section{Emi1 D-box Engages the Cdh1 and APC10 Co-receptors}

The most obvious region of the structure to validate is the D-box binding site between the $\boldsymbol{\beta}$-propeller surface of Cdh1 and the jelly-roll fold of APC10, as this is a well-established substrate recruitment mechanism of the APC/C (Passmore, McCormack et al. 2003, Carroll, Enquist-Newman et al. 2005, Buschhorn, Petzold et al. 2011). By examining both the density map (EMD: 2924) and the model associated with it (PDB ID 4UI9)(Chang, Zhang et al. 2015), it is evident that Emi1 is recruited to these co-receptors as expected (Figure 5-1). Though the published model contains a modified D-box motif within Emi1, (T323I), it is reasonable to expect that the native Emil D-box sequence, although relatively weak, is capable of acting as a pseudo-substrate motif and inhibits substrate recruitment in this way.

\section{Emi1 ZBR Alanine Scan Informs on Residues in the Interface}

We next analyze the electron density ascribed to the Emi1 ZBR. This region of the electron density map is very convincingly correct for both placement and orientation of the ZBR structure that was solved in our lab. The structured ZBR fits quite well within map density, even at low contour and provides insight to the direction of travel from the N-terminus to C-terminus, which is useful when considering the Linker domain between the D-box motif and ZBR domain. When comparing the modeled structure with our Alanine scanning mutagenesis results (Figure 5-2), no major discrepancies are observed. In fact, the surface that was suggested as an APC/C interacting motif points directly to the RING subunit of APC11. When taking the biochemistry and structures together, the function of these residues is likely a mix between inter-molecular contacts with APC11 and intramolecular contacts supporting and stabilizing the structure of the ZBR itself as well as the disordered regions following the structured Linker helix. Furthermore, the APC11 RING is implicated as the catalytic module for the APC/C, and direct binding to this mobile element restrains its mobility and directly inhibits the CRL catalytic mechanism of $\mathrm{APC} / \mathrm{C}$. 


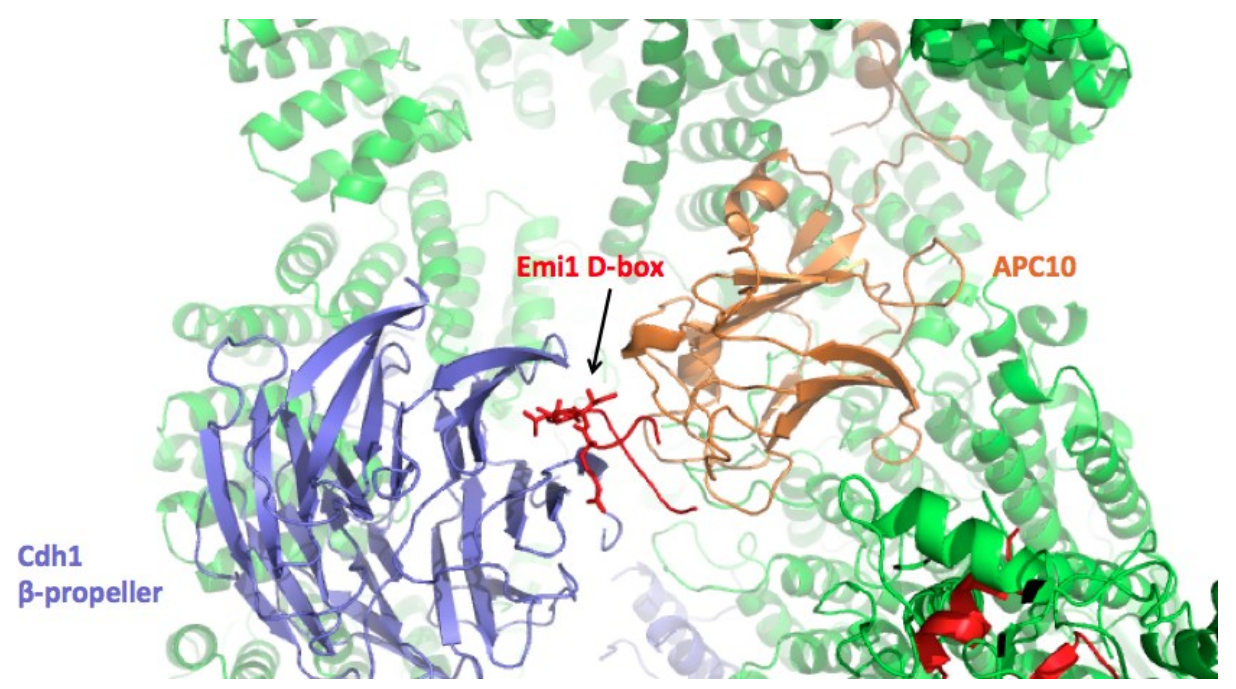

Figure 5-1. Emi1 D-box Is Co-recruited to Cdh1 and APC10.

Analysis of APC/C-Cdh1-Emil structural model PDB: 4UI9 from the Barford lab. Cdh1 is colored purple, Emi1 is red, and APC10 is orange, all other components of the model are green. Emi1 is co-recruited to Cdh1 and APC10 in the same way substrates have been shown to bind. 


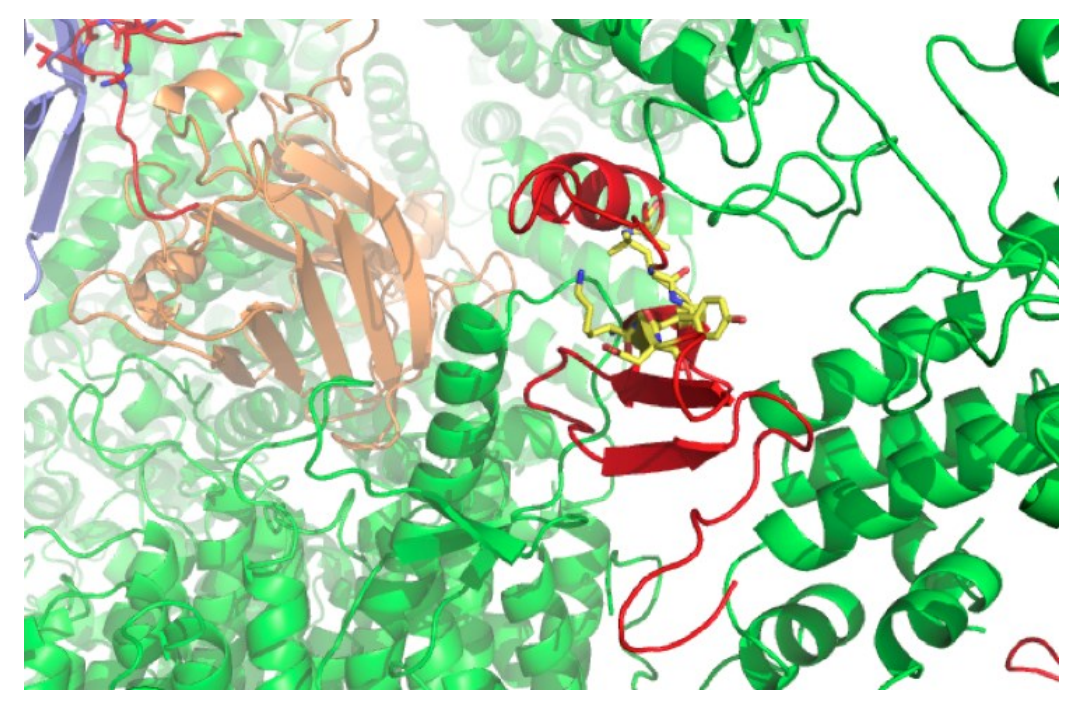

Figure 5-2. Emi1 ZBR Associates with APC11 and Utilizes the Surface Discovered in the ZBR Alanine Scan, and the Functional Linker Forms a Helix Between APC11 and APC1

Emi1, red, is represented as a cartoon with "very deficient" mutants colored in yellow. These mutations map to a surface that helps to organize the helical, essential Linker domain, and may bind directly to $\mathrm{APC} / \mathrm{C}$. 


\section{Functional Linker Domain Between the D-box and ZBR Is Visualized and Localizes to APC1 and APC11}

In the electron density maps, there is evidence for a structured region of Emil that protrudes from the N-terminus of the folded ZBR domain. The Linker domain of Emil is perfectly suited to fill this density, as it is directly N-terminal of the ZBR and has been shown through mutational analysis to be essential for function. Though it is difficult to be certain of the register of the helix shown in the maps due to lack of side-chain density at the achieved resolution, the published model for Emil in this region places residues Y356 and R358 in positions for contact with APC1 and APC11. Since mutation of these residues, and not deletion of 10 residues directly $\mathrm{N}$-terminal of them, causes a defect in Emil's APC/C inhibition, the model likely confirms our mutational analysis of this region.

\section{Emi1 Tail Binds APC/C at the Base of the Platform and Inhibits Ube2s Tail}

Finally, a small helical portion of Emil's Tail is visualized binding to the base of the APC/C platform region, and makes contacts specifically with APC2 and APC4. Importantly, the published manuscript also visualizes the C-terminal tail of Ube $2 \mathrm{~s}$ binding to this same region in a moderate-resolution structure of a Ubch10-Ube2s fusion protein. Though the model suggested by the authors does not place the perfectly conserved and critical LRRL tail of these proteins in the density, it does account for Em1i's ability to specifically inhibit the activity of Ube2s in our assays. Furthermore, the overall orientation of the entirety of Emil is exactly as we report it to be, with the D-box bound to the coactivator Cdh1 at the top of the catalytic cavity, the ZBR interfering with catalytic machinery in the peripheral center of the cavity, and the Emi1 C-terminal tail associating near the base of the platform (Figure 5-3).

\section{Retrospective Analysis of BPA Incorporation Methodologies}

A combination of two methodologies for incorporation of BPA to target proteins was presented in this dissertation. Amber suppression technology has been developed for more than 10 years and the newest systems are easy to use and are capable of generating milligrams of pure BPA-containing protein per liter of culture. Though this technique has limitations and drawbacks, I would suggest that amber suppression for in vivo incorporation of a wide variety of unnatural amino acids is the more robust system for a number of reasons. By scaling up the volume of bacterial culture, it is quite easy to overcome the problem of inefficient incorporation and reduced expression. Furthermore, these problems can likely be overcome by shifting the position of the amber stop codon to residues surrounding the residue of interest as this seems to have a random but strong effect on both protein expression and UAA incorporation. Typically genes of interest are expressed with $\mathrm{C}$-terminal affinity tags, allowing for immediate separation of prematurely truncated proteins, and this makes amber suppression a powerful and simple technique for scanning through several positions of a protein to isolate conditions that 

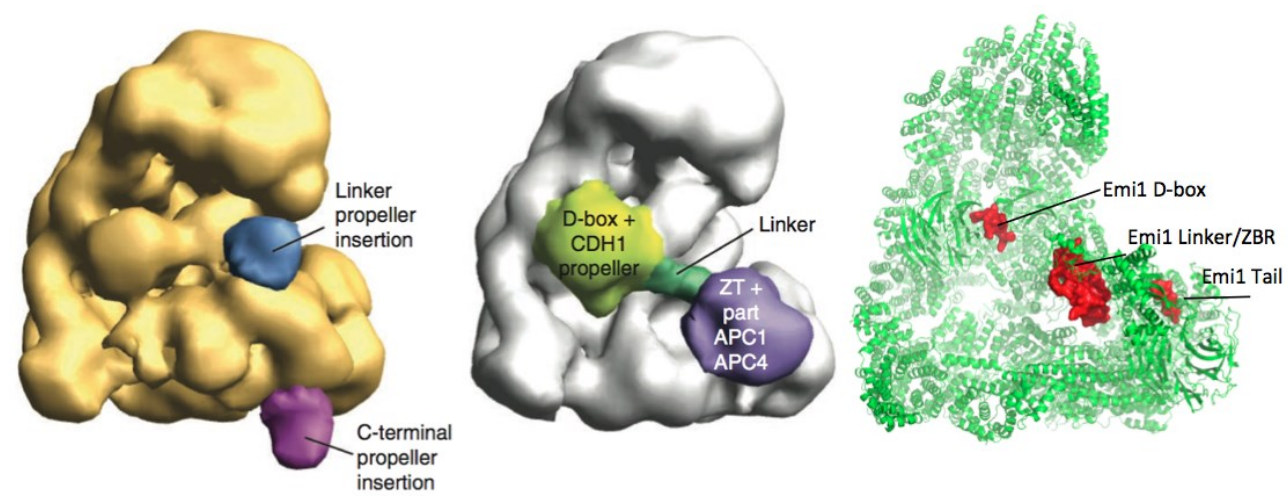

Figure 5-3. Emi1 Traverses the APC/C Architecture as Visualized by Negative Stain EM Experiments.

Left, Negative stain reconstructions of APC/C-Emi1 with Doal propeller insertions, compared with Emil-DLZT lacking insertions, Middle, allowed us to visualize the overall topology of APC/C-Cdh1-Emi1. This is consistent with Emi1 spanning the catalytic core as in PDB ID 4UI9, Right. 
enable site-specific crosslinking and inform on the biology of protein-protein interactions.

Both Emi1 and Ube2s have essential C-terminal tail residues that must be preserved and therefore these proteins cannot tolerate affinity tags at the C-terminus. As explained previously, this makes in vivo incorporation of BPA to residues near the Cterminus impossible as the incorporation defects are unable to be isolated from full-length proteins. To circumvent this issue, we established a method that allows for BPA incorporation to a C-terminal peptide, which is subsequently ligated to the protein through sortase-mediated transpeptidation. The unmodified protein is then smaller than the modified protein by an entire $\sim 20-40$ residue peptide, even in cases where the UAA is at positions near the extreme $\mathrm{C}$-terminus, and this allows for purification by size, or in our case by ion exchange chromatography mediated by the highly basic C-terminal tail.

The second method, although essential for overcoming our specific problem, has a number of drawbacks that make it an impractical method for large-scale use. Firstly, the final yield of protein is limited by the initial yield of peptide. By pre-incorporating BPA via Fmoc chemistry, the final quantity of peptide represents the upper limit for peptide-incorporated protein. In fact, for $\mathrm{C}$-terminal labeling, the best sortase reaction efficiency is achieved by having the peptide in vast excess over protein, and this makes the yields of full-length protein quite limiting, on the order of $50 \mu \mathrm{g}$ to $500 \mu \mathrm{g}$, depending on the scale of the enzymatic reaction and the success of the purification strategy.

Purification from the enzyme following the reaction is also critical, as any contaminating sortase enzyme can readily cleave the product and remove the BPA-peptide. For this, we purify our $1 \mathrm{~mL}$ reaction mixtures over gradient $\mathrm{NaCl}$ IEX, followed by $\mathrm{SEC}$, a strategy which further decreases the overall yield. A variety of other methodologies, including self-splicing C-terminal inteins (Batjargal, Walters et al. 2015) and cell strains that lack the ability to truncate (Lajoie, Rovner et al. 2013) have been developed recently, and are likely a more practical and useful method for overcoming this problem.

\section{Multisite Binding as a General Mechanism of Inhibition}

\section{Multivalency Is Common in Biology}

We discover here a multisite, avid mechanism of APC/C inhibition by Emi1. Emil's exhibition of multivalent inhibition is not unique; rather it is representative of an entire class of inhibitors, both natural and designed. Even beyond inhibition, multivalency mediates many biological and synthetic interactions, and investigation into the properties of other multivalent interactions of both the protein and drug-design frameworks helps to better place Emil's functionalities and critical role among a wellestablished mechanism of biological function.

Multivalent interactions can be loosely defined as cooperative interactions of multiple connected binding groups during a single binding process. An oversimplified 
example is Velcro, in which many very weak hook-fiber interactions are connected on a single surface and work together to create a stronger interaction. This definition necessitates both a multisite receptor (APC/C in our case) and a multisite ligand (Emi1 in our case), as a large number of ligands with only one site of interaction for the receptor do not exhibit cooperativity as a connected binding group. Early studies of these types of phenomenon derived from characterization of interactions in inorganic chemistry including chelation and other metallic properties, and only later were similar cooperative binding effects discovered occurring in organic molecules and subsequently throughout biology. It is now known that multivalent interactions occur throughout the protein interactome, with extensive characterization of lectin interactions with carbohydrates and sugars (Lepenies, Lee et al. 2013, Wittmann and Pieters 2013, Visini, Jin et al. 2015), and toxin interactions with cell-surface receptors (Wolfhagen, Torensma et al. 1994, Nishikawa 2003). Other, more simple 2-site interactions such as a single p27 protein binding both to Skp2 and Cks1 (Hao, Zheng et al. 2005), Cand1 inhibition of Cul1-Roc1 (Goldenberg, Cascio et al. 2004), Cbl proteins as multivalent adapters for tyrosine kinase functions (Tsygankov, Teckchandani et al. 2001, Swaminathan and Tsygankov 2006) exhibit the same principle of multi-site interactions, and recently, useful tools such as structural databases (Meyer and Knapp 2014) have been developed to aid in the molecular understanding of these natural interactions.

One such biological interaction is observed and found to be essential at the telomeres of DNA by multivalent association of the proteins Rif1 and Rif2 with Rap1. These proteins bind to the telomeric DNA repeats and form a sterically occlusive cap called a telosome that inhibits telomerase cleavage and transcriptional silencing. A recent study aims to characterize how single or multivalent interactions between Rifl and Rap1 as well as Rif2 and Rap1 lead to higher-order associations with DNA, considering only Rap1 is believed to bind DNA (Leuthauser, Thomas et al. 1992, Shi, Bunker et al. 2013). Two Rif1 sites are capable of binding two different, distant Rap1 sites or molecules, which can simultaneously be bound by another Rif1 or Rif 2 molecule. In this case, multivalency seems to be less important for avidity affects leading to high affinity interactions, and more important for establishing a network of linked interactions which, through multiple binding sites for both Rif1 and Rif2 at distinct locations within Rap1, enables the dissociation of each of these single protein-protein interactions to be overcome by having multiple association events. From this perspective, Emil multivalency can also be characterized as a series of connected binding events. Not only do the multiple binding sites of Emil each contribute to the combined kinetics of association with $\mathrm{APC} / \mathrm{C}$, but they also lessen the overall dissociation constant, increasing the stability of the APC/C-Emil complex. For instance, temporary dissociation of the relatively weak D-box is overcome by association kinetics of the Linker, ZBR, and Tail regions of Emi1, such that Emil does not wholly dissociate, but self-stabilizes on the APC/C. This may account for the ability to maintain stoichiometric complex throughout the relatively long purification of APC/C-Emi1 complexes for EM, including an overnight gradient centrifugation step in vitro, and throughout interphase of the cell-cycle in vivo. 
Perhaps more importantly, though, are the applications of this natural phenomenon to the rational design of synthetic inhibitors and multivalent drug-like molecules for treatment of a wide range of human pathologies. Indeed, both targeted development of specific systems, such as trimeric PCNA binding peptides (Bozza, Yang et al. 2012), selectivity of inhibitory compounds of the BCL-2 family (Bruncko, Wang et al. 2015), and hundreds of other structure guided drug design efforts, as well as broadly developed biotechnologies like multivalent architectural scaffolds and nanostructures ( $\mathrm{Li}$, Choi et al. 2014) have enabled significant improvements in therapeutic discoveries in recent years. Rational drug design efforts typically utilize known structural information of both the target and the inhibitor to intelligently enhance drug potency or specificity. This enables biochemists to build larger or more kinetically productive inhibitors, or to specifically target only certain proteins or complexes within structurally or functionally similar families.

Analogous to rational drug design, sequence-directed population studies of libraries of modified inhibitory peptides are also a powerful technique for improving known inhibitors. For example, a group of Italian researchers modify a known CamKII inhibitory peptide and established a library of similar but non-identical peptides to probe the functional consequences of their mutations (Gomez-Monterrey, Sala et al. 2013). The authors identify a 17-mer peptide with improved specificity for CamKII that is capable of penetrating cells and inhibiting the RAS/RAF/MEK/ERK cellular signaling pathway. To a certain extent, our work mimics this mutational analysis approach for peptide enhancement, such as our generation of a Super-D-box chimera, and it is possible that even milder mutations of this $\mathrm{APC} / \mathrm{C}$ recruitment motif would be superior to Emil's native D-box, like the T323I mutation observed in the Barford structure. In consideration of developing peptides or chemicals that mimic Emil form or function, studies like these provide an exciting glance at the possible outcomes of these works. Similarly, the structural and biochemical information we have discovered about Emil presented here could be developed further into more potent or selective APC/C inhibitory compounds. Through visualization of the surfaces of $\mathrm{APC} / \mathrm{C}$ that are important for catalysis, and by studying the interactions that dictate Emil association with several functionally diverse regions of the complex, it is easy to imagine development of small molecules or peptides which would mimic these functions.

\section{Targeting APC/C with Pharmacological Inhibitors}

A variety of activating mutations have been shown to dysregulate the APC/C and lead to cancers (Penas, Ramachandran et al. 2011), and blocking mitotic exit is an effective approach for stimulating tumor cell death. For these reasons, the APC/C has very recently become an attractive target for development of pharmacological inhibitors. Only recently has sufficient biochemical and structural data been generated to enable $\mathrm{APC} / \mathrm{C}$ targeted drug development, and as such, only 2 non-biological inhibitors have been established for the APC/C to date; APCin (APC inhibitor) and TAME (tosylarginine-methyl-ester) (Zeng and King 2012, Sackton, Dimova et al. 2014, Lub, Maes et al. 2015). APCin shares structural similarity to the RxxL D-box motif of substrates, and 
a Cdc20-APCin cocrystal structure reveals that the inhibitor binds competitively to the coactivator's D-box binding site. This substrate-recruitment inhibitor causes stabilization of APC/C substrates in mitotic Xenopus laevis extracts, making for a promising target in APC/C regulation. TAME mimics an essential C-terminal IR tail of Cdc20, Cdh1, and APC10. Each of these proteins is coordinated by an IR-tail binding groove within APC3 (Yamaguchi, Yu et al. 2015). Both APCin and TAME inhibit the APC/C at distinct sites, and their combination treatment yields a synergistic effect in Xenopus extracts (Sackton, Dimova et al. 2014).

These pharmacological inhibitors have been developed to mimic and therefore block the biological activation of $\mathrm{APC} / \mathrm{C}$ and have established therapeutic potential by stimulating cell death of multiple myeloma cells. Our biochemical and structural characterization of the biological inhibitor, Emi1, reveals novel functionalities within $\mathrm{APC} / \mathrm{C}$ that are ideal drug targets. Much like the C-terminal IR-tail interaction of the coactivator proteins with APC3, our conserved C-terminal RL tail of Emi1 is absolutely essential both for its function as an inhibitor, and for Ube2s's function as an E2.

Evolutionary pressure has already developed a regulated inhibitor of Ube2s recruitment, and this site is likely an ideal target for small molecule mimic of an RL tail. Our studies with Emil also reveal an unfortunate truth: much remains unknown about the true mechanisms of action of this critically important cell cycle regulator. In our process of isolating the function of a very small inhibitory subdomain, we discovered 4 functional elements blocking 3 critical functionalities on a single face of our 1,200 kDa complex. It is quite possible that further regulation of this complex is yet to be discovered, and that a number of critical protein-protein interaction sites have not been visualized and will be viable targets for future drug discovery as well. Indeed, all of the Emil data generated here has highlighted the necessity of future studies of this complex and it's workings, and provides a framework for piecing together the complex networks of interactions that regulate and activate the $\mathrm{APC} / \mathrm{C}$ 's function.

\section{Inhibition of APC/C}

Utilizing what we have learned about APC/C activity from our studies with Emi1 and from recent high-resolution information, we can further analyze the mechanism of the other inhibitors, including the other major biological APC/C inhibitor, the Mitotic Checkpoint Complex. Although limited by the low resolution of current human APC/CMCC structures, it seems likely that the MCC blocks the substrate recruitment mechanism of APC/C based on structures observed in crystals and EM (Herzog, Primorac et al. 2009, Chao, Kulkarni et al. 2012). What is unclear is whether the MCC is capable of inhibiting one or both of the APC/C specific E2s, Ubch10 and Ube2s. By directly contacting and covering much of the catalytic core, it is plausible that Ubch10 is precluded from its canonical APC/C binding sites (Brown, VanderLinden et al. 2015), but it is also conceivable that Emil potently inhibits Ube2s recruitment where MCC inhibits only Ubch10 recruitment. This could provide a means for regulation of E2specific ubiquitination activities, as it is known that the extent and topology of 
ubiquitination regulates the fate of the target, from degradative targeting to signaling and other outcomes.

\section{Cand1 Is Both a Competitor and Activator of CRLs.}

Canonical CRL complexes are engaged by another protein, CAND1, which, like Emi1, was long considered to be a general inhibitor. CAND1 associates with Cullins blocking their activation by Nedd8ylation, and obstructing Skp1 association with F-box proteins. Despite structural evidence supporting competitive inhibition of SCF, and in vitro assays characterizing the effect, many in vivo experiments suggest CAND1dependent activation of SCF activity in cells. This paradox persisted for several years until recent experiments discover a cryptic mechanism that supports both in vitro inhibition and in vivo activation of SCF by CAND1. In this case, the answer comes from binding kinetics: CAND1 drastically increases the dissociation of F-box proteins from Cullin, but has no effect on F-box association constants. By effectively removing a stably bound accessory protein, CAND1 serves as an exchange factor to enable Cullin protein assembly with the hundreds of known adaptor complexes.

Analysis of the multisite, multifunctional binding of CAND1 allows speculation about a general model of SCF assembly and activation in a broader, cellular context: Perhaps, since CAND1 is unable to bind to Nedd8-modified Cullin proteins, a novel mechanism is employed by SCF to degrade large pools of a subset of substrates, and then Cullin returns to promiscuous association with F-box proteins to sample a variety of new targets. In this model, a CRL encounters a substrate, nedd8ylation activates the CRL, and CAND1 association is not possible. The absence of the CAND1 exchange factor allows specific, processive destruction of substrates recruited only by the currently associated Fbox protein. In time, deneddylases remove Nedd8, and CAND1 association allows Cullin to collaborate with new F-box proteins, targeting new substrate pools. This model couples CRL activity with substrate availability, F-box protein expression and localization, and the competitive interplay between neddylation and CAND1 association, providing ample means of regulatory control by cellular cues.

\section{Could Emi1's Multisite Binding Provide More Than an Inhibitory Role?}

Due to the cryptic, multisite CAND1 activation mechanism, this exchange factor was mistaken as a competitive inhibitor of CRLs. Emil also employs a similar multisite association with the many functional domains within $\mathrm{APC} / \mathrm{C}$, which begs the question: is Emil doing more than $\mathrm{APC} / \mathrm{C}$ association and inhibition? Kinetic studies of Emil as performed by a postdoc in the lab, Nick Brown, in conjunction with this work suggest that the multisite binding of Emil creates an overall affinity so tight that it cannot be measured in our assays, likely in the picomolar range. This distinguishes Emil's constants for dissociation and association from those of Cand1, suggesting that it is not an exchange factor by the same mechanism. It is also possible that by associating with a variety of distant parts of the $\mathrm{APC} / \mathrm{C}$, that Emil could provide a means of stabilization of 
the multi-protein APC/C. Indeed, Emil lowers the inherently flexibility of the APC/C in our EM studies and therefore allows for higher resolution structural information to be obtained.

\section{What Is the Rest of Emi1 for?}

Our characterization of Emil function paired with recent structural information only accounts for the C-terminal 1/3 of Emi1's sequence. Though a few residues within the N-terminal sequence of Emil have been shown to be responsible for Emil's own regulation, it is not clear that this is the only function of this part of the protein.

Interestingly, Emil contains an F-box that is benign for $\mathrm{APC} / \mathrm{C}$ inhibition, but may serve other roles in the cell. F-box proteins are well-established functional partners the CRL family of ligases, and Emil's F-box binds with high affinity to Skp1, another major Cullin-associating protein. As of yet a functional relationship between Emil's F-box and CRL activity have not been established, but beyond Emil's original discovery based on Skp1 association, the F-box has not been studied extensively. There may be cell-type specific, or stress response related functions of this domain that are yet to be understood.

Furthermore, residues besides the well-characterized phosphodegrons have been shown to be post-translationally modified with phosphorylation by the action of Cyclindependent-kinases (Moshe, Bar-On et al. 2011). This modification of Emil's C-terminus renders it insufficient at inhibiting the $\mathrm{APC} / \mathrm{C}$, providing a Plk1-mediated degradation independent manner of Emi1 regulation. A further six phosphorylation sites in the Nterminus of Emil have been discovered, but no kinase or functional outcome of phosphorylation has been tested. It is plausible that environment-specific modification of Emil by a variety of factors represents a tunable control of Emi1 regulation, and therefore regulation of $\mathrm{APC} / \mathrm{C}$ E3 ligase activity and regulation of cellular signaling pathways in which APC/C substrates are involved. 


\section{LIST OF REFERENCES}

Ban, K. H., J. Z. Torres, J. J. Miller, A. Mikhailov, M. V. Nachury, J. J. Tung, C. L. Rieder and P. K. Jackson (2007). "The END network couples spindle pole assembly to inhibition of the anaphase-promoting complex/cyclosome in early mitosis." Dev Cell 13(1): 29-42.

Batjargal, S., C. R. Walters and E. J. Petersson (2015). "Inteins as traceless purification tags for unnatural amino acid proteins." J Am Chem Soc 137(5): 1734-1737.

Berndsen, C. E. and C. Wolberger (2014). "New insights into ubiquitin E3 ligase mechanism." Nat Struct Mol Biol 21(4): 301-307.

Bochis, O. V., B. Fetica, C. Vlad, P. Achimas-Cadariu and A. Irimie (2015). "The Importance of Ubiquitin E3 Ligases, SCF and APC/C, in Human Cancers." Clujul Med 88(1): 9-14.

Bolscher, J. G., M. J. Oudhoff, K. Nazmi, J. M. Antos, C. P. Guimaraes, E. Spooner, E. F. Haney, J. J. Garcia Vallejo, H. J. Vogel, W. van't Hof, H. L. Ploegh and E. C. Veerman (2011). "Sortase A as a tool for high-yield histatin cyclization." FASEB J 25(8): 2650-2658.

Bozza, W. P., K. Yang, J. Wang and Z. Zhuang (2012). "Developing peptide-based multivalent antagonists of proliferating cell nuclear antigen and a fluorescence-based PCNA binding assay." Anal Biochem 427(1): 69-78.

Bremm, A. and D. Komander (2011). "Emerging roles for Lys11-linked polyubiquitin in cellular regulation." Trends Biochem Sci 36(7): 355-363.

Brown, N. G., R. VanderLinden, E. R. Watson, R. Qiao, C. R. Grace, M. Yamaguchi, F. Weissmann, J. J. Frye, P. Dube, S. Ei Cho, M. L. Actis, P. Rodrigues, N. Fujii, J. M. Peters, H. Stark and B. A. Schulman (2015). "RING E3 mechanism for ubiquitin ligation to a disordered substrate visualized for human anaphase-promoting complex." Proc Natl Acad Sci U S A 112(17): 5272-5279.

Brown, N. G., E. R. Watson, F. Weissmann, M. A. Jarvis, R. VanderLinden, C. R. Grace, J. J. Frye, R. Qiao, P. Dube, G. Petzold, S. E. Cho, O. Alsharif, J. Bao, I. F. Davidson, J. J. Zheng, A. Nourse, I. Kurinov, J. M. Peters, H. Stark and B. A. Schulman (2014). "Mechanism of polyubiquitination by human anaphase-promoting complex: RING repurposing for ubiquitin chain assembly." Mol Cell 56(2): 246-260.

Bruncko, M., L. Wang, G. S. Sheppard, D. C. Phillips, S. K. Tahir, J. Xue, S. Erickson, S. Fidanze, E. Fry, L. Hasvold, G. J. Jenkins, S. Jin, R. A. Judge, P. J. Kovar, D. Madar, P. Nimmer, C. Park, A. M. Petros, S. H. Rosenberg, M. L. Smith, X. Song, C. Sun, Z. F. Tao, X. Wang, Y. Xiao, H. Zhang, C. Tse, J. D. Leverson, S. W. Elmore and A. J. Souers 
(2015). "Structure-guided design of a series of MCL-1 inhibitors with high affinity and selectivity." J Med Chem 58(5): 2180-2194.

Buschhorn, B. A., G. Petzold, M. Galova, P. Dube, C. Kraft, F. Herzog, H. Stark and J. M. Peters (2011). "Substrate binding on the APC/C occurs between the coactivator Cdh1 and the processivity factor Doc1." Nat Struct Mol Biol 18(1): 6-13.

Carroll, C. W., M. Enquist-Newman and D. O. Morgan (2005). "The APC subunit Doc1 promotes recognition of the substrate destruction box." Curr Biol 15(1): 11-18.

Cenciarelli, C., D. S. Chiaur, D. Guardavaccaro, W. Parks, M. Vidal and M. Pagano (1999). "Identification of a family of human F-box proteins." Curr Biol 9(20): 11771179.

Chang, L., Z. Zhang, J. Yang, S. H. McLaughlin and D. Barford (2015). "Atomic structure of the APC/C and its mechanism of protein ubiquitination." Nature 522(7557): 450-454.

Chao, W. C., K. Kulkarni, Z. Zhang, E. H. Kong and D. Barford (2012). "Structure of the mitotic checkpoint complex." Nature 484(7393): 208-213.

Chatterjee, A., J. Guo, H. S. Lee and P. G. Schultz (2013). "A genetically encoded fluorescent probe in mammalian cells." J Am Chem Soc 135(34): 12540-12543.

Chin, J. W., T. A. Cropp, J. C. Anderson, M. Mukherji, Z. Zhang and P. G. Schultz (2003). "An expanded eukaryotic genetic code." Science 301(5635): 964-967.

Chin, J. W., T. A. Cropp, S. Chu, E. Meggers and P. G. Schultz (2003). "Progress toward an expanded eukaryotic genetic code." Chem Biol 10(6): 511-519.

Chin, J. W., A. B. Martin, D. S. King, L. Wang and P. G. Schultz (2002). "Addition of a photocrosslinking amino acid to the genetic code of Escherichiacoli." Proc Natl Acad Sci U S A 99(17): 11020-11024.

Chin, J. W., S. W. Santoro, A. B. Martin, D. S. King, L. Wang and P. G. Schultz (2002). "Addition of p-azido-L-phenylalanine to the genetic code of Escherichia coli." J Am Chem Soc 124(31): 9026-9027.

da Fonseca, P. C., E. H. Kong, Z. Zhang, A. Schreiber, M. A. Williams, E. P. Morris and D. Barford (2011). "Structures of APC/C(Cdh1) with substrates identify Cdh1 and Apc10 as the D-box co-receptor." Nature 470(7333): 274-278.

Deiters, A., T. A. Cropp, M. Mukherji, J. W. Chin, J. C. Anderson and P. G. Schultz (2003). "Adding amino acids with novel reactivity to the genetic code of Saccharomyces cerevisiae." J Am Chem Soc 125(39): 11782-11783.

Deshaies, R. J. and C. A. Joazeiro (2009). "RING domain E3 ubiquitin ligases." Annu Rev Biochem 78: 399-434. 
Dikic, I., S. Wakatsuki and K. J. Walters (2009). "Ubiquitin-binding domains - from structures to functions." Nature reviews. Molecular cell biology 10(10): 659-671.

Dimova, N. V., N. A. Hathaway, B. H. Lee, D. S. Kirkpatrick, M. L. Berkowitz, S. P. Gygi, D. Finley and R. W. King (2012). "APC/C-mediated multiple monoubiquitylation provides an alternative degradation signal for cyclin B1." Nat Cell Biol 14(2): 168-176.

Dong, X., K. H. Zavitz, B. J. Thomas, M. Lin, S. Campbell and S. L. Zipursky (1997). "Control of G1 in the developing Drosophila eye: rca1 regulates Cyclin A." Genes Dev 11(1): 94-105.

Dou, H., L. Buetow, G. J. Sibbet, K. Cameron and D. T. Huang (2012). "BIRC7-E2 ubiquitin conjugate structure reveals the mechanism of ubiquitin transfer by a RING dimer." Nat Struct Mol Biol 19(9): 876-883.

Duda, D. M., L. A. Borg, D. C. Scott, H. W. Hunt, M. Hammel and B. A. Schulman (2008). "Structural insights into NEDD8 activation of cullin-RING ligases: conformational control of conjugation." Cell 134(6): 995-1006.

Eletr, Z. M., D. T. Huang, D. M. Duda, B. A. Schulman and B. Kuhlman (2005). "E2 conjugating enzymes must disengage from their E1 enzymes before E3-dependent ubiquitin and ubiquitin-like transfer." Nat Struct Mol Biol 12(10): 933-934.

Evans, T., E. T. Rosenthal, J. Youngblom, D. Distel and T. Hunt (1983). "Cyclin: a protein specified by maternal mRNA in sea urchin eggs that is destroyed at each cleavage division." Cell 33(2): 389-396.

Freemont, P. S., I. M. Hanson and J. Trowsdale (1991). "A novel cysteine-rich sequence motif." Cell 64(3): 483-484.

Frye, J. J., N. G. Brown, G. Petzold, E. R. Watson, C. R. Grace, A. Nourse, M. A. Jarvis, R. W. Kriwacki, J. M. Peters, H. Stark and B. A. Schulman (2013). "Electron microscopy structure of human APC/C(CDH1)-EMI1 reveals multimodal mechanism of E3 ligase shutdown." Nat Struct Mol Biol 20(7): 827-835.

Furman, J. L., M. Kang, S. Choi, Y. Cao, E. D. Wold, S. B. Sun, V. V. Smider, P. G. Schultz and C. H. Kim (2014). "A genetically encoded aza-Michael acceptor for covalent cross-linking of protein-receptor complexes." J Am Chem Soc 136(23): 8411-8417.

Garnett, M. J., J. Mansfeld, C. Godwin, T. Matsusaka, J. Wu, P. Russell, J. Pines and A. R. Venkitaraman (2009). "UBE2S elongates ubiquitin chains on APC/C substrates to promote mitotic exit." Nat Cell Biol 11(11): 1363-1369.

Goldenberg, S. J., T. C. Cascio, S. D. Shumway, K. C. Garbutt, J. Liu, Y. Xiong and N. Zheng (2004). "Structure of the Cand1-Cul1-Roc1 complex reveals regulatory mechanisms for the assembly of the multisubunit cullin-dependent ubiquitin ligases." Cell 119(4): 517-528. 
Gomez-Monterrey, I., M. Sala, M. R. Rusciano, S. Monaco, A. S. Maione, G. Iaccarino, P. Tortorella, A. M. D'Ursi, M. Scrima, A. Carotenuto, G. De Rosa, A. Bertamino, E. Vernieri, P. Grieco, E. Novellino, M. Illario and P. Campiglia (2013). "Characterization of a selective CaMKII peptide inhibitor." Eur J Med Chem 62: 425-434.

Guimaraes, C. P., M. D. Witte, C. S. Theile, G. Bozkurt, L. Kundrat, A. E. Blom and H. L. Ploegh (2013). "Site-specific C-terminal and internal loop labeling of proteins using sortase-mediated reactions." Nat Protoc 8(9): 1787-1799.

Hansen, D. V., A. V. Loktev, K. H. Ban and P. K. Jackson (2004). "Plk1 regulates activation of the anaphase promoting complex by phosphorylating and triggering SCFbetaTrCP-dependent destruction of the APC Inhibitor Emi1." Mol Biol Cell 15(12): 5623-5634.

Hao, B., N. Zheng, B. A. Schulman, G. Wu, J. J. Miller, M. Pagano and N. P. Pavletich (2005). "Structural basis of the Cks1-dependent recognition of p27(Kip1) by the SCF(Skp2) ubiquitin ligase." Mol Cell 20(1): 9-19.

He, J., W. C. Chao, Z. Zhang, J. Yang, N. Cronin and D. Barford (2013). "Insights into degron recognition by APC/C coactivators from the structure of an Acm1-Cdh1 complex." Mol Cell 50(5): 649-660.

Hershko, A. and H. Heller (1985). "Occurrence of a polyubiquitin structure in ubiquitinprotein conjugates." Biochem Biophys Res Commun 128(3): 1079-1086.

Herzog, F., I. Primorac, P. Dube, P. Lenart, B. Sander, K. Mechtler, H. Stark and J. M. Peters (2009). "Structure of the anaphase-promoting complex/cyclosome interacting with a mitotic checkpoint complex." Science 323(5920): 1477-1481.

Hsu, J. Y., J. D. Reimann, C. S. Sorensen, J. Lukas and P. K. Jackson (2002). "E2Fdependent accumulation of hEmi1 regulates S phase entry by inhibiting APC(Cdh1)." Nat Cell Biol 4(5): 358-366.

Huang, D. T., D. W. Miller, R. Mathew, R. Cassell, J. M. Holton, M. F. Roussel and B. A. Schulman (2004). "A unique E1-E2 interaction required for optimal conjugation of the ubiquitin-like protein NEDD8." Nat Struct Mol Biol 11(10): 927-935.

Huang, D. T., A. Paydar, M. Zhuang, M. B. Waddell, J. M. Holton and B. A. Schulman (2005). "Structural basis for recruitment of Ubc12 by an E2 binding domain in NEDD8's E1." Mol Cell 17(3): 341-350.

Ikeda, F. and I. Dikic (2008). "Atypical ubiquitin chains: new molecular signals. 'Protein Modifications: Beyond the Usual Suspects' review series." EMBO Rep 9(6): 536-542.

Jarvis, M. A., N. G. Brown, E. R. Watson, R. VanderLinden, B. A. Schulman and J. M. Peters (2016). "Measuring APC/C-Dependent Ubiquitylation In Vitro." Methods Mol Biol 1342: 287-303. 
Javahishvili, T., A. Manibusan, S. Srinagesh, D. Lee, S. Ensari, M. Shimazu and P. G. Schultz (2014). "Role of tRNA orthogonality in an expanded genetic code." ACS Chem Biol 9(4): 874-879.

King, R. W., J. M. Peters, S. Tugendreich, M. Rolfe, P. Hieter and M. W. Kirschner (1995). "A 20S complex containing CDC27 and CDC16 catalyzes the mitosis-specific conjugation of ubiquitin to cyclin B." Cell 81(2): 279-288.

Komander, D. and M. Rape (2012). "The ubiquitin code." Annu Rev Biochem 81: 203229.

Lajoie, M. J., A. J. Rovner, D. B. Goodman, H. R. Aerni, A. D. Haimovich, G. Kuznetsov, J. A. Mercer, H. H. Wang, P. A. Carr, J. A. Mosberg, N. Rohland, P. G. Schultz, J. M. Jacobson, J. Rinehart, G. M. Church and F. J. Isaacs (2013). "Genomically recoded organisms expand biological functions." Science 342(6156): 357-360.

Latres, E., D. S. Chiaur and M. Pagano (1999). "The human F box protein beta-Trcp associates with the Cul1/Skp1 complex and regulates the stability of beta-catenin." Oncogene 18(4): 849-854.

Lee, H. S., R. D. Dimla and P. G. Schultz (2009). "Protein-DNA photo-crosslinking with a genetically encoded benzophenone-containing amino acid." Bioorg Med Chem Lett 19(17): 5222-5224.

Lepenies, B., J. Lee and S. Sonkaria (2013). "Targeting C-type lectin receptors with multivalent carbohydrate ligands." Adv Drug Deliv Rev 65(9): 1271-1281.

Leuthauser, S. W., J. E. Thomas and D. L. Guernsey (1992). "Oncogenes in X-raytransformed C3H 10T1/2 mouse cells and in X-ray-induced mouse fibrosarcoma (RIF-1) cells." Int J Radiat Biol 62(1): 45-51.

Li, M. H., S. K. Choi, P. R. Leroueil and J. R. Baker, Jr. (2014). "Evaluating binding avidities of populations of heterogeneous multivalent ligand-functionalized nanoparticles." ACS Nano 8(6): 5600-5609.

Lin, Y., W. C. Hwang and R. Basavappa (2002). "Structural and functional analysis of the human mitotic-specific ubiquitin-conjugating enzyme, UbcH10." J Biol Chem 277(24): 21913-21921.

Liu, C. C., A. V. Mack, M. L. Tsao, J. H. Mills, H. S. Lee, H. Choe, M. Farzan, P. G. Schultz and V. V. Smider (2008). "Protein evolution with an expanded genetic code." Proc Natl Acad Sci U S A 105(46): 17688-17693.

Lu, D., J. R. Girard, W. Li, A. Mizrak and D. O. Morgan (2015). "Quantitative framework for ordered degradation of APC/C substrates." BMC Biol 13(1): 96. 
Lu, D., J. Y. Hsiao, N. E. Davey, V. A. Van Voorhis, S. A. Foster, C. Tang and D. O. Morgan (2014). "Multiple mechanisms determine the order of APC/C substrate degradation in mitosis." J Cell Biol 207(1): 23-39.

Lub, S., A. Maes, K. Maes, K. De Veirman, E. De Bruyne, E. Menu, K. Fostier, A. Kassambara, J. Moreaux, D. Hose, X. Leleu, R. W. King, K. Vanderkerken and E. Van Valckenborgh (2015). "Inhibiting the anaphase promoting complex/cyclosome induces a metaphase arrest and cell death in multiple myeloma cells." Oncotarget.

Margottin-Goguet, F., J. Y. Hsu, A. Loktev, H. M. Hsieh, J. D. Reimann and P. K. Jackson (2003). "Prophase destruction of Emil by the SCF(betaTrCP/Slimb) ubiquitin ligase activates the anaphase promoting complex to allow progression beyond prometaphase." Dev Cell 4(6): 813-826.

Meyer, T. and E. W. Knapp (2014). "Database of protein complexes with multivalent binding ability: Bival-Bind." Proteins 82(5): 744-751.

Miller, J. J., M. K. Summers, D. V. Hansen, M. V. Nachury, N. L. Lehman, A. Loktev and P. K. Jackson (2006). "Emil stably binds and inhibits the anaphase-promoting complex/cyclosome as a pseudosubstrate inhibitor." Genes Dev 20(17): 2410-2420.

Min, M., T. E. Mevissen, M. De Luca, D. Komander and C. Lindon (2015). "Efficient APC/C substrate degradation in cells undergoing mitotic exit depends on K11 ubiquitin linkages." Mol Biol Cell 26(24): 4325-4332.

Morgan, D. O. (2007). The Cell Cycle: Principles of Control.

Moshe, Y., O. Bar-On, D. Ganoth and A. Hershko (2011). "Regulation of the action of early mitotic inhibitor 1 on the anaphase-promoting complex/cyclosome by cyclindependent kinases." J Biol Chem 286(19): 16647-16657.

Nagai, M. and T. Ushimaru (2014). "Cdh1 is an antagonist of the spindle assembly checkpoint." Cell Signal 26(10): 2217-2222.

Nakamura, Y., K. Nakano, T. Umehara, M. Kimura, Y. Hayashizaki, A. Tanaka, M. Horikoshi, B. Padmanabhan and S. Yokoyama (2007). "Structure of the oncoprotein gankyrin in complex with S6 ATPase of the 26S proteasome." Structure 15(2): 179-189.

Nishikawa, K. (2003). "[Shiga toxin neutralizers with multivalent carbohydrates]." Seikagaku 75(7): 604-609.

Ohe, M., D. Inoue, Y. Kanemori and N. Sagata (2007). "Erp1/Emi2 is essential for the meiosis I to meiosis II transition in Xenopus oocytes." Dev Biol 303(1): 157-164.

Ohe, M., Y. Kawamura, H. Ueno, D. Inoue, Y. Kanemori, C. Senoo, M. Isoda, N. Nakajo and N. Sagata (2010). "Emi2 inhibition of the anaphase-promoting complex/cyclosome absolutely requires Emi2 binding via the C-terminal RL tail." Mol Biol Cell 21(6): 905913. 
Olsen, S. K. and C. D. Lima (2013). "Structure of a ubiquitin E1-E2 complex: insights to E1-E2 thioester transfer." Mol Cell 49(5): 884-896.

Ostapenko, D., J. L. Burton and M. J. Solomon (2012). "Identification of anaphase promoting complex substrates in S. cerevisiae." PLoS One 7(9): e45895.

Pashkova, N., L. Gakhar, S. C. Winistorfer, L. Yu, S. Ramaswamy and R. C. Piper (2010). "WD40 repeat propellers define a ubiquitin-binding domain that regulates turnover of $\mathrm{F}$ box proteins." Mol Cell 40(3): 433-443.

Passmore, L. A., E. A. McCormack, S. W. Au, A. Paul, K. R. Willison, J. W. Harper and D. Barford (2003). "Doc1 mediates the activity of the anaphase-promoting complex by contributing to substrate recognition." EMBO J 22(4): 786-796.

Penas, C., V. Ramachandran and N. G. Ayad (2011). "The APC/C Ubiquitin Ligase: From Cell Biology to Tumorigenesis." Front Oncol 1: 60.

Pendergrast, P. S., Y. Chen, Y. W. Ebright and R. H. Ebright (1992). "Determination of the orientation of a DNA binding motif in a protein-DNA complex by photocrosslinking." Proc Natl Acad Sci U S A 89(21): 10287-10291.

Peters, J. M. (2006). "The anaphase promoting complex/cyclosome: a machine designed to destroy." Nat Rev Mol Cell Biol 7(9): 644-656.

Philipps, B., M. Forstner and L. M. Mayr (2005). "A baculovirus expression vector system for simultaneous protein expression in insect and mammalian cells." Biotechnol Prog 21(3): 708-711.

Pickart, C. M. and M. J. Eddins (2004). "Ubiquitin: structures, functions, mechanisms." Biochim Biophys Acta 1695(1-3): 55-72.

Plechanovova, A., E. G. Jaffray, M. H. Tatham, J. H. Naismith and R. T. Hay (2012). "Structure of a RING E3 ligase and ubiquitin-loaded E2 primed for catalysis." Nature 489(7414): 115-120.

Popp, M. W., J. M. Antos and H. L. Ploegh (2009). "Site-specific protein labeling via sortase-mediated transpeptidation." Curr Protoc Protein Sci Chapter 15: Unit 1513.

Popp, M. W., S. K. Dougan, T. Y. Chuang, E. Spooner and H. L. Ploegh (2011). "Sortase-catalyzed transformations that improve the properties of cytokines." Proc Natl Acad Sci U S A 108(8): 3169-3174.

Pruneda, J. N., P. J. Littlefield, S. E. Soss, K. A. Nordquist, W. J. Chazin, P. S. Brzovic and R. E. Klevit (2012). "Structure of an E3:E2 approximately Ub Complex Reveals an Allosteric Mechanism Shared among RING/U-box Ligases." Mol Cell 47(6): 933-942. 
Reimann, J. D., E. Freed, J. Y. Hsu, E. R. Kramer, J. M. Peters and P. K. Jackson (2001). "Emil is a mitotic regulator that interacts with $\mathrm{Cdc} 20$ and inhibits the anaphase promoting complex." Cell 105(5): 645-655.

Reimann, J. D., B. E. Gardner, F. Margottin-Goguet and P. K. Jackson (2001). "Emi1 regulates the anaphase-promoting complex by a different mechanism than Mad2 proteins." Genes Dev 15(24): 3278-3285.

Sackton, K. L., N. Dimova, X. Zeng, W. Tian, M. Zhang, T. B. Sackton, J. Meaders, K. L. Pfaff, F. Sigoillot, H. Yu, X. Luo and R. W. King (2014). "Synergistic blockade of mitotic exit by two chemical inhibitors of the APC/C." Nature 514(7524): 646-649.

Sarikas, A., T. Hartmann and Z. Q. Pan (2011). "The cullin protein family." Genome Biol 12(4): 220.

Sato, S., S. Mimasu, A. Sato, N. Hino, K. Sakamoto, T. Umehara and S. Yokoyama (2011). "Crystallographic study of a site-specifically cross-linked protein complex with a genetically incorporated photoreactive amino acid." Biochemistry 50(2): 250-257.

Schreiber, A., F. Stengel, Z. Zhang, R. I. Enchev, E. H. Kong, E. P. Morris, C. V. Robinson, P. C. da Fonseca and D. Barford (2011). "Structural basis for the subunit assembly of the anaphase-promoting complex." Nature 470(7333): 227-232.

Scott, D. C., V. O. Sviderskiy, J. K. Monda, J. R. Lydeard, S. E. Cho, J. W. Harper and B. A. Schulman (2014). "Structure of a RING E3 Trapped in Action Reveals Ligation Mechanism for the Ubiquitin-like Protein NEDD8." Cell 157(7): 1671-1684.

Shi, T., R. D. Bunker, S. Mattarocci, C. Ribeyre, M. Faty, H. Gut, A. Scrima, U. Rass, S. M. Rubin, D. Shore and N. H. Thoma (2013). "Rif1 and Rif2 shape telomere function and architecture through multivalent Rap1 interactions." Cell 153(6): 1340-1353.

Strijbis, K. and H. L. Ploegh (2014). "Secretion of circular proteins using sortase." Methods Mol Biol 1174: 73-83.

Studier, F. W. (2005). "Protein production by auto-induction in high density shaking cultures." Protein Expr Purif 41(1): 207-234.

Sudakin, V., D. Ganoth, A. Dahan, H. Heller, J. Hershko, F. C. Luca, J. V. Ruderman and A. Hershko (1995). "The cyclosome, a large complex containing cyclin-selective ubiquitin ligase activity, targets cyclins for destruction at the end of mitosis." Mol Biol Cell 6(2): 185-197.

Summers, M. K., B. Pan, K. Mukhyala and P. K. Jackson (2008). "The unique N terminus of the UbcH10 E2 enzyme controls the threshold for APC activation and enhances checkpoint regulation of the APC." Mol Cell 31(4): 544-556.

Swaminathan, G. and A. Y. Tsygankov (2006). "The Cbl family proteins: ring leaders in regulation of cell signaling." J Cell Physiol 209(1): 21-43. 
Swee, L. K., C. P. Guimaraes, S. Sehrawat, E. Spooner, M. I. Barrasa and H. L. Ploegh (2013). "Sortase-mediated modification of alphaDEC205 affords optimization of antigen presentation and immunization against a set of viral epitopes." Proc Natl Acad Sci U S A 110(4): 1428-1433.

Tang, W., J. Q. Wu, C. Chen, C. S. Yang, J. Y. Guo, C. D. Freel and S. Kornbluth (2010). "Emi2-mediated inhibition of E2-substrate ubiquitin transfer by the anaphasepromoting complex/cyclosome through a D-box-independent mechanism." Mol Biol Cell 21(15): 2589-2597.

Tenno, T., K. Fujiwara, H. Tochio, K. Iwai, E. H. Morita, H. Hayashi, S. Murata, H. Hiroaki, M. Sato, K. Tanaka and M. Shirakawa (2004). "Structural basis for distinct roles of Lys63- and Lys48-linked polyubiquitin chains." Genes Cells 9(10): 865-875.

Theile, C. S., M. D. Witte, A. E. Blom, L. Kundrat, H. L. Ploegh and C. P. Guimaraes (2013). "Site-specific N-terminal labeling of proteins using sortase-mediated reactions." Nat Protoc 8(9): 1800-1807.

Tian, W., B. Li, R. Warrington, D. R. Tomchick, H. Yu and X. Luo (2012). "Structural analysis of human Cdc20 supports multisite degron recognition by APC/C." Proc Natl Acad Sci U S A 109(45): 18419-18424.

Tischer, T., E. Hormanseder and T. U. Mayer (2012). "The APC/C inhibitor XErp1/Emi2 is essential for Xenopus early embryonic divisions." Science 338(6106): 520-524.

Tsygankov, A. Y., A. M. Teckchandani, E. A. Feshchenko and G. Swaminathan (2001). "Beyond the RING: CBL proteins as multivalent adapters." Oncogene 20(44): 63826402.

Varadan, R., O. Walker, C. Pickart and D. Fushman (2002). "Structural properties of polyubiquitin chains in solution." J Mol Biol 324(4): 637-647.

Verschuren, E. W., K. H. Ban, M. A. Masek, N. L. Lehman and P. K. Jackson (2007). "Loss of Emil-dependent anaphase-promoting complex/cyclosome inhibition deregulates E2F target expression and elicits DNA damage-induced senescence." Mol Cell Biol 27(22): 7955-7965.

Visini, R., X. Jin, M. Bergmann, G. Michaud, F. Pertici, O. Fu, A. Pukin, T. R. Branson, D. M. Thies-Weesie, J. Kemmink, E. Gillon, A. Imberty, A. Stocker, T. Darbre, R. J. Pieters and J. L. Reymond (2015). "Structural Insight into Multivalent Galactoside Binding to Pseudomonas aeruginosa Lectin LecA." ACS Chem Biol 10(11): 2455-2462.

Visintin, R., S. Prinz and A. Amon (1997). "CDC20 and CDH1: a family of substratespecific activators of APC-dependent proteolysis." Science 278(5337): 460-463.

Wang, L., A. Brock, B. Herberich and P. G. Schultz (2001). "Expanding the genetic code of Escherichia coli." Science 292(5516): 498-500. 
Wang, L. and P. G. Schultz (2001). "A general approach for the generation of orthogonal tRNAs." Chem Biol 8(9): 883-890.

Wang, W. and M. W. Kirschner (2013). "Emil preferentially inhibits ubiquitin chain elongation by the anaphase-promoting complex." Nat Cell Biol 15(7): 797-806.

Willems, A. R., M. Schwab and M. Tyers (2004). "A hitchhiker's guide to the cullin ubiquitin ligases: SCF and its kin." Biochim Biophys Acta 1695(1-3): 133-170.

Wittmann, V. and R. J. Pieters (2013). "Bridging lectin binding sites by multivalent carbohydrates." Chem Soc Rev 42(10): 4492-4503.

Wolfhagen, M. J., R. Torensma, A. C. Fluit, C. J. Aarsman, M. Jansze and J. Verhoef (1994). "Multivalent binding of toxin A from Clostridium difficile to carbohydrate receptors." Toxicon 32(1): 129-132.

Wu, N., A. Deiters, T. A. Cropp, D. King and P. G. Schultz (2004). "A genetically encoded photocaged amino acid." J Am Chem Soc 126(44): 14306-14307.

Wu, P. Y., M. Hanlon, M. Eddins, C. Tsui, R. S. Rogers, J. P. Jensen, M. J. Matunis, A. M. Weisman, C. Wolberger and C. M. Pickart (2003). "A conserved catalytic residue in the ubiquitin-conjugating enzyme family." Embo J 22(19): 5241-5250.

Wu, T., Y. Merbl, Y. Huo, J. L. Gallop, A. Tzur and M. W. Kirschner (2010). "UBE2S drives elongation of K11-linked ubiquitin chains by the anaphase-promoting complex." Proc Natl Acad Sci U S A 107(4): 1355-1360.

Xie, J., L. Wang, N. Wu, A. Brock, G. Spraggon and P. G. Schultz (2004). "The sitespecific incorporation of p-iodo-L-phenylalanine into proteins for structure determination." Nat Biotechnol 22(10): 1297-1301.

Yamaguchi, M., S. Yu, R. Qiao, F. Weissmann, D. J. Miller, R. VanderLinden, N. G. Brown, J. J. Frye, J. M. Peters and B. A. Schulman (2015). "Structure of an APC3APC16 complex: insights into assembly of the anaphase-promoting complex/cyclosome." J Mol Biol 427(8): 1748-1764.

Ye, Y. and M. Rape (2009). "Building ubiquitin chains: E2 enzymes at work." Nat Rev Mol Cell Biol 10(11): 755-764.

Yeh, F. L., L. Tung and T. H. Chang (2016). "Detection of Protein-Protein Interaction Within an RNA-Protein Complex Via Unnatural-Amino-Acid-Mediated Photochemical Crosslinking." Methods Mol Biol 1421: 175-189.

Young, T. S., I. Ahmad, J. A. Yin and P. G. Schultz (2010). "An enhanced system for unnatural amino acid mutagenesis in E. coli." J Mol Biol 395(2): 361-374. 
Yu, H., R. W. King, J. M. Peters and M. W. Kirschner (1996). "Identification of a novel ubiquitin-conjugating enzyme involved in mitotic cyclin degradation." Curr Biol 6(4): 455-466.

Zeng, X. and R. W. King (2012). "An APC/C inhibitor stabilizes cyclin B1 by prematurely terminating ubiquitination." Nat Chem Biol 8(4): 383-392.

Zhang, Z., L. Chang, J. Yang, N. Conin, K. Kulkarni and D. Barford (2013). "The four canonical tpr subunits of human APC/C form related homo-dimeric structures and stack in parallel to form a TPR suprahelix." J Mol Biol 425(22): 4236-4248. 


\section{VITA}

Edmond Watson was born in San Diego, California in 1987. He graduated from Lambuth University in Jackson, TN with a Bachelor of Science degree in 2009.

Following a 15-month research internship with the USDA at University of Tennessee's WTREC in Jackson, TN, he moved to Memphis, TN and joined the Integrated Program in Biomedical Sciences at the University of Tennessee Health Science Center in 2010. He carried out his dissertation research in the lab of Dr. Brenda Schulman at St. Jude Children's Research Hospital and is expected to receive his Ph.D. in May 2016.

\section{Publications}

*Brown, N.G., *R. VanderLinden, *E. R. Watson, et.al, in review.

Brown, N. G., R. VanderLinden, E. R. Watson, R. Qiao, C. R. Grace, M. Yamaguchi, F. Weissmann, J. J. Frye, P. Dube, S. Ei Cho, M. L. Actis, P. Rodrigues, N. Fujii, J. M. Peters, H. Stark and B. A. Schulman (2015). "RING E3 mechanism for ubiquitin ligation to a disordered substrate visualized for human anaphase-promoting complex." Proc Natl Acad Sci U S A 112(17): 5272-5279.

Brown, N. G., E. R. Watson, F. Weissmann, M. A. Jarvis, R. VanderLinden, C. R. Grace, J. J. Frye, R. Qiao, P. Dube, G. Petzold, S. E. Cho, O. Alsharif, J. Bao, I. F. Davidson, J. J. Zheng, A. Nourse, I. Kurinov, J. M. Peters, H. Stark and B. A. Schulman (2014). "Mechanism of polyubiquitination by human anaphase-promoting complex: RING repurposing for ubiquitin chain assembly." Mol Cell 56(2): 246-260.

Frye, J. J., N. G. Brown, G. Petzold, E. R. Watson, C. R. Grace, A. Nourse, M. A. Jarvis, R. W. Kriwacki, J. M. Peters, H. Stark and B. A. Schulman (2013). "Electron microscopy structure of human APC/C(CDH1)-EMI1 reveals multimodal mechanism of E3 ligase shutdown." Nat Struct Mol Biol 20(7): 827-835.

Jarvis, M. A., N. G. Brown, E. R. Watson, R. VanderLinden, B. A. Schulman and J. M. Peters (2016). "Measuring APC/C-Dependent Ubiquitylation In Vitro." Methods Mol Biol 1342: 287-303.

Li, G., W. Ci, S. Karmakar, K. Chen, R. Dhar, Z. Fan, Z. Guo, J. Zhang, Y. Ke, L. Wang, M. Zhuang, S. Hu, X. Li, L. Zhou, X. Li, M. F. Calabrese, E. R. Watson, S. M. Prasad, C. Rinker-Schaeffer, S. E. Eggener, T. Stricker, Y. Tian, B. A. Schulman, J. Liu and K. P. White (2014). "SPOP promotes tumorigenesis by acting as a key regulatory hub in kidney cancer." Cancer Cell 25(4): 455-468.

Lu, H., L. Li, E. R. Watson, R. W. Williams, E. E. Geisert, M. M. Jablonski and L. Lu (2011). "Complex interactions of Tyrp1 in the eye." Mol Vis 17: 2455-2468. 
Pierce, W. K., C. R. Grace, J. Lee, A. Nourse, M. R. Marzahn, E. R. Watson, A. A. High, J. Peng, B. A. Schulman and T. Mittag (2015). "Multiple Weak Linear Motifs Enhance Recruitment and Processivity in SPOP-Mediated Substrate Ubiquitination." J Mol Biol.

* denotes equal author contribution 